\title{
POWER SYSTEM PROTECTION
}

by

\author{
Ankitkumar Naik \\ A project \\ presented to Ryerson University \\ in partial fulfillment of the \\ requirements for the degree of \\ Master of Engineering \\ in the Program of
}

Bachelor of Applied Science, University of Waterloo, June 2013

Electrical and Computer Engineering

Toronto, Ontario, Canada, 2015

(C) Ankitkumar Naik, 2015 


\begin{abstract}
AUTHOR'S DECLARATION
I hereby declare that I am the sole author of this project. This is a true copy of the project, including any required final revisions, as accepted by my examiners.

I authorize Ryerson University to lend this project to other institutions or individuals for the purpose of scholarly research.

I further authorize Ryerson University to reproduce this project by photocopying or by other means, in total or in part, at the request of other institutions or individuals for the purpose of scholarly research.

I understand that my project may be made electrically available to the public.
\end{abstract}




\title{
POWER SYSTEM PROTECTION \\ Ankitkumar Naik \\ Master of Engineering \\ Electrical and Computer Engineering \\ Ryerson University, Toronto, 2015
}

\begin{abstract}
This report provides review of importance of power system protection and presents different techniques available in practical situations. The material provided in this report is available online on different resources. Moreover, this report examines different types of faults in power system and discusses the consequences of the faults. Moreover, it also talks about different methods of protection schemes applied for various faults occurred on power system equipment such as transformer, generator, bus, transmission and distribution lines and motors. Furthermore, different relaying techniques are also discussed briefly which are used extensively throughout the report for explaining the importance of these techniques in fault detection and damage prevention. SKM power tool is used for simulation purpose. The simulation result are displayed and explained. Moreover, short circuit calculation and equipment selection method is also discussed in this report.
\end{abstract}




\section{Acknowledgements}

I would like to thank everyone who has supported me throughout the completion of my thesis report. I am thankful for their advice and help in finishing the thesis report on time. Moreover, I am also obliged for sharing their thoughts and providing constructive feedback on a number of issues related to the report.

First of all, I would like to thank Dr. Kaamran Raahemifar for having faith in me and allowing me to do MEng project. His efforts in helping with project, providing constructive

feedback, encouraging and quick responses are extraordinary and without his support I could not have finished his project.

Moreover, I would also like to thank Mr. Wahiduzzamam Bhuiyan for his help in report material. His input in explanation equipment maintenance procedure was very helpful. 


\section{Table of Content}

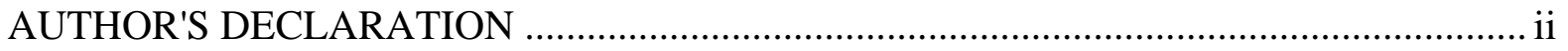

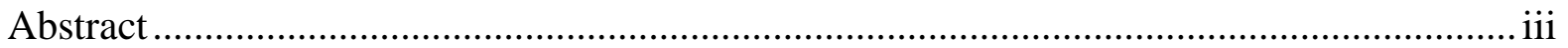

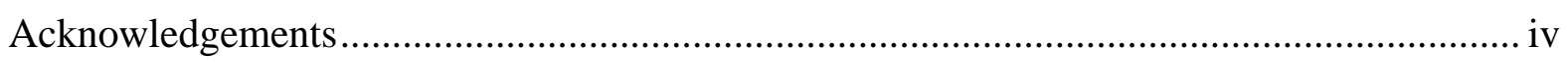

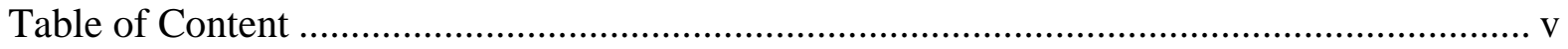

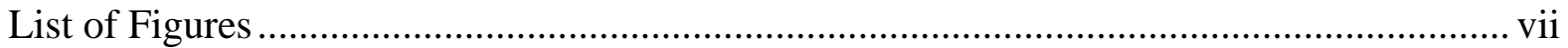

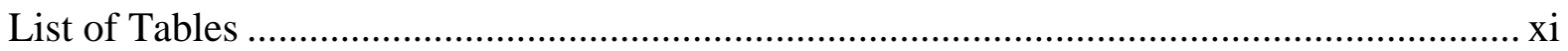

List of ANSI Device Number ......................................................................................

Chapter 1 Introduction ................................................................................................... 1

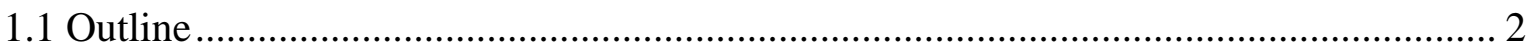

1.2 Causes of abnormalities and types of fault........................................................... 3

Chapter 2 Power system and symmetrical components............................................................ 6

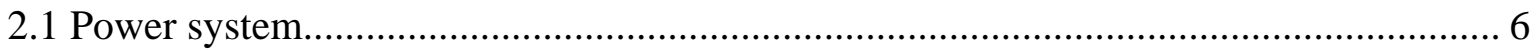

2.2 Phasors and symmetrical components.................................................................... 7

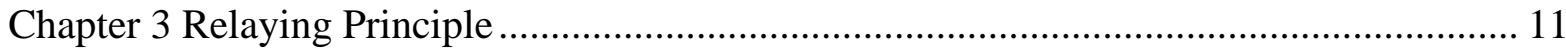

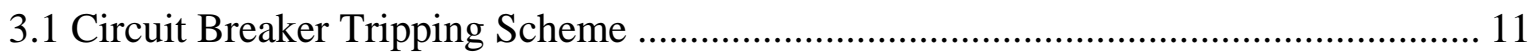

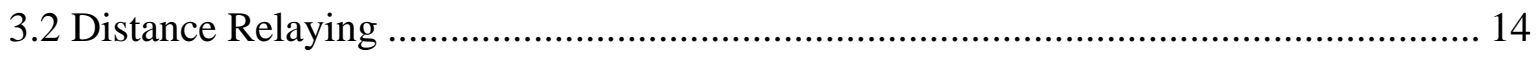

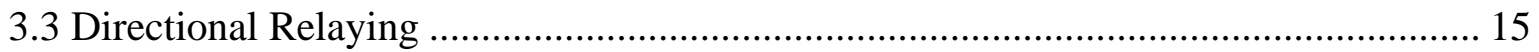

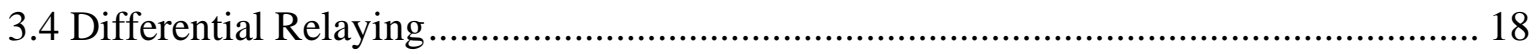

Chapter 4 Instrumentation, Protection and Coordination .................................................... 21

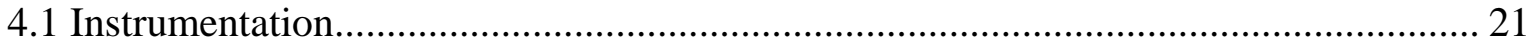

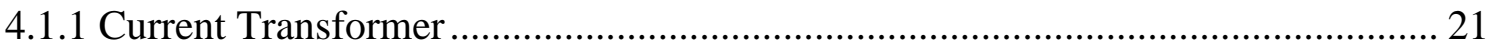

4.1.2 Voltage Transformer or Potential Transformer ................................................. 25

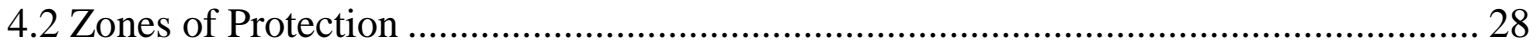

4.3 Overcurrent Protection and Coordination ................................................................. 29

Chapter 5 Generation Protection.......................................................................................... 35

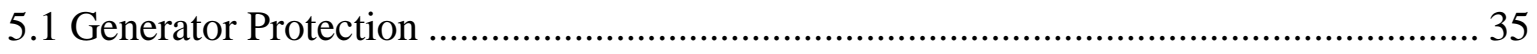

5.1.1 Generator Phase Faults ...................................................................................... 40 


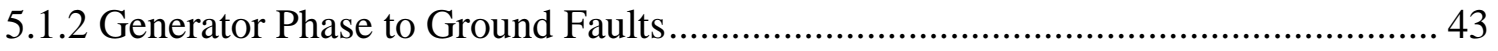

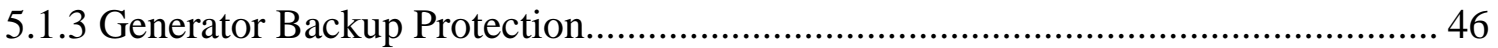

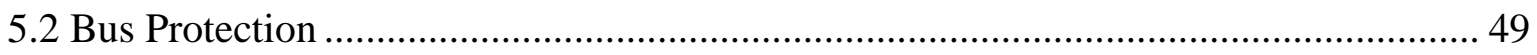

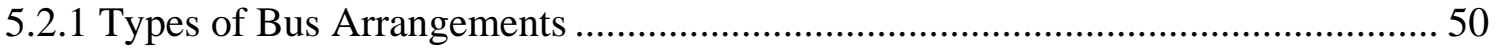

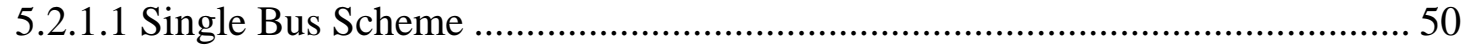

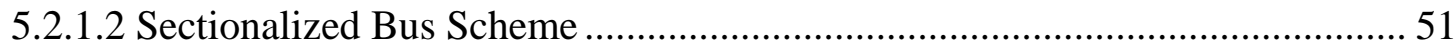

5.2.1.3 Main and Transfer Bus Scheme ............................................................... 52

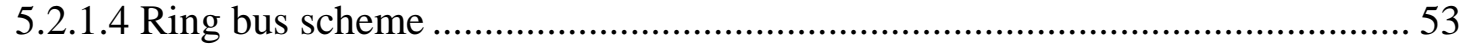

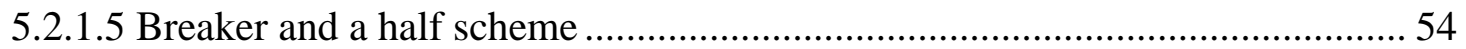

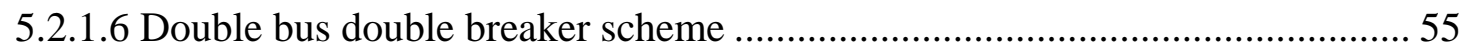

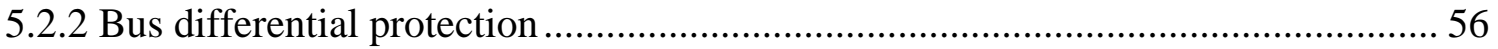

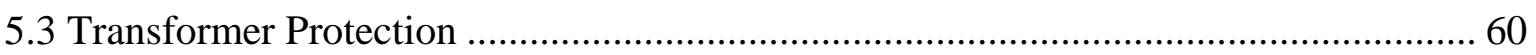

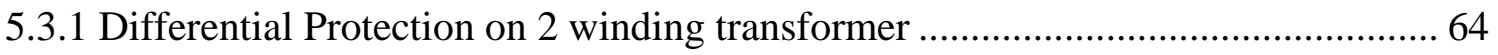

5.3.2 Differential Protection on 3 winding transformer ......................................... 70

5.3.3 Ground Fault Protection .................................................................................. 74

5.3.4 General Protection Scheme of Transformer .................................................... 77

Chapter 6 Transmission and Distribution Line Protection ............................................... 79

6.1 Overcurrent protection on radial system ............................................................. 80

6.2 Overcurrent Protection of Loop System.............................................................. 84

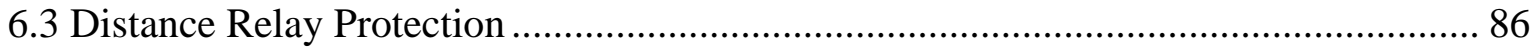

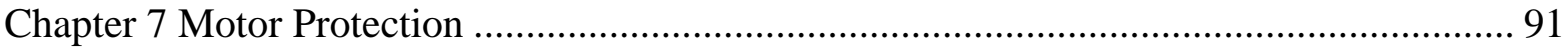

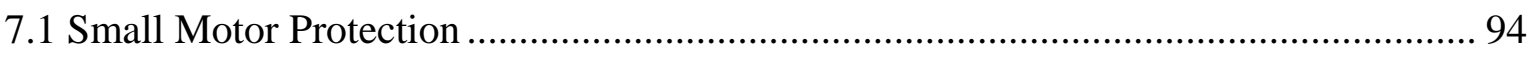

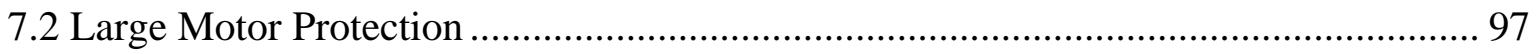

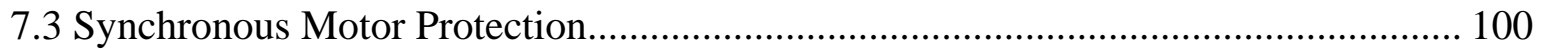

Chapter 8 Simulation and Calculation ..................................................................... 104

Chapter 9 Conclusion and Future Recommendation ................................................... 113

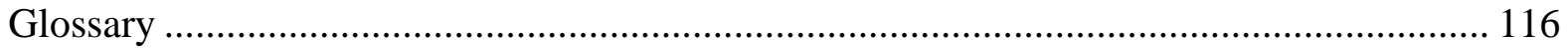

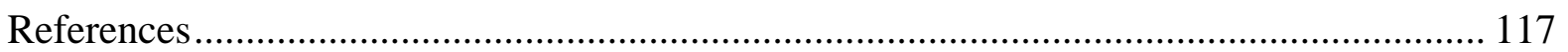




\section{List of Figures}

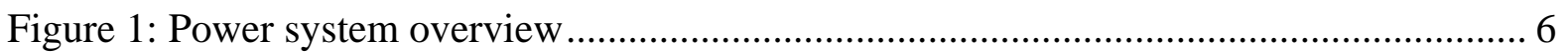

Figure 2: Wye connected system with different faults for phasor representation .................. 7

Figure 3: Positive, Negative and Zero Sequence Voltage ................................................. 8

Figure 4: Phasor diagram of balanced three phase wye connected system prior to fault ........ 9

Figure 5: Basic Protection Scheme for relay operation ............................................ 11

Figure 6: Relay tripping circuit (Before fault condition) .............................................. 12

Figure 7: Relay tripping circuit (After fault condition) ............................................. 13

Figure 8: Relay tripping circuit (manual switch closed) ............................................. 13

Figure 9: Explanation of Distance Relay principle by balance beam concept ..................... 14

Figure 10: Distance relay protection scheme ............................................................. 15

Figure 11: Distribution substation configuration for illustration of directional relay ........... 16

Figure 12: Fault on line A in distribution substation configuration................................... 16

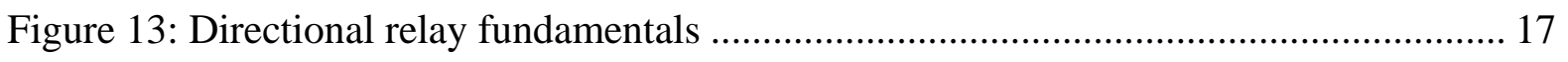

Figure 14: External fault at differential relay ............................................................. 18

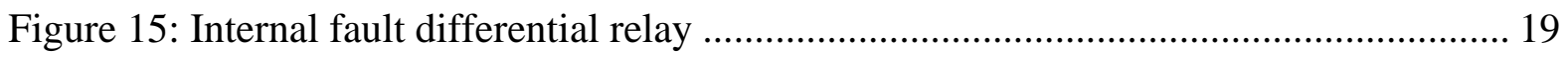

Figure 16: High Voltage Current transformer ........................................................... 21

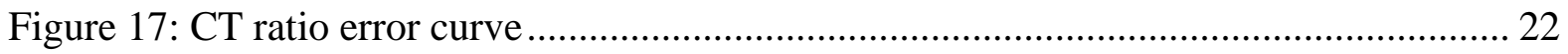

Figure 18: Relation between CT current and flux without saturation .............................. 23

Figure 19: Relation between CT current and flux with saturation.................................... 24

Figure 20: Typical overcurrent ratio curve for a T class CT ….................................... 25

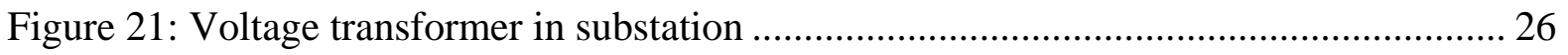

Figure 22: Open delta configuration for line to line voltage .......................................... 27

Figure 23: Three VT configuration for line to neutral voltage ........................................ 27

Figure 24: Power system protection zones ............................................................. 28

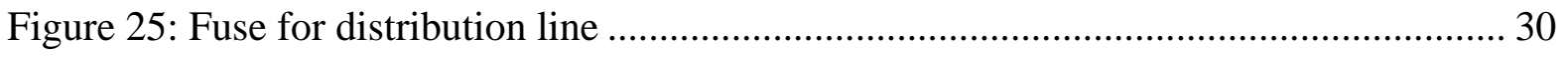

Figure 26: Protection and coordination using instantaneous relay ................................... 30

Figure 27: Protection and coordination using time delayed relay operation ....................... 31 
Figure 28: Types of inverse time relay characteristics ............................................... 32

Figure 29: Automatic Circuit Reclosers ......................................................................... 33

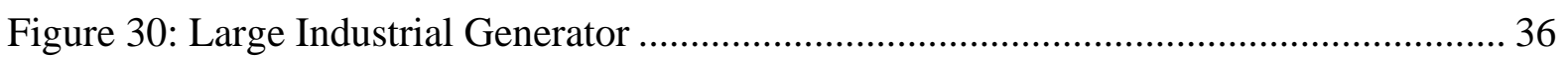

Figure 31: Small generator connection to common bus ............................................... 37

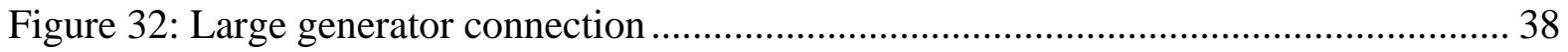

Figure 33: Turbine Generator before fault ................................................................... 39

Figure 34: Turbine generator after fault..................................................................... 39

Figure 35: Differential protection scheme for the $\mathrm{Y}$-connected generator .......................... 40

Figure 36: Differential protection scheme for the $\Delta$-connected generator ......................... 41

Figure 37: Single line diagram of generator protection scheme ........................................ 42

Figure 38: Protection scheme for generator directly connected to Bus ............................... 42

Figure 39: Generator ground fault protection ............................................................ 43

Figure 40: Ground differential protection for multiple generators ................................. 45

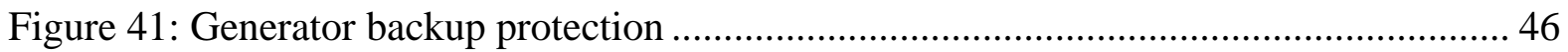

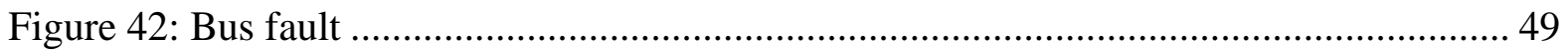

Figure 43: Single bus configuration with ground fault at the bus................................... 50

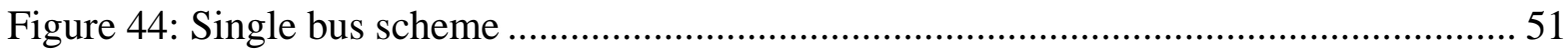

Figure 45: Sectionalized bus scheme ….................................................................... 52

Figure 46: Main and transfer bus scheme ................................................................ 53

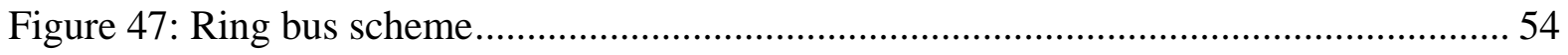

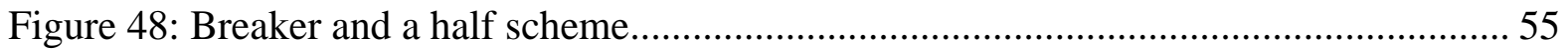

Figure 49: Double bus double breaker scheme ........................................................ 56

Figure 50: Bus Differential Protection with internal fault ............................................... 57

Figure 51: Bus differential protection with external fault ........................................... 58

Figure 52: Bus differential relay with multiple restraint coils ....................................... 59

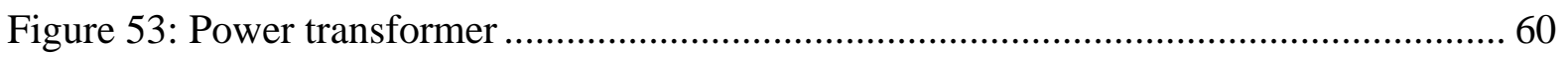

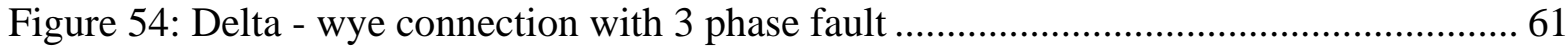

Figure 55: Delta - wye with phase to phase fault..................................................... 61

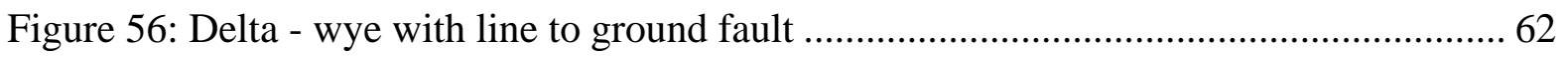




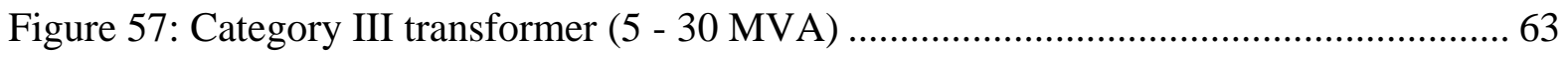

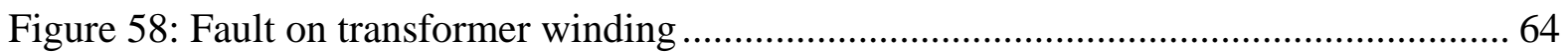

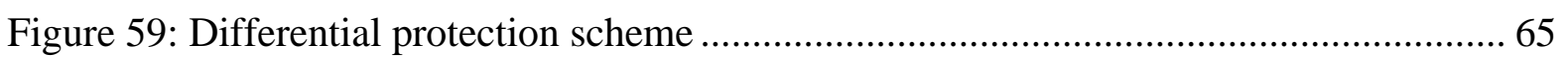

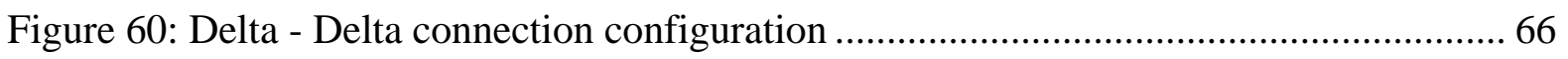

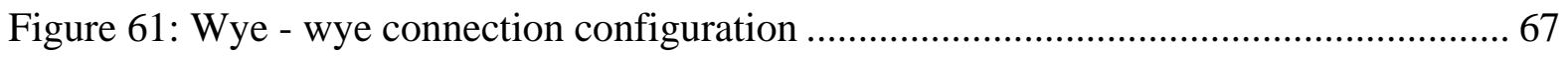

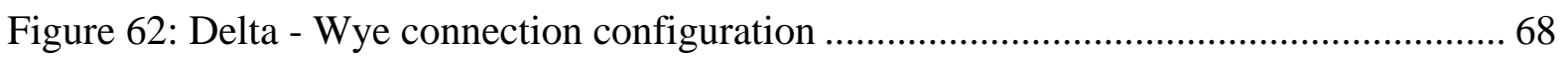

Figure 63: Differential protection of transformer example................................................. 69

Figure 64: Three winding transformer configuration ........................................................... 71

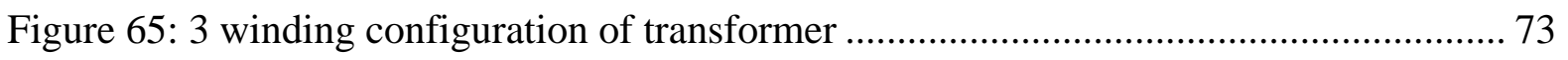

Figure 66: System configuration for illustration of ground fault protection ........................... 74

Figure 67: Ground differential relay protection scheme with external fault ........................... 75

Figure 68: Ground differential relay protection scheme with internal fault ............................ 76

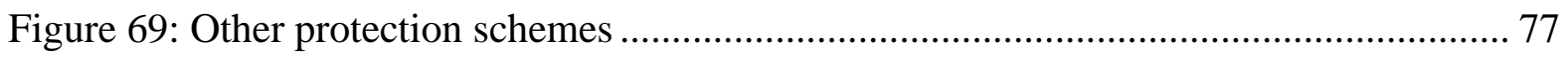

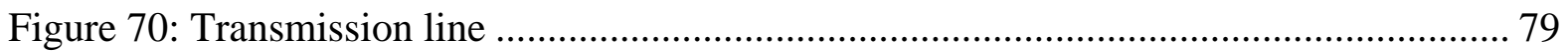

Figure 71: Transmission line structure failure …………….............................................. 80

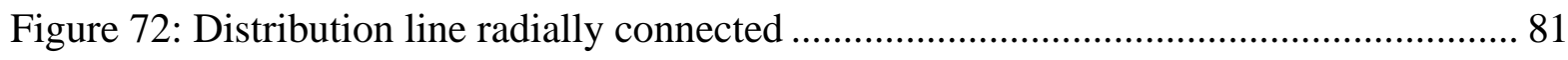

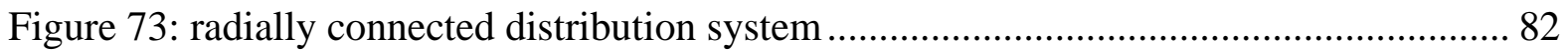

Figure 74: Protection against ground fault protection in the radial line ............................... 83

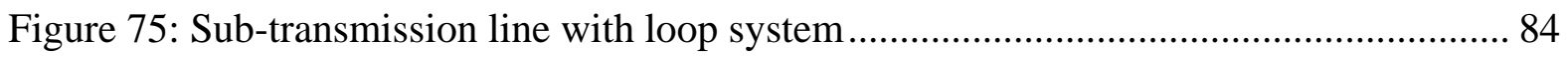

Figure 76: Distance relay protection on transmission line....................................................... 86

Figure 77: Example of Under-reaching fault detection in transmission line .......................... 88

Figure 78: Example of Over-reaching fault detection in transmission line ............................ 89

Figure 79: Motor start up curve ……….......................................................................... 91

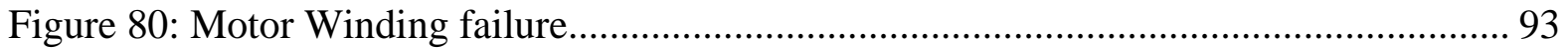

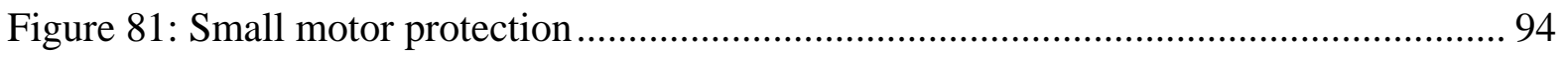

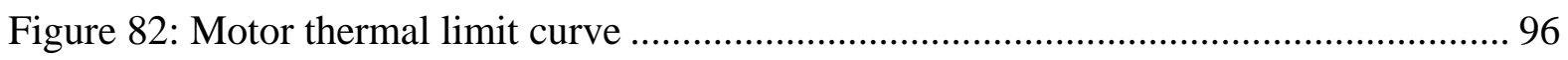

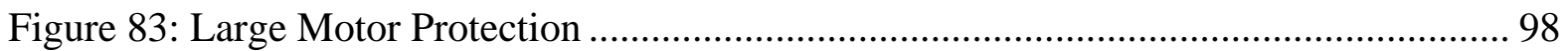

Figure 84: Toroidal CT configuration stator ground fault ................................................. 99

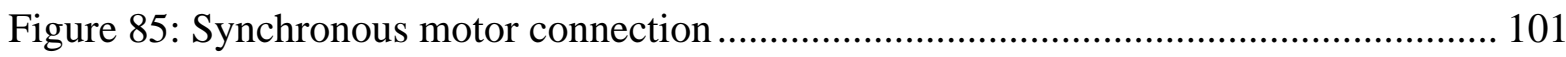




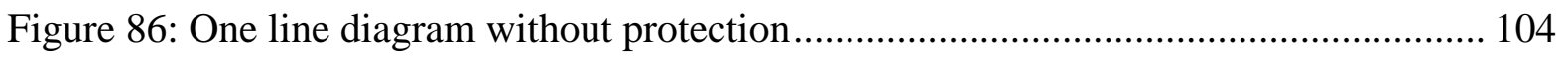

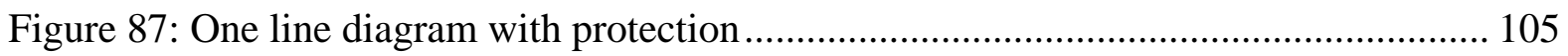

Figure 88: Time current coordination of existing system without changes made ................ 106

Figure 89: Time current coordination of existing system with changed relay settings ........ 107 


\section{List of Tables}

Table 1: Different types of faults, description and chance of occurrence ............................ 4

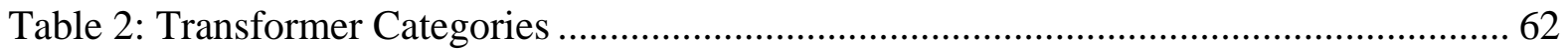

Table 3: Transformer short-time thermal overload capability ......................................... 63

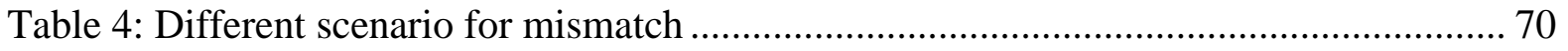

Table 5: Mismatch calculation for differential relay protection ........................................ 72

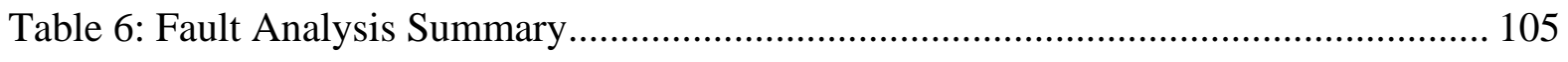

Table 7: Parameters for common substation cables (600V Insulation) .............................. 112 


\section{List of ANSI Device Number}

\section{Device Number}

\section{Description}

\author{
Distance Relay
}

Under-voltage relay

Directional power relay

Loss of Field Relay

Negative sequence relay

Phase sequence relay

Thermal Relay

Instantaneous relay

Overcurrent relay

Voltage restraint overcurrent relay

Power factor relay

Overvoltage relay

Gas Pressure Relay

Directional Relay

Out of step relay

Differential Protection Relay

xii 


\section{Chapter 1}

\section{Introduction}

Often when it comes to design electrical systems, protection is considered to be the most important aspect. Either it is a safety of a personnel or safety of equipment or system. The objective of this report is to provide educational material about the importance of power system protection to students in the field of electrical engineering. In power industry, protective relaying is absolutely vital part of power system. It impacts on all areas of the system such as power generation, transmission, distribution and utilization. Therefore protection must be provided to all these areas. A system can easily collapse under a fault where adequate protection is not provided. From the point of electricity generation to utilization, there are numerous reasons to which a fault can occur and protection scheme is designed considering these conditions. However, if the protection scheme do not operate correctly then it can affect the reliability of power supplied to customers as well as the result can be extensive damage with high repair cost and perhaps long outage times. It can affect the daily life of millions of users. The primary objective of all power systems is to maintain continuity of service to customers. When fault occurs, the protection equipment must function as expected to reduce damage to minimum and at the same time minimize, outage time to all customers.

This report discusses working principles of power system equipment such as motor, generator and transformer. Moreover, it also discusses different type of faults on power system equipment such as generator, bus, lines, transformer and motor. Furthermore, various protection schemes to prevent such faults are also discussed. Reading the material included in this report will provide better understanding, of what types of faults, where it occurs and why such protection scheme is used, to the reader. The purpose of power system protection is to provide safety to public, improvement of system stability, protect the system against overloading conditions and minimize the damage to the system under abnormal conditions. The main objective of the power system protection is to provide isolation to the system from

the faulted section so that system can be prevented from severe damage and continuous power can be supplied. 


\subsection{Outline}

This report is divided into 9 chapters. Chapter 2 discusses power system and phasors and symmetrical components. Chapter 3 introduces the concept of relaying principle. Main purpose of this chapter is to discuss different types of relaying schemes such as differential protection, directional protection and distance protection. Moreover, circuit breaker tripping scheme is also discussed in this section. Instrumentation, Protection and coordination is discussed in chapter 4 . This chapter is divided into 3 subsections. First subsection talks about instrument transformers which includes current and voltage transformers. Second sub-section talks about zones of protection. Each equipment or part of system is divided into different protection zones and its importance is discussed. Last subsection discusses overcurrent protection and coordination. It discusses overcurrent protection devices such as fuses, reclosers and relays and its operation. Chapter 5 outlines the generation protection. This chapter includes three main subsections which discuss generator protection, bus protection and transformer protection. In first subsection of generator protection, different type of faults, such as phase to phase faults, ground faults, backup protection and system disturbances, and its protection scheme is explained in 4 subsections. Bus protection is explained in second subsection. In bus protection, various types of bus arrangements and its advantages and disadvantages are shown. Moreover, bus differential protection is also discussed. Last subsection discusses the protection schemes of transformer. In this section, Differential protection on 2 winding and 3 winding transformer is described. Furthermore, protection against ground fault is also explained in a subsection. In addition to the common faults, other protection, such as thermal protection and gas accumulation, are discussed in a subsection titled general protection scheme of transformer. Protection for transmission and distribution line is discussed in chapter 6. Radial lines and loop connections are discussed in subsection. Moreover, major importance is given to the discussion of distance relay protection which is used widely in line protection worldwide. Chapter 7 discusses about motor protection. This chapter discusses the motor protection against insulation failure, overload, stalling of motor,

unbalanced power supply, under-voltage and loss of power. Moreover, synchronous motor protection is also discussed in this chapter. 


\subsection{Causes of abnormalities and types of fault}

Main causes of abnormal conditions are usually natural events, physical accidents, equipment failure or faulty-operation. The natural events which can cause problems to power systems are lightning strike, earthquake, snow storm, falling tree or fire explosion. On the other hand, physical accidents can be results of vehicle crashing into electricity distribution pole, animal or human coming into contact with live equipment, a flying object coming into contact with live transmission lines or digging into underground cables during construction. Moreover, breakdown of insulation in a transformer or in cables due to water-trees can be considered as equipment failure. Furthermore, faulty operation would be if the operator unintentionally or carelessly closed the breaker to energize a line which was still solidly grounded. All of these abnormal conditions will result in a fault of phase - phase or phase ground connection.

In power system, chances of occurrence of phase to ground fault is high. It can be due to over-current or due to bad insulation or it can also happen due to contact of physically grounded material. When the power factor is low, the current flowing through the transmission lines is high and it causes stress on insulation of the machine, overhead lines as well as equipment connected to system. Therefore, chances of phase - phase and phase ground fault increases. Power can be transmitted through overhead lines as well as underground cables. Table 1 shows the historical data of chances of fault occurrence. Three phase shorted is the severest fault that can occur in the system therefore engineers use that fault as a base to calculate material strength required for distribution cable and other power system equipment. From table 1, the chances of single phase to ground fault occurrence is

$70 \%$ but the other faults listed in table 1 rely on single phase to ground fault. The chances of those faults to occur increases due to phase to ground fault. 
Table 1: Different types of faults, description and chance of occurrence

\begin{tabular}{|c|c|c|c|c|}
\hline NO & $\begin{array}{l}\text { Type of } \\
\text { short } \\
\text { circuit }\end{array}$ & Description & Representation & $\begin{array}{l}\text { Percentage } \\
\text { occurrence }\end{array}$ \\
\hline 1 & $\begin{array}{l}\text { Single } \\
\text { Phase to } \\
\text { Ground }\end{array}$ & $\begin{array}{l}\text { Due to breakdown of } \\
\text { insulation between one } \\
\text { of the phases and } \\
\text { ground. }\end{array}$ & \begin{tabular}{l|l} 
& \\
& \\
$\underline{-}$
\end{tabular} & $70 \%$ \\
\hline 2 & $\begin{array}{l}\text { Phase to } \\
\text { phase }\end{array}$ & $\begin{array}{l}\text { Due to breakdown of } \\
\text { insulation between } \\
\text { either of the two } \\
\text { phases. }\end{array}$ & & $15 \%$ \\
\hline 3 & $\begin{array}{l}\text { Two } \\
\text { phase to } \\
\text { ground }\end{array}$ & $\begin{array}{l}\text { Due to the breakdown } \\
\text { of insulation between } \\
\text { two phases and } \\
\text { ground. }\end{array}$ & & $10 \%$ \\
\hline 4 & $\begin{array}{l}\text { Phase to } \\
\text { phase } \\
\text { and } \\
\text { third } \\
\text { phase to } \\
\text { ground }\end{array}$ & $\begin{array}{l}\text { Due to breakdown of } \\
\text { insulation between two } \\
\text { phases and } \\
\text { simultaneous } \\
\text { breakdown of } \\
\text { insulation between } \\
\text { third phase and } \\
\text { ground. }\end{array}$ & & 2 or $3 \%$ \\
\hline 5 & $\begin{array}{l}\text { All } \\
\text { three } \\
\text { phase to } \\
\text { ground }\end{array}$ & $\begin{array}{l}\text { Due to breakdown of } \\
\text { insulation between all } \\
\text { three phases and } \\
\text { ground. }\end{array}$ & $\stackrel{1}{=}$ & 2 or $3 \%$ \\
\hline 6 & $\begin{array}{l}\text { All } \\
\text { three } \\
\text { phase } \\
\text { shorted }\end{array}$ & $\begin{array}{l}\text { Due to breakdown of } \\
\text { insulation between all } \\
\text { three phases. }\end{array}$ & & 2 or $3 \%$ \\
\hline
\end{tabular}

Due to the physical protection underground cable suffer from faults quite rarely. One cause might be due to digging into a cable and causing short circuit during construction. Moreover, underground cable could also suffer from insulation breakdown perhaps due to 
faulty manufacture or maybe due to extended periods of overload. In most of these cases, the result will be a short circuit between phase conductors and phase to ground.

On the other hand, on overhead lines, faults can be caused by flashover due to lightning. Extremely high peak voltage of the lightning strike causes a flashover on the line insulator to ground and once this is started, fault current will continue to flow even after the lightning stroke has passed. This phase to ground fault will remain as long as power is being supplied to the line. Faults due to lightning are temporary in nature and it disappear as soon as the breakers are open. If two conductors are affected by the lightning strike, then it will be phase to phase to ground fault. The fault has to be cleared quickly to prevent damage to the line and equipment provides power supply to the line. The protection against the faults due to lightning strike can be protected by reclosing arrangement. If there is a fault, the relay or switch will open isolating faulty section. However, the recloser will close after few seconds (a time set for the relay to reclose). If the fault is a permanent fault then associated breaker will open again and reclosing device will lockout so as to leave the line isolated. 


\section{Chapter 2}

\section{Power system and symmetrical components}

\subsection{Power system}

The power system overview is shown in figure 1. It shows all aspect of power system from generation to utilization. First part of the system is electricity generation. As shown in the figure electricity is generated at hydroelectric and thermal generation facility and connected to a step-up transformer. This step-up transformer increases the voltage level required for electricity generation. Generated electricity is transmitted through transmission line to the switching terminal station. From switching terminal station, electricity is transmitted through sub transmission lines to large industrial customers. However, if the customer is a small facility or commercial or residential customer then it is further stepped down to transmit to these customers through distribution lines.

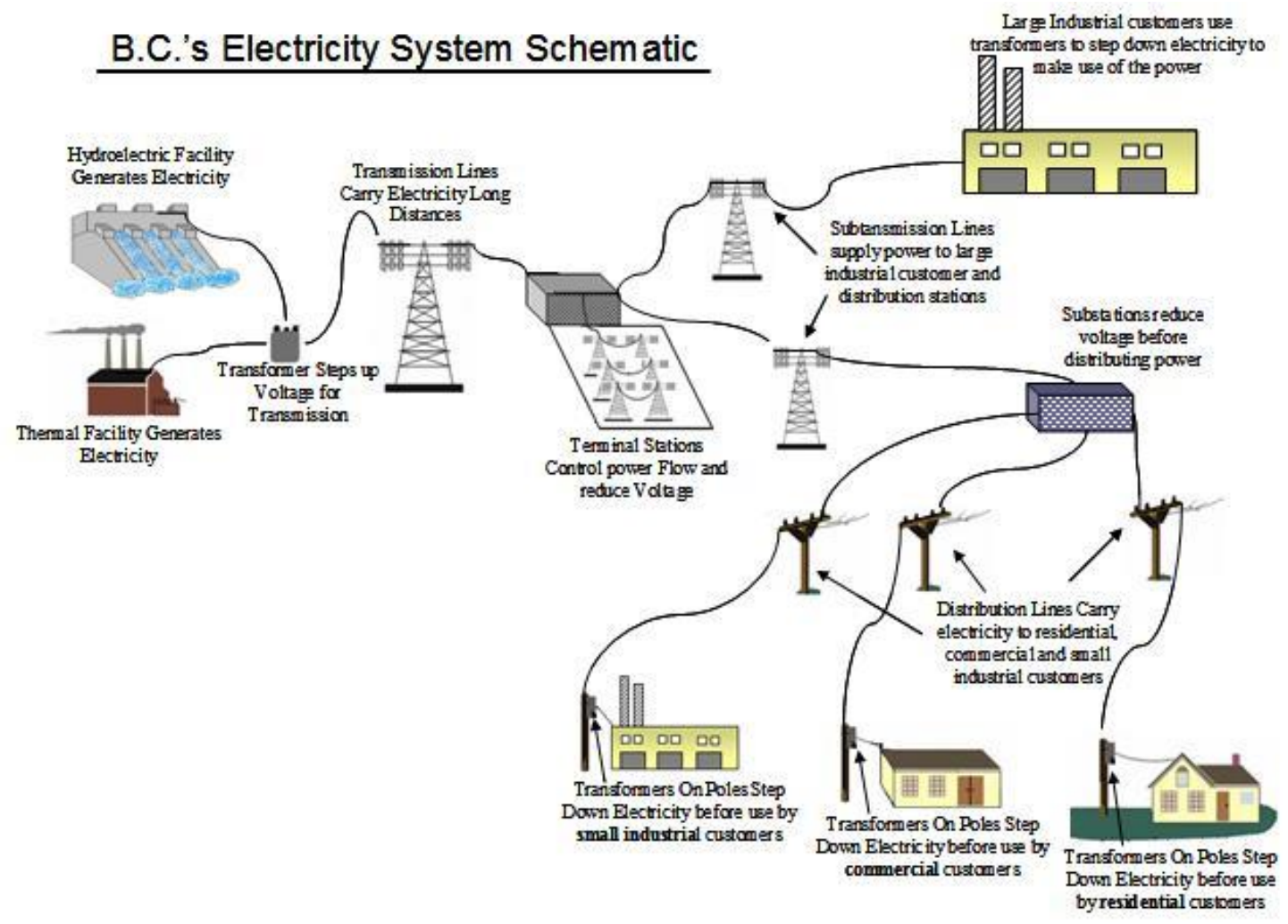

Figure 1: Power system overview 


\subsection{Phasors and symmetrical components}

Figure 2 shows three phase wye connected system with neutral solidly grounded. In wye connected system line current and phase currents are same but line voltages and phase voltages are different. $F_{1}, F_{2}, F_{3}$ and $F_{4}$ represents 3 phase bolted fault, phase to phase fault, phase to phase to ground fault and phase to ground fault respectively. When the system is working in normal operating condition and assuming the system is balance, the phase representation of currents $\left(\mathrm{I}_{\mathrm{A}}, \mathrm{I}_{\mathrm{B}}, \mathrm{I}_{\mathrm{C}}\right.$ ), line to line voltages $\left(\mathrm{V}_{\mathrm{AB}}, \mathrm{V}_{\mathrm{BC}}, \mathrm{V}_{\mathrm{CA}}\right)$ and phase voltages $\left(\mathrm{V}_{\mathrm{AN}}, \mathrm{V}_{\mathrm{BN}}, \mathrm{V}_{\mathrm{CN}}\right)$ are shown in figure 4 . The line voltages lead the phase voltages by $30^{\circ}$ and the angle difference between line voltages and between phase voltages will be $120^{\circ}$.

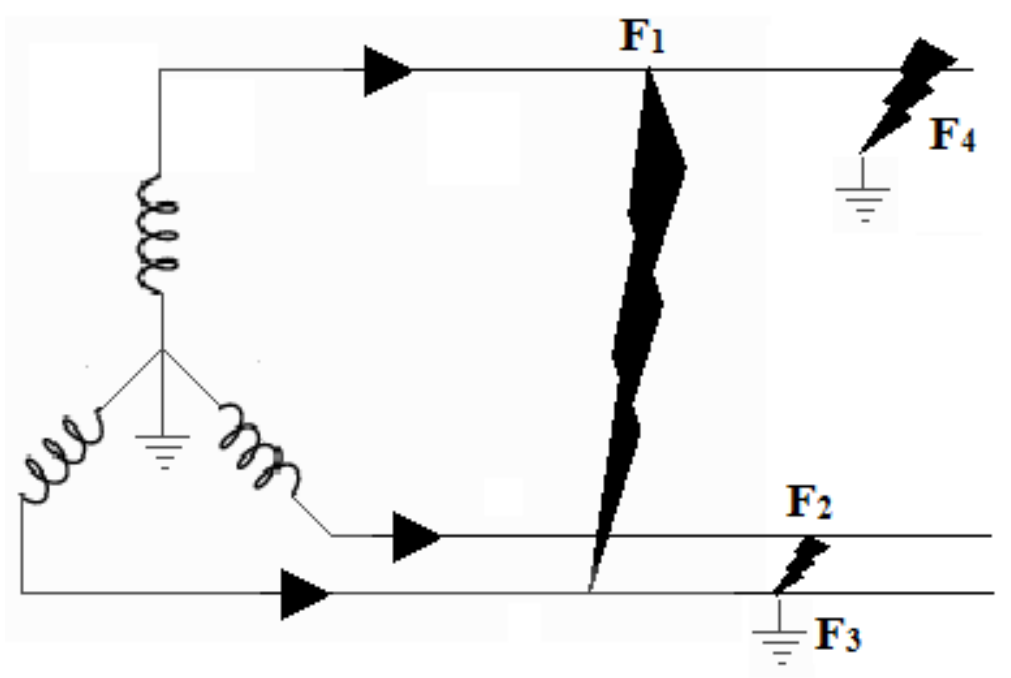

Figure 2: Wye connected system with different faults for phasor representation

Only positive sequence current is flowing under balance conditions. In figure 3 the positive sequence voltages are shown as $\mathrm{V}_{\mathrm{A} 1}, \mathrm{~V}_{\mathrm{B} 1}$ and $\mathrm{V}_{\mathrm{C} 1}$, Negative sequence voltages are shown as $\mathrm{V}_{\mathrm{A} 2}, \mathrm{~V}_{\mathrm{B} 2}$ and $\mathrm{V}_{\mathrm{C} 2}$ and zero sequence voltages are shown as $\mathrm{V}_{\mathrm{A} 0}, \mathrm{~V}_{\mathrm{B} 0}$ and $\mathrm{V}_{\mathrm{C} 0}$. The current sequence components are similarly balanced.

Now suppose there is a 3 phase fault, $F_{1}$, as shown in figure 2. In this situation the system will be still balanced. Therefore, it will still maintain the phase relationship of line voltages leading phase voltages by $30^{\circ}$ as it is shown in figure 4 . However, the magnitude of line and phase voltages will reduce drastically and the current in the system will increase. The angle of line current is determined by the nature of the system impedance, generator 
impedance and line impedance, to the fault. In this type of fault, only positive sequence current will flow in the system because there is no change in phase relationship between voltages and currents.

On the other hand, phase to phase fault, $F_{2}$, makes a big impact on voltages and currents because the system will be unbalanced. The line voltages and phase voltages will be much lower on faulted lines B and C. Moreover, the angle between the phase voltages will be less than $120^{\circ}$ due to unbalanced conditions. This causes a change in phase relationship between $\mathrm{V}_{\mathrm{AB}}$ and $\mathrm{V}_{\mathrm{AN}}$ and it will be less than $30^{\circ}$. Since the fault includes phase $\mathrm{B}$, the magnitude of line voltage $\mathrm{V}_{\mathrm{AB}}$ will reduce as well. Furthermore, the current $\mathrm{I}_{\mathrm{A}}$ will be zero because all the current will flow to feed the fault. However, current magnitude of $I_{B}$ and $I_{C}$ will increase.
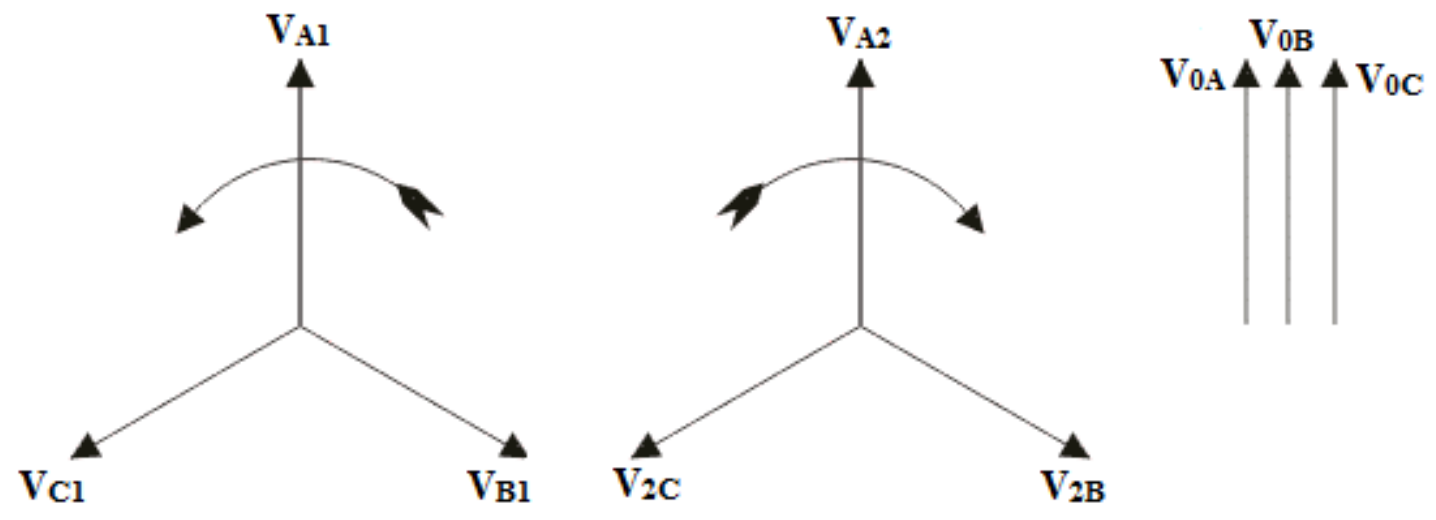

Figure 3: Positive, Negative and Zero Sequence Voltage

When there is a phase to phase fault, the phase voltage $V_{\mathrm{AN}}$ does not have any impact on its magnitude. During the fault, generator is still supplying positive sequence voltage. However, negative sequence voltages are generated due to the fault and imposed on positive sequence voltages. The phase voltages $\mathrm{V}_{\mathrm{BN}}$ and $\mathrm{V}_{\mathrm{CN}}$ are reduced considerably.

The effect of voltage reduction can be explained by introducing the negative sequence voltages which are imposed upon the positive sequence voltage to get the fault voltages. Therefore, when there is a fault, positive sequence voltages are reduces so does the phase voltages. As a result imposing reduced positive sequence voltages by negative sequence voltages gives us the phase relation of negative sequence voltages. The negative sequence 
components phase sequence is opposite of positive phase sequence currents as shown in figure $3[1]$.

Now when phase to phase to ground fault occurs, as shown in figure 2 , fault current $\mathrm{I}_{\mathrm{B}}$ and $\mathrm{I}_{\mathrm{C}}$ will flow to the ground. Magnitude of phase and line voltages and current will be same as phase to phase fault situation. However, phase voltages $V_{B N}$ and $V_{C N}$ will be $120^{\circ}$ apart compared to phase to phase fault.

Another fault, single line to ground fault, will cause the currents $I_{B}$ and $I_{C}$ to be zero because the current will flow to line A to feed the fault. Since it is a single line to ground fault on line $A$, phase voltages $V_{B N}, V_{C N}$ and line voltage $V_{B C}$ will remain the same. However, the magnitude of voltages $\mathrm{V}_{\mathrm{AN}}, \mathrm{V}_{\mathrm{AB}}$ and $\mathrm{V}_{\mathrm{CA}}$ will decrease and current magnitude of $\mathrm{I}_{\mathrm{A}}$ will increase. There is a yet another quantity included in phasor diagram which is zero sequence voltages. The phase sequence does not matter in zero sequence components. In order to get the phase voltage at the fault, all the sequential quantities are added.

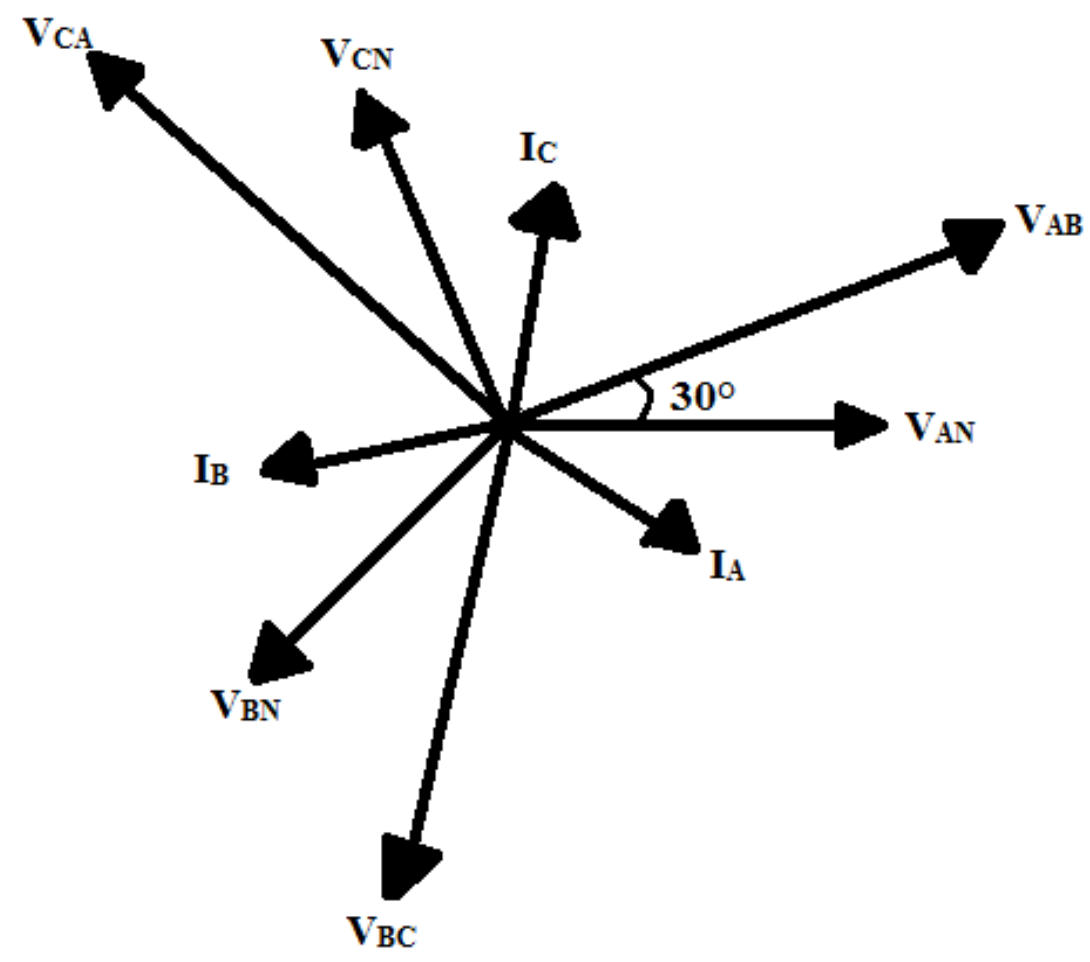

Figure 4: Phasor diagram of balanced three phase wye connected system prior to fault

$$
V_{A}=V_{A 1}+V_{A 2}+V_{A 0}
$$


Same can be said about the current sequence components

$$
\begin{aligned}
& I_{A}=I_{A 1}+I_{A 2}+I_{A 0} \\
& I_{B}=I_{B 1}+I_{B 2}+I_{B 0}
\end{aligned}
$$

The current in phase $B$ is zero. Therefore the addition of these three sequence currents will yield zero value.

In summary, power system protection is very important part of the system in providing reliable power supply, safely operating conditions, system stability and safety to equipment by minimizing damage. Faults occur due to natural events, physical accidents, equipment failure or faulty operation. Moreover, types of fault includes phase to phase, phase to ground, two phase to ground, three phase bolted fault and three phase to ground fault. In these faults, phase to ground fault is the most common fault that occurs on the system or equipment.

In wye connected system, phase currents and line current are same but phase voltages and line voltages are different. Line voltages lead phase voltages by $30^{\circ}$. The angle difference between phase components and between line components is $120^{\circ}$. Under balance operating conditions, only positive sequence component flows in the system. But when there is a phase to phase fault negative sequence currents arises and zero sequence current arises when there is a ground fault. The phase angle relationship changes when there is an unbalance in the system due to fault. 


\section{Chapter 3 \\ Relaying Principle}

Protective relay is a device which detects fault in the system and trips associated circuit breaker. Most relays use the same logic of input, measurement, determination and output. The input represents current or voltage from current transformer or voltage transformer respectively. A relay measures these values and then determines if the circuit operating conditions are within normal parameters. Under normal operating conditions, relay contacts are set to either open or close at rest depending on relay configuration. However, when there is a fault in the system, relay outputs a trip signal to the control circuit. The signal is then fed to one or more circuit breakers to cause them to open so as to isolate the faulty circuit. In this study, it is assumed that the relay contacts are open at rest and the explanation is shown based on this configuration.

\subsection{Circuit Breaker Tripping Scheme}

Figure 5 shows a basic protection scheme for relay and circuit breaker operation for illustration purpose. As it can be seen, input of the relay is voltage coming from secondary of the potential transformer and current coming from secondary of the current transformer [2]. The bus voltage is $33 \mathrm{kV}$ and secondary of the potential transformer provides $120 \mathrm{~V}$ to relay. However, voltage to the relay may rise or fall in proportion to variations in bus voltage. Moreover, current level may change according to the fault in the system.

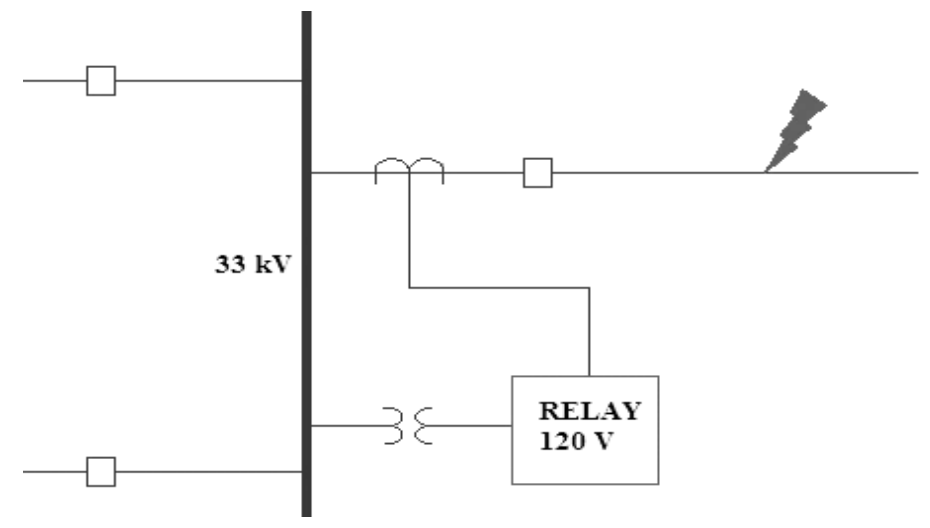

Figure 5: Basic Protection Scheme for relay operation 
Suppose there is a fault in the system at location shown in figure 5. Relay will detect high current and send a tripping signal to open circuit breaker. However, there are different types of relays used in the power system such as over voltage, under-voltage, over-frequency and under-frequency. These relays are discussed in this report.

Figure 6 shows the tripping circuit of circuit breaker. A 125 VDC is provided for operation of the breakers. Circuit breaker closing and tripping contacts are energized by 125 VDC from station battery as it provides a continuous and reliable power supply. When circuit breaker is closed, elementary tripping circuit will be as shown in figure 7. The auxiliary contracts are closed because breaker is closed but the tripping coil will not be energized until either protective relay contacts close or manual switching contacts are operated [3]. Circuit breaker tripping coil and its auxiliary contacts are normally located at the circuit breaker inside of cabinet. However, relay operating contacts are located inside the relay. Manual switching contacts are normally located in the control panel.

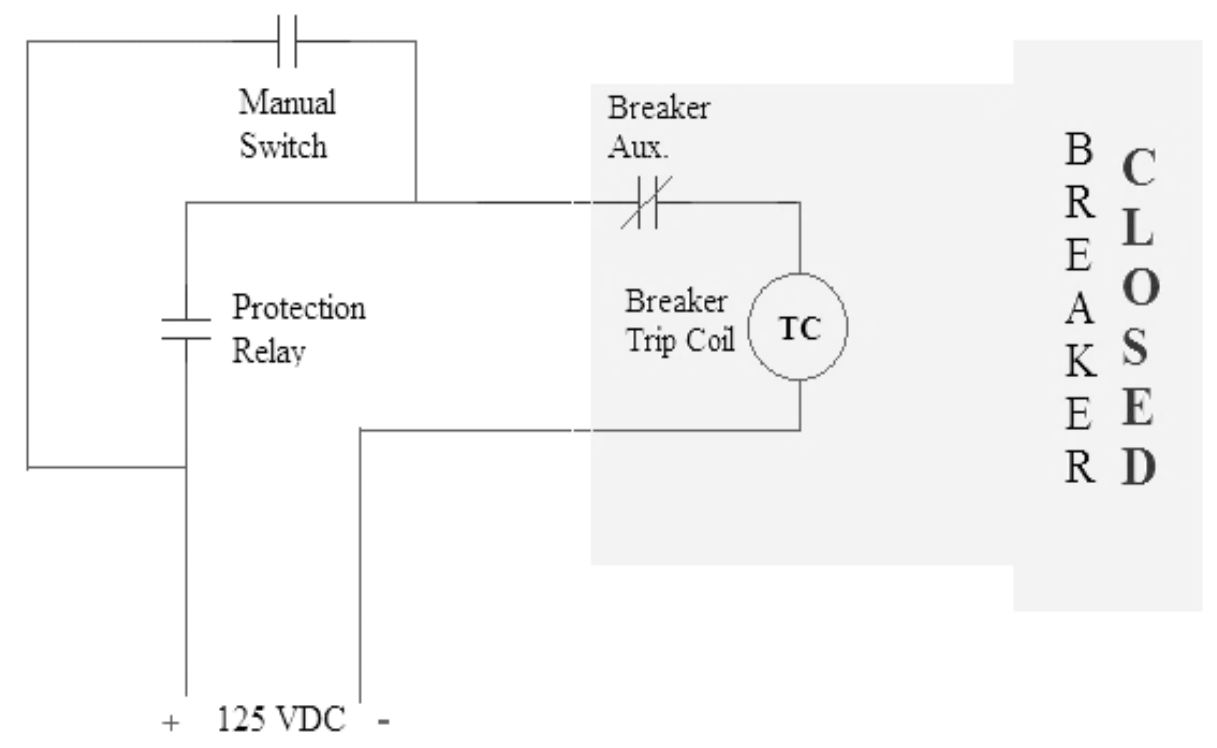

Figure 6: Relay tripping circuit (Before fault condition)

Now when the relay operates due to sensing intolerable conditions, relay contacts will close and this will energize breaker tripping coil as shown in figure 7. This in turn causes the breaker to open and also causes the auxiliary contact to open so breaking DC tripping circuit. 


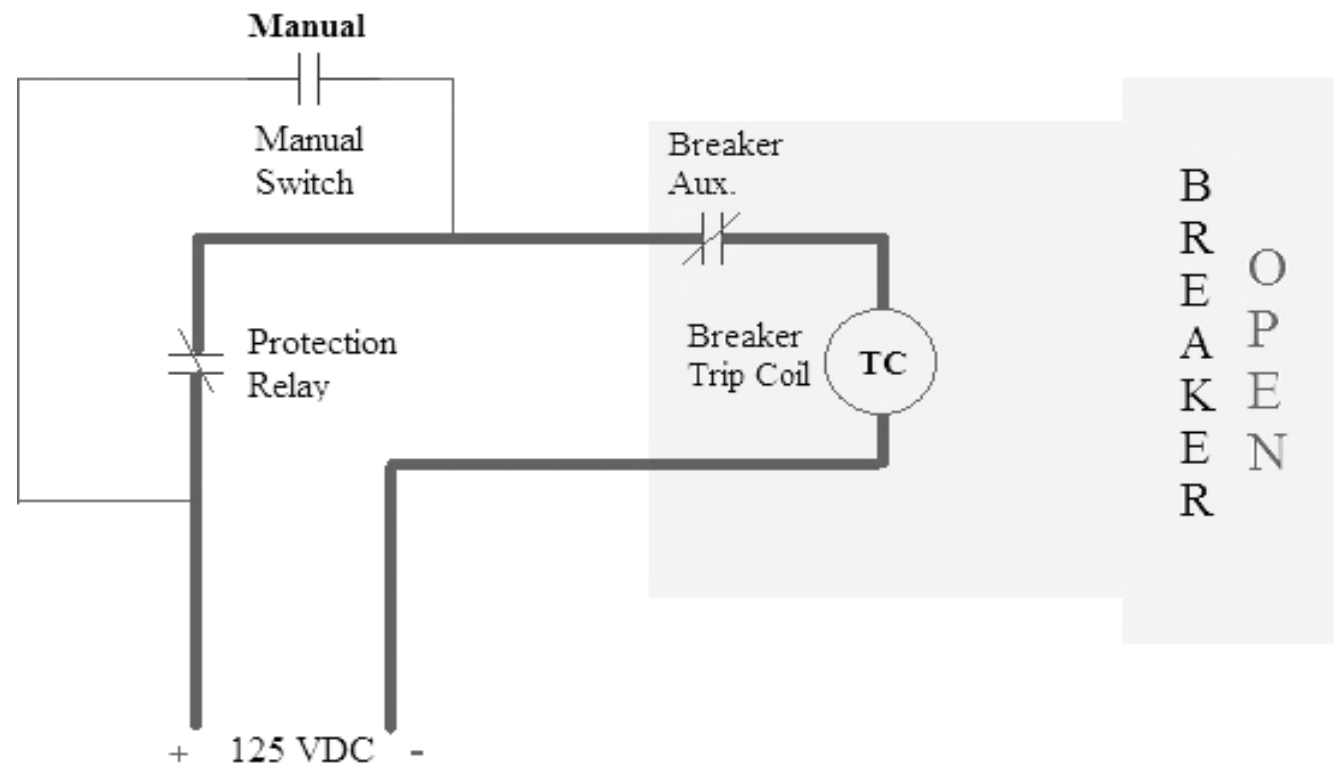

Figure 7: Relay tripping circuit (After fault condition)

Figure 8 shows the configuration when manual switching contacts are operated. Manual switch contacts are closed and breaker tripping coil is energized. When circuit breaker opens, the breaker auxiliary contact opens and hence the breaker tripping circuit is de-energized.

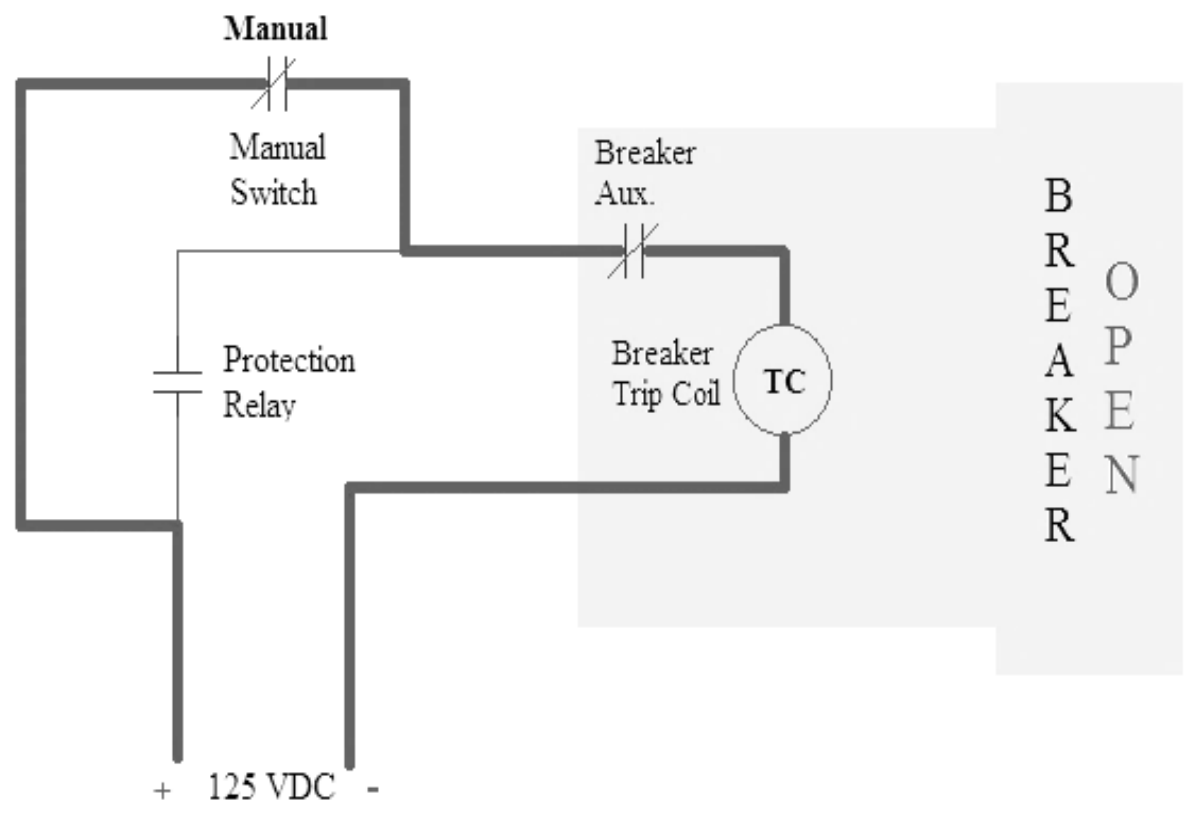

Figure 8: Relay tripping circuit (manual switch closed) 


\subsection{Distance Relaying}

Distance relay operates based on the impedance between fault and relay location. The working principle of the distance relay can be easily explained by balance beam principle shown in figure 9.

Operation of this relay depends on predetermined values of voltage and current fed from potential transformer or bus in line and current transformer respectively. Voltage produces the restoring torque and the current produces the deflecting torque [4]. Under normal operating conditions, voltage is quite larger than current. As a result the restoring torque is higher than the deflecting torque. Therefore contact will be at rest as shown in figure 9 .

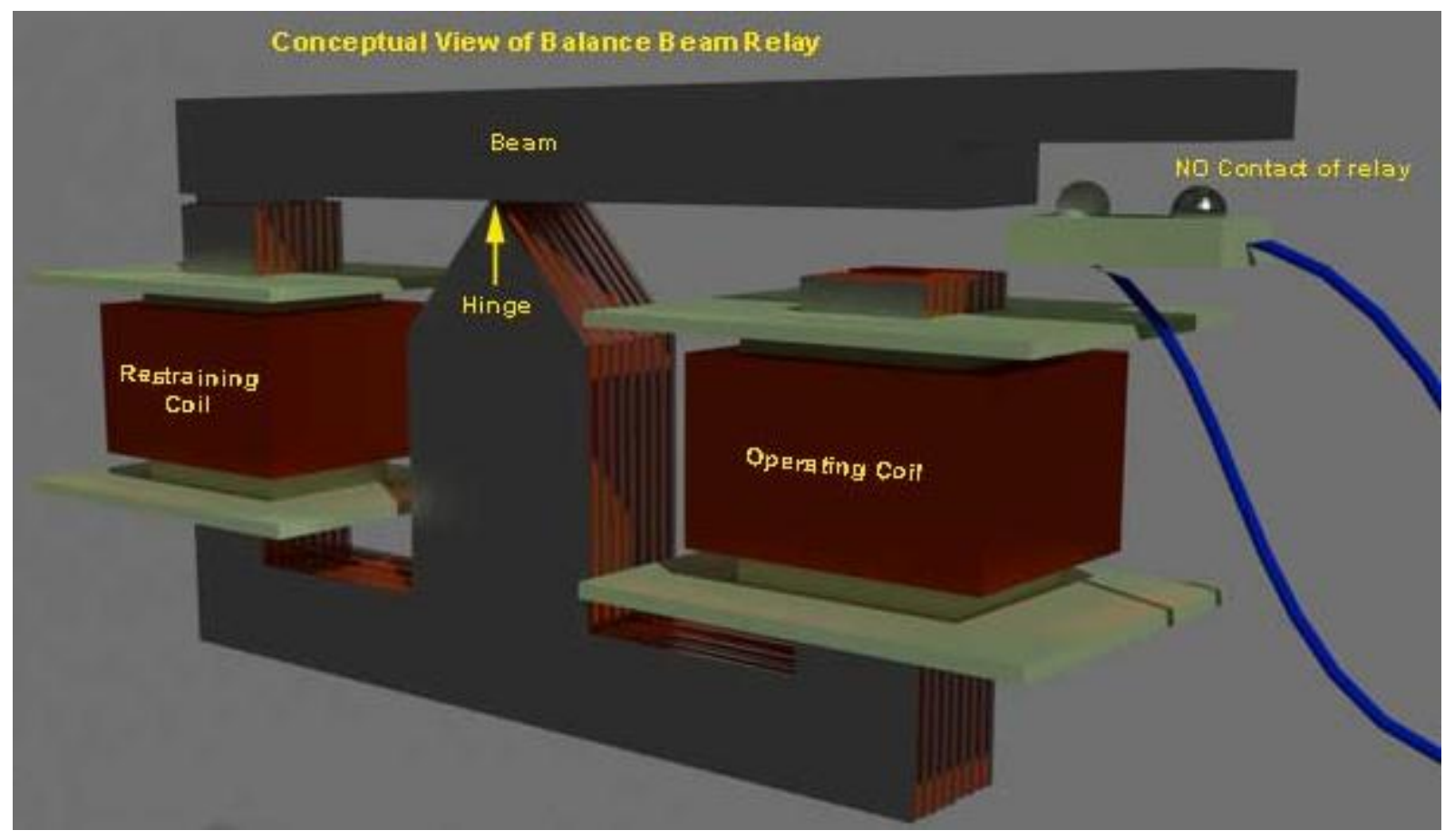

Figure 9: Explanation of Distance Relay principle by balance beam concept

When there is a fault in the system, current will increase drastically and voltage decrease accordingly. Hence the deflecting torque increases and restoring torque decreases and the dynamic parts of the relay starts operating which ultimately close the normally open contact of relay. Since the input of relay is the ratio between voltage and current, this relay is also called impedance relay. Figure 10 shows the distance relay protection scheme. 


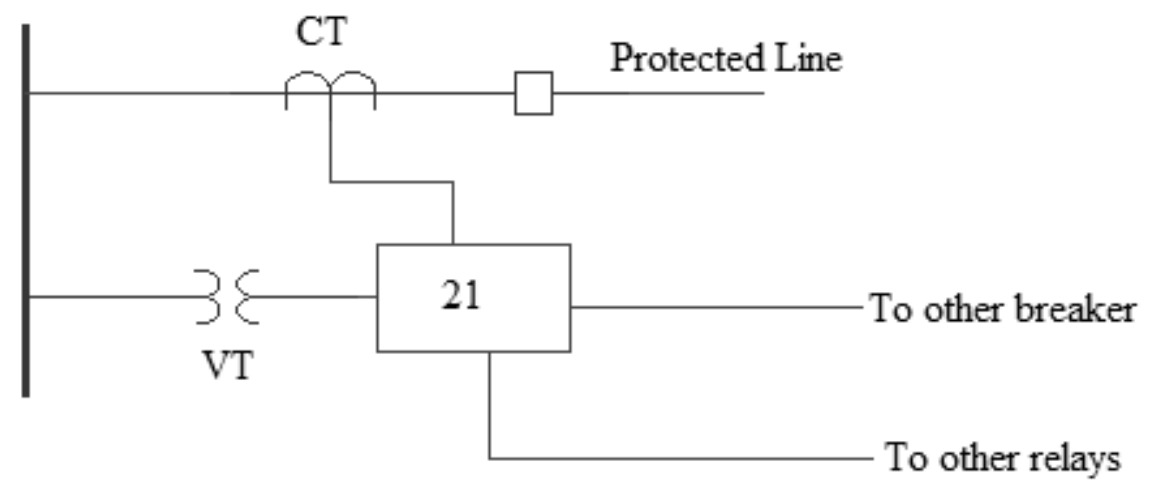

Figure 10: Distance relay protection scheme

When there is a fault in line, the impedance of line is only that of the conductor themselves which is a very small value. Due to the fault, current increases in such a high magnitude. Therefore relay is set to operate when measured impedance falls below a specific value. If the impedance per mile of line conductors is known then the impedance relay can be set to trip for faults within any particular distance from the relay. Moreover, as the impedance of the transmission line is directly proportional to its length, it can be said that the distance relay only operates within predetermined fault distance.

\subsection{Directional Relaying}

When the overcurrent relay senses fault current, it will operate irrespective of the direction of current. Figure 11 shows the configuration of high voltage bus in a distribution substation. It is fed from sub transmission lines which are part of a continuous loop. In this arrangement, current may flow in or out of sub transmission line depending upon the conditions or system configuration in other parts of loop. If there is a fault on one of line, then the second line will feed continuous power supply to the load.

Now suppose a fault occurs on line A as shown in figure 12. Fault current will flow from line B through the bus to feed the fault on line A in addition to the load on the bus. Overcurrent relay on line A senses the overcurrent situation and begin to operate according to its characteristic. However, current in line B has also increased to feed the fault therefore the breaker on line B will also sense high-level current and start the trip in process. In fact line B 
is also feeding the distribution load and therefore passes greater current than line A. If the relay on line B trips then the substation is left without any power supply at all.

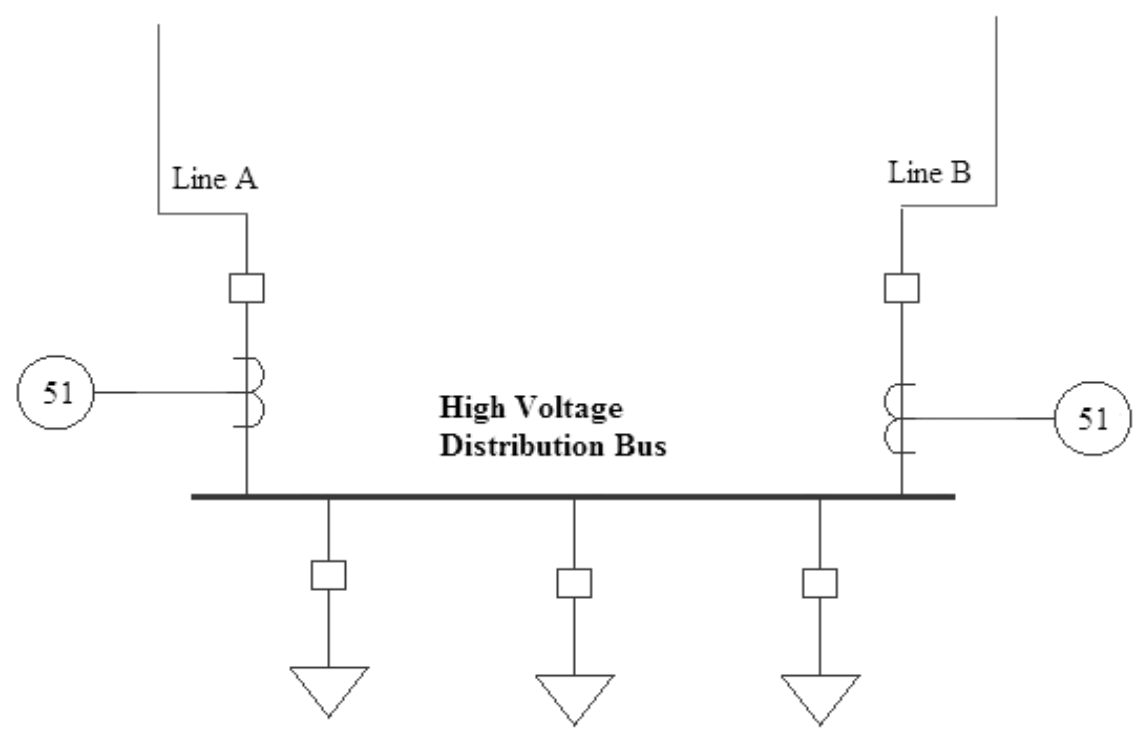

Figure 11: Distribution substation configuration for illustration of directional relay

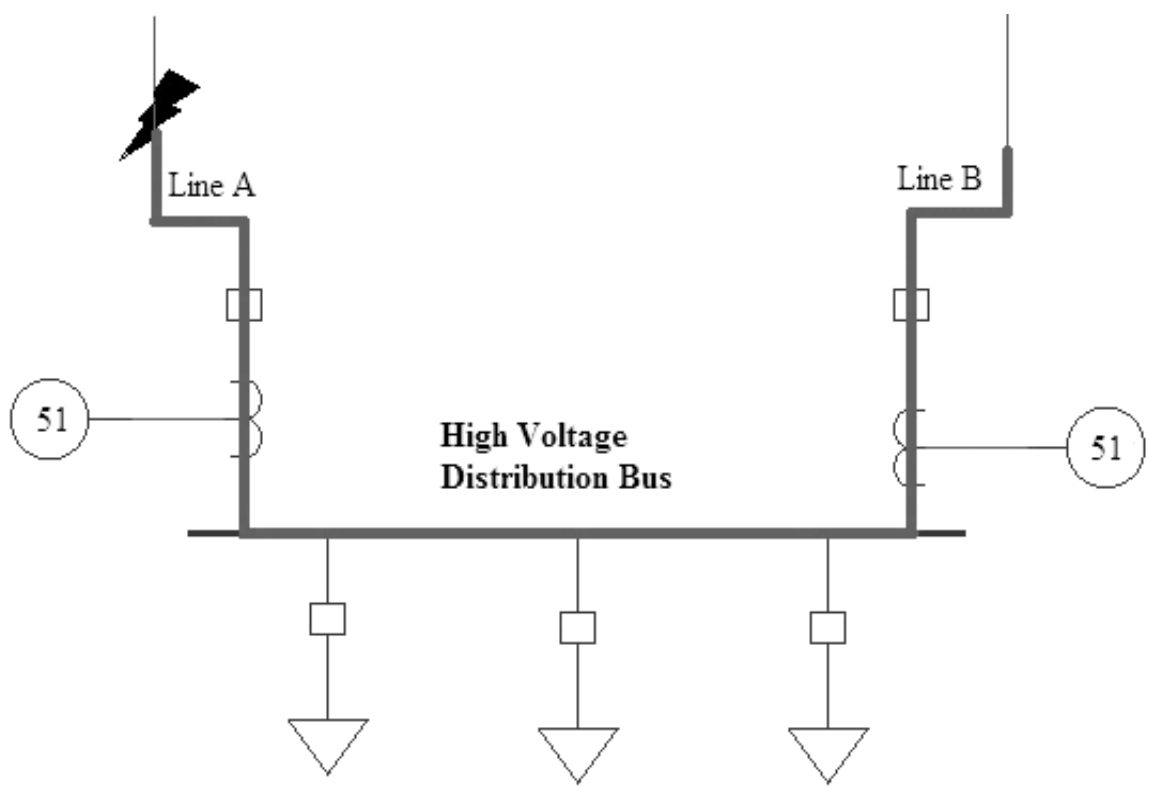

Figure 12: Fault on line $A$ in distribution substation configuration 
In order to avoid this situation, directional overcurrent relay is used. Now with line A fault, the directional element blocks overcurrent relay on line B from tripping when current flow is into the bus. However, it will allow the operation of overcurrent relay A to trip when the current flow is out of the bus. For both these lines the correct tripping direction is when current flow is out of the bus into the line. In the case of a bus fault, current will flow into the bus from both feeders. Then both overcurrent relays will be blocked from operation by their respective direction relays. The fault would be cleared by other protection relays tripping out the same breakers.

The principle of directional relay is to compare the direction of current flow with some fixed reference of current or voltage. The phase angle of the current is compared with reference. The important point is that the polarity of the reference quantity voltage or current must not change even under different fault conditions. Figure 13 shows that the reference quantity is voltage obtained from potential transformer and current is measured by CT in the protected line.

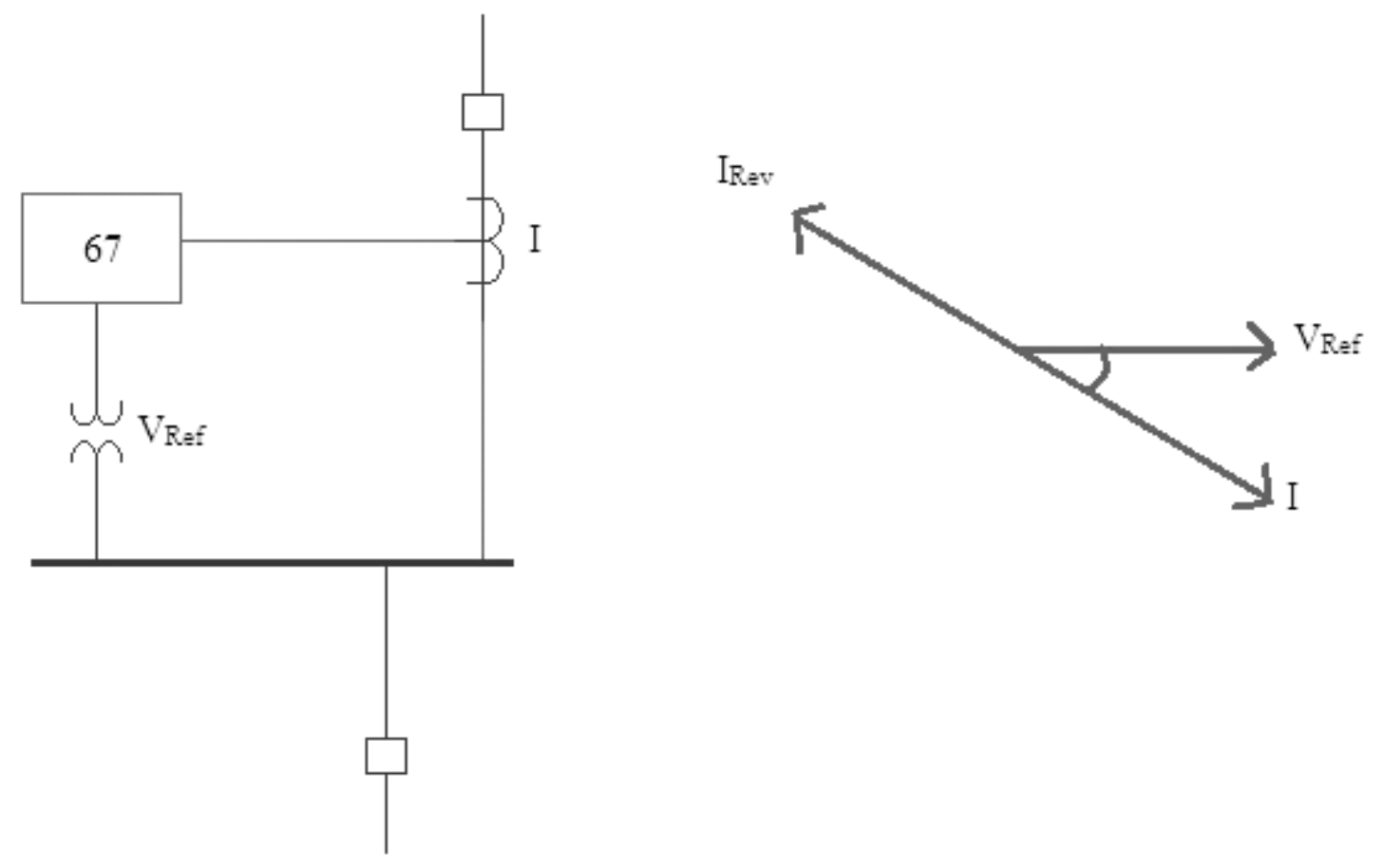

Figure 13: Directional relay fundamentals 
As it can be seen in the figure above that the phase angle of the current is lagging the voltage by 20 degrees. However, during faulty condition where current flow reverses the phase angle will change by 180 degrees. This large change in phase angle will be easy for relay to detect and activate the directional element.

\subsection{Differential Relaying}

In some situations, it is difficult to apply overcurrent relays due to coordination problem and excessive fault clearance time problems. In these cases differential protection is applied. Basic principle of differential protection is to measure current at each end of the selected zone and to operate where there is a difference between them [5]. In figure 14, simple differential protection scheme is illustrated. The protected circuit can be any equipment such as transformer, generator, motor and transmission line. Primary and secondary currents of the system are denoted by $I_{p}$ and $I_{s}$ respectively. In normal operating conditions, the secondary current flowing through CT 1 and CT 2 are the same. As a result there is no current flowing through differential relay.

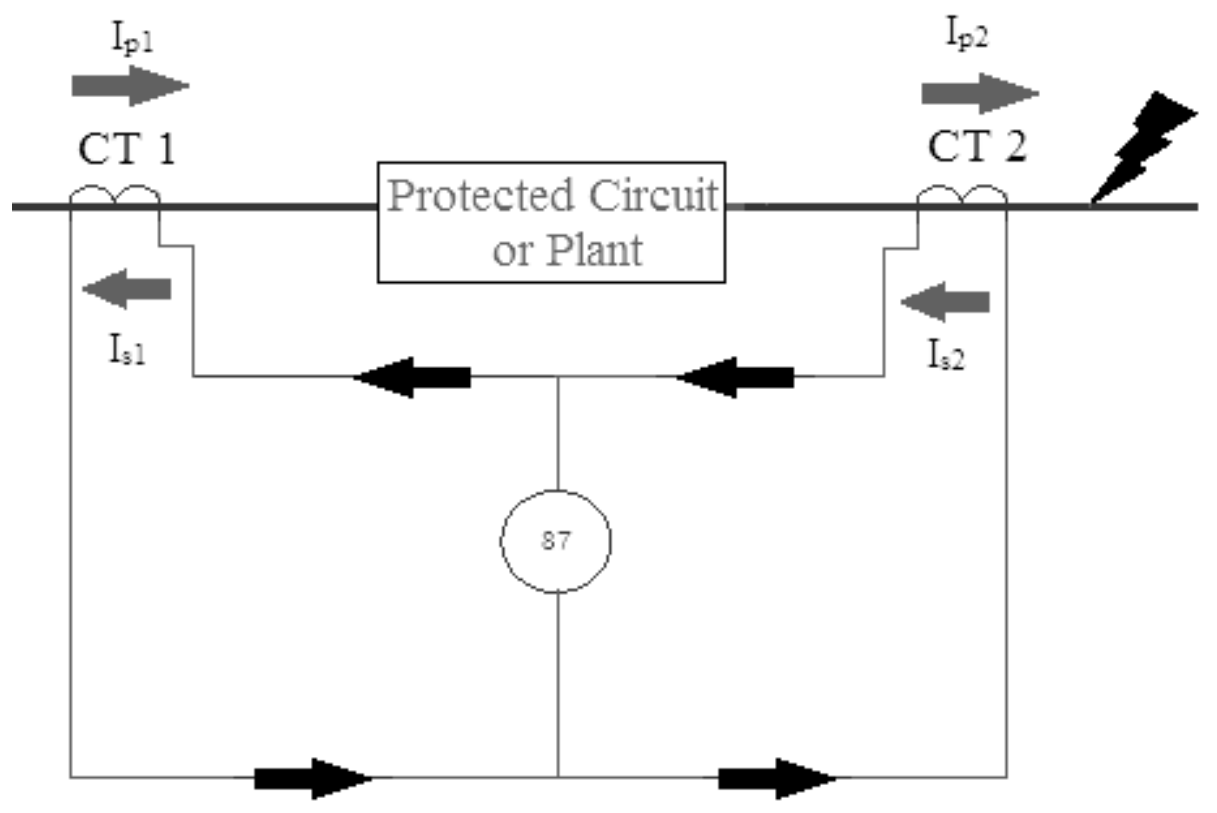

Figure 14: External fault at differential relay 
Now taking scenario 1 into consideration, there is a fault outside of the zone as shown in figure 14. The fault current will pass through both CTs to the fault. Since the fault current passing through both CTs is the same, secondary current of both CTs will be the same as well. Therefore, the relay will not sense the fault. Even though the fault current is very high, based on the differential relay configuration, there will be no current flowing through the relay path. However, the differential relay will operate during the internal fault. Figure 15 shows the differential relay configuration with internal fault. When there is an internal fault, as shown in figure 15, the current will flow through both CTs but in opposite direction. Hence there will be difference in current which will flow through the differential relay and the relay will send trip signal to the circuit breaker.

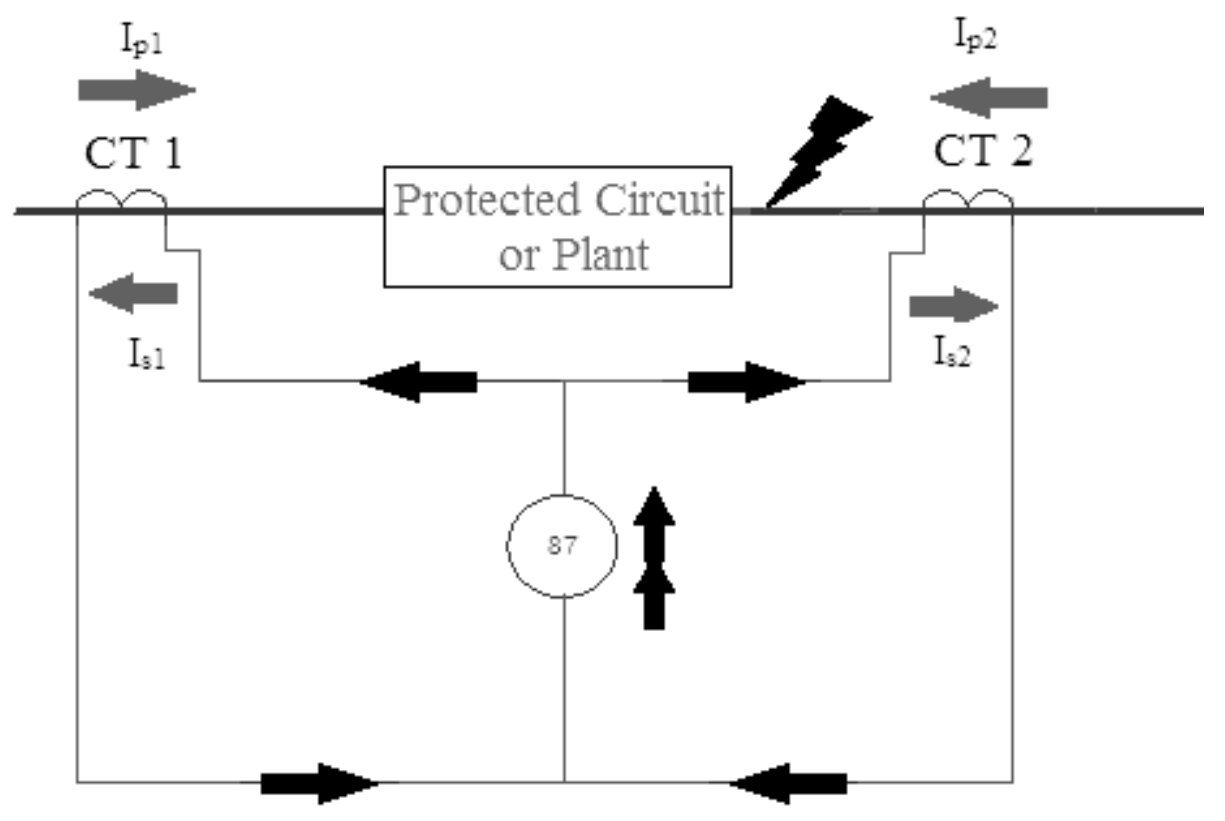

Figure 15: Internal fault differential relay

The problem with differential protection is the location of two current transformers. When the differential protection is applied to the equipment such as transformer then the CT location will be local but in case of transmission lines, the location will be remote which might cause problems if adequate pilot protection scheme is not applied. 
In summary, the circuit breaker will trip after getting a trip signal from relay. Trip signal can be sent for either fault which produces high current in the system or through manual switching contacts when the breaker needs to be out for maintenance. In relaying techniques, there are 3 techniques explained in this chapter. Distance relaying takes current and voltage as input and measures impedance. Based on the current and voltage in the system, the distance relay is set to operate. So when there is a fault in the system, the impedance falls below the zone of protection which is set to operate. Another technique is directional relay protection. Current or voltage quantity is taken as reference. Polarity of the reference quantity voltage or current must not change even under different fault conditions. If the direction of current flow changes then phase angle changes by $180^{\circ}$. This large change in phase angle will be easy for relay to detect and activate the directional element. The last protection scheme is differential protection which works based on measurement of current at each end of the selected zone and operate where there is a difference between them. Differential relay will operate only when there is a fault only inside of protection zone. When there is a fault outside protection zone then current will pass through both CTs to the fault. However, the fault current passing in both CTs primary and secondary will be same. Therefore the relay will not operate. But there is an internal fault, the current will flow through both CTs but in opposite direction. Hence there will be difference in current which will be detected by differential relay and it will send trip signal to the circuit breaker. 


\section{Chapter 4}

\section{Instrumentation, Protection and Coordination}

\subsection{Instrumentation}

In power system, high voltage circuit have voltage in kilo volts $(\mathrm{kV})$ and current is in kilo amperes $(\mathrm{kA})$. Therefore in order to measure voltage and current, it is not vise to connect relays directly to the grid. Moreover, relays cannot be operated at that level due to protection and safety of equipment and personnel. Therefore it is necessary to bring these voltage and current down to a level that can be safely operated. Current transformers (CT) and voltage transformers (VT), also called potential transformer (PT), step down the power system current and voltage to a safe working levels. This provides significant protection to the relay and also to personnel working on the protection equipment. Low voltage and current also cause the relay equipment to be made small. Precise measurement of current and voltage is important to provide proper protection to the power system.

\subsubsection{Current Transformer}

The current transformer is a device that produces an alternating current in secondary proportional to measured current in primary.

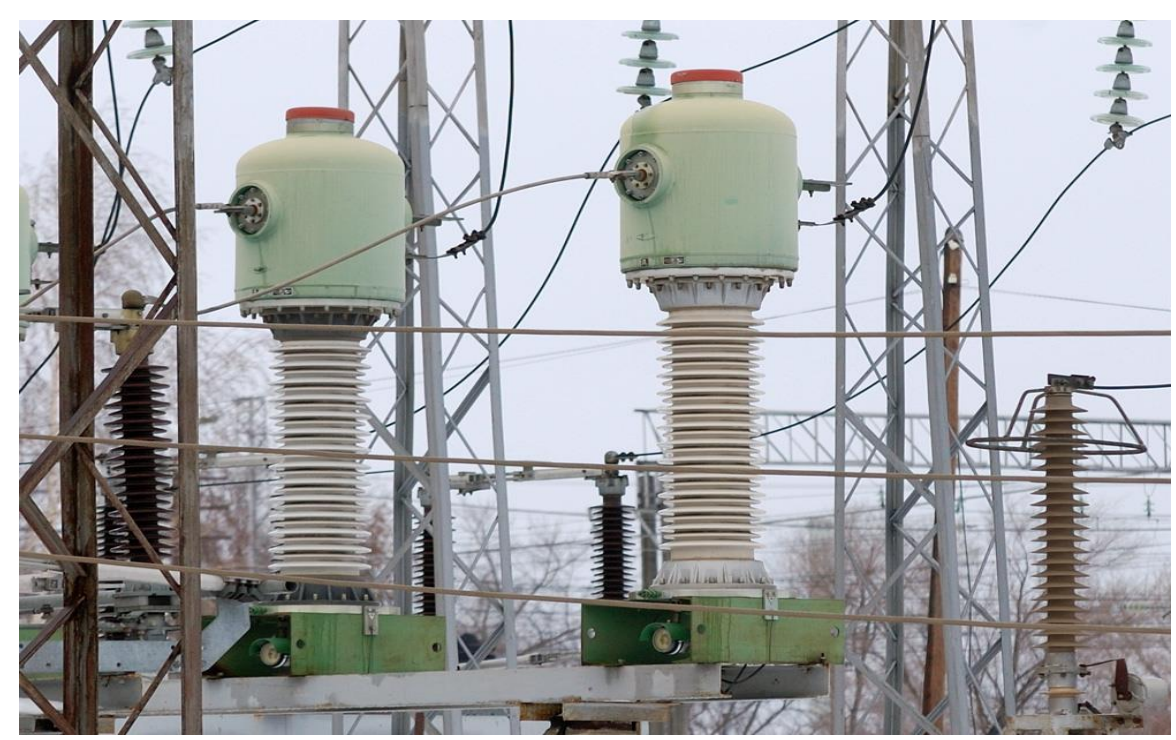

Figure 16: High Voltage Current transformer 
A high voltage current transformer installed in switchyard is shown in figure 16. Compared to primary winding, which has fewer turns, secondary winding has higher number of turns to reduce the current measured to a small amount, usually at a standard of 1A to 5A, for monitoring purposes. The primary and secondary current and number of turns have a relationship shown below.

$$
\frac{N_{P}}{N_{S}}=\frac{I_{S}}{I_{P}}
$$

In an ideal CT the ratio can be calculated from the equation shown above. The maximum current that flows through the system which does not overload any equipment or components is considered when designing CTs. This current then needs to be reduced to a standard value of $1 \mathrm{~A}$ to $5 \mathrm{~A}$. Using equation 1 , the number of turns is calculated. During the design of current transformer the core has to be magnetized which can be done by using a small amount of current supplied to the primary. This will result in current distortion which is induced in secondary of current transformer which leads to errors in result. There are two errors encountered due to this distortion. One is a ratio error and second is a phase angle error. In order to compensate for these errors, correction factors are calculated and provided by the manufacturer. The phase angel error is mainly affects the metering. Therefore it is not discussed in detail in this report. Figure 17 shows the ratio error correction factor curve for current transformer. For normal full load current, the ratio correction factor is negligible. However, ratio correction factor increases as the secondary current increases significantly over rated value. To obtain true ratio, current transformer ratio must be multiplied by ratio correction factor [8]

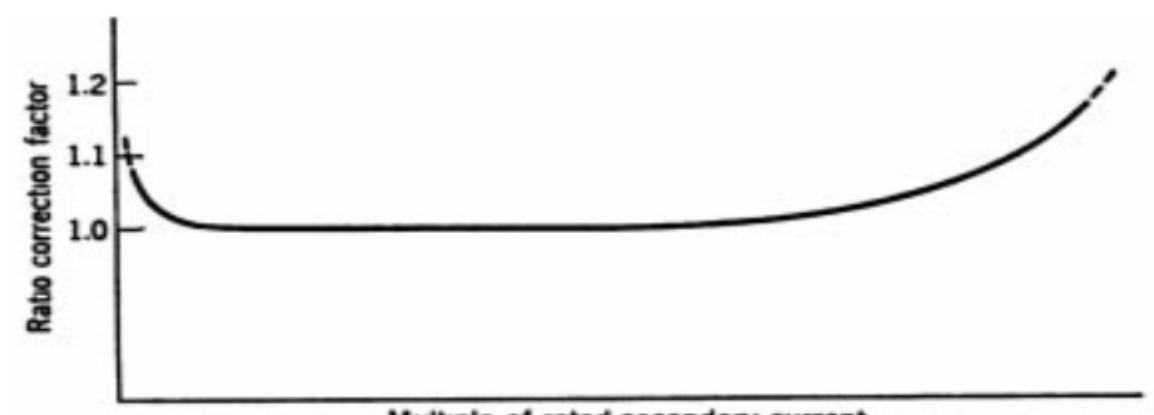

Multiple of rated secondary current

Figure 17: CT ratio error curve 
The main characteristic affecting CT accuracy is the magnetic saturation. The amount of magnetic flux circulating in the core is proportional to the current in the primary winding. As the current increases the flux increases. However, the amount of flux that can flow through core depends upon the size of the core. At a certain point, the core becomes saturated and flux will not increase in proportion to current in primary winding. Therefore, primary to secondary current relationship shown in the equation above will not be true in that case. As a result, an error will generate which affects the relay measurement.

Figure 18 shows the relation between CT current and flux under normal operating condition. As discussed earlier, primary current is proportional to the flux. Moreover, primary and secondary current is proportional to the turn ratio.
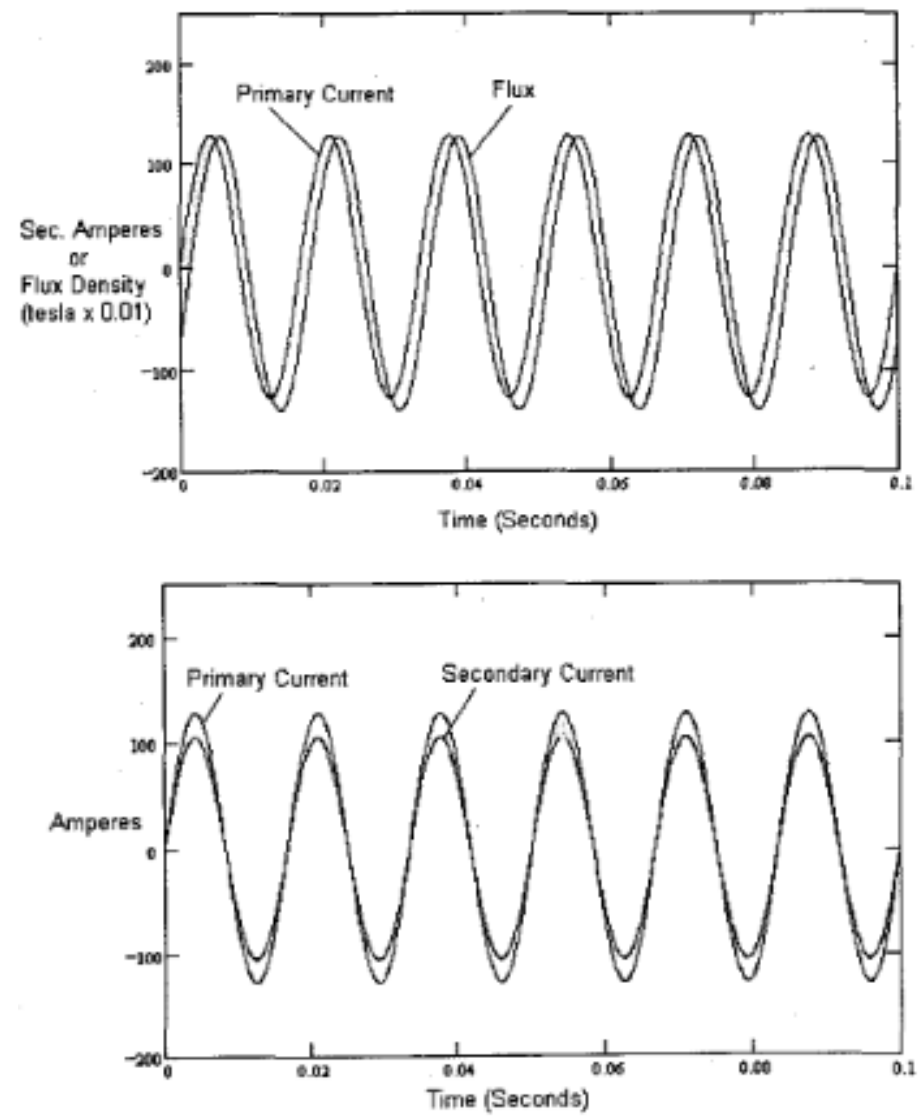

Figure 18: Relation between CT current and flux without saturation

Figure 19 shows the relation between CT current and flux when the core gets saturated. As the core gets saturated the flux will not increase proportional to the primary 
current. Therefore, the current induced in the secondary winding will also be affected. The standard classification of $\mathrm{CT}$ allows $10 \%$ error for current flow up to 20 times the rated current [9].
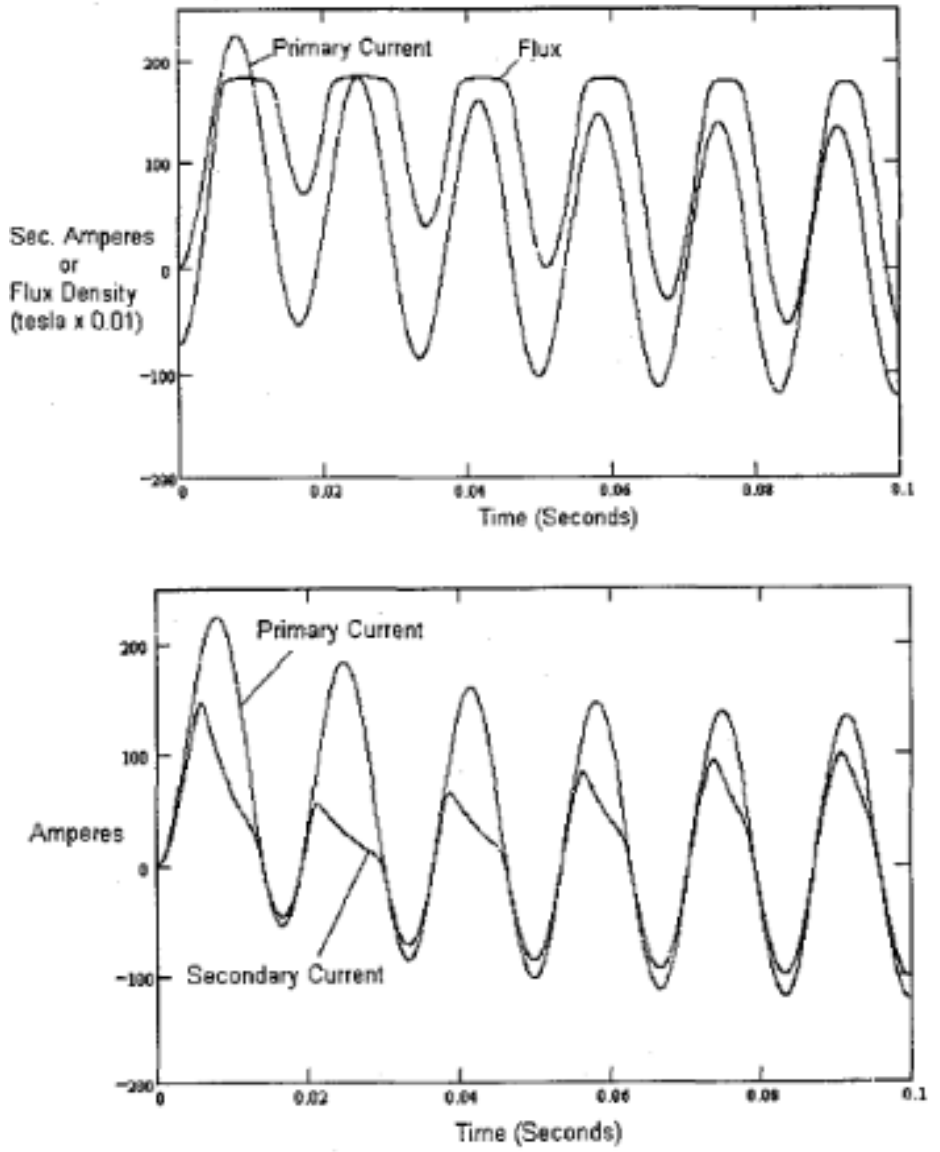

Figure 19: Relation between CT current and flux with saturation

One more important factor is the burden on CTs which is number of relays feeding from CT secondary. Saturation curve is also affected by the burden on CT. The term burden indicates load on the secondary of instrument transformer. Figure 20 displays the typical saturation curve where $1 \Omega, 2 \Omega, 4 \Omega$ or $8 \Omega$ shows the burden on CT. As the burden increases which mean number of relays on the CT secondary increases, the accuracy of the instrument transformer decreases. Moreover, adding more relays on the secondary of the transformer will increase the impedance and therefore more distorted current in secondary of the current transformer. For $1 \Omega$ burden, the operating range is up to around 20 times the rated current, 
the secondary current correlate with the primary current. However, as the primary current increases beyond the knee of the curve, the secondary current does not represent the primary. Moreover, as the burden increases on current transformer to $2 \Omega, 4 \Omega$ or $8 \Omega$ the distortion starts earlier. At $8 \Omega$ the CT secondary current is only accurate up to 4 times the rated current.

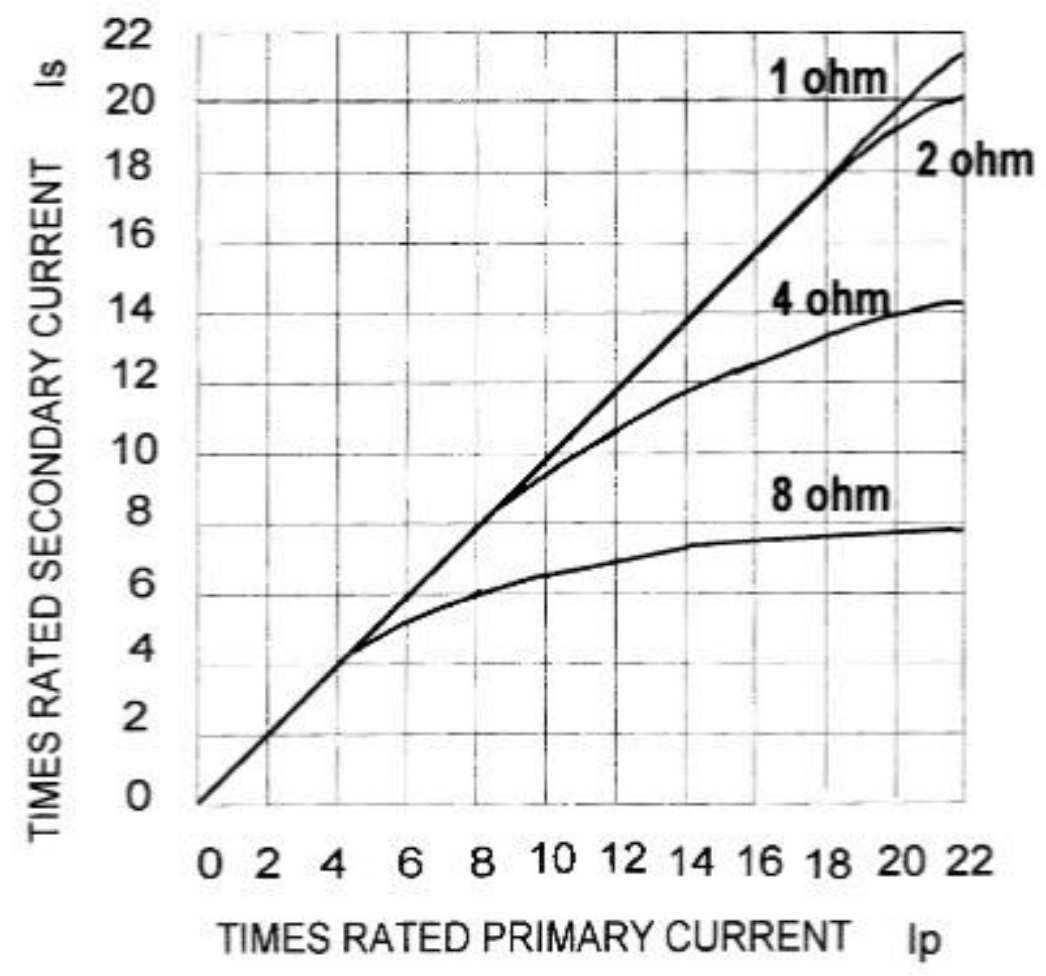

Figure 20: Typical overcurrent ratio curve for a $\mathrm{T}$ class $\mathrm{CT}$

\subsubsection{Voltage Transformer or Potential Transformer}

Voltage transformer is a device that produces an alternating voltage in secondary proportional to measured voltage in primary. Figure 21 shows high voltage potential transformer which can be seen in substation. In contrast to the $\mathrm{CT}$, the voltage transformer has primary and secondary windings of many turns with high resistance current flow. As a result of this high impedance, current flow is very low and voltage in the secondary suffers little or no distortion in representing primary voltage. The secondary voltage is usually 120 volts for monitoring purposes. The primary and secondary voltage and number of turns have a relationship shown below. 


$$
\frac{N_{P}}{N_{S}}=\frac{V_{P}}{V_{S}}
$$

Equation (2)

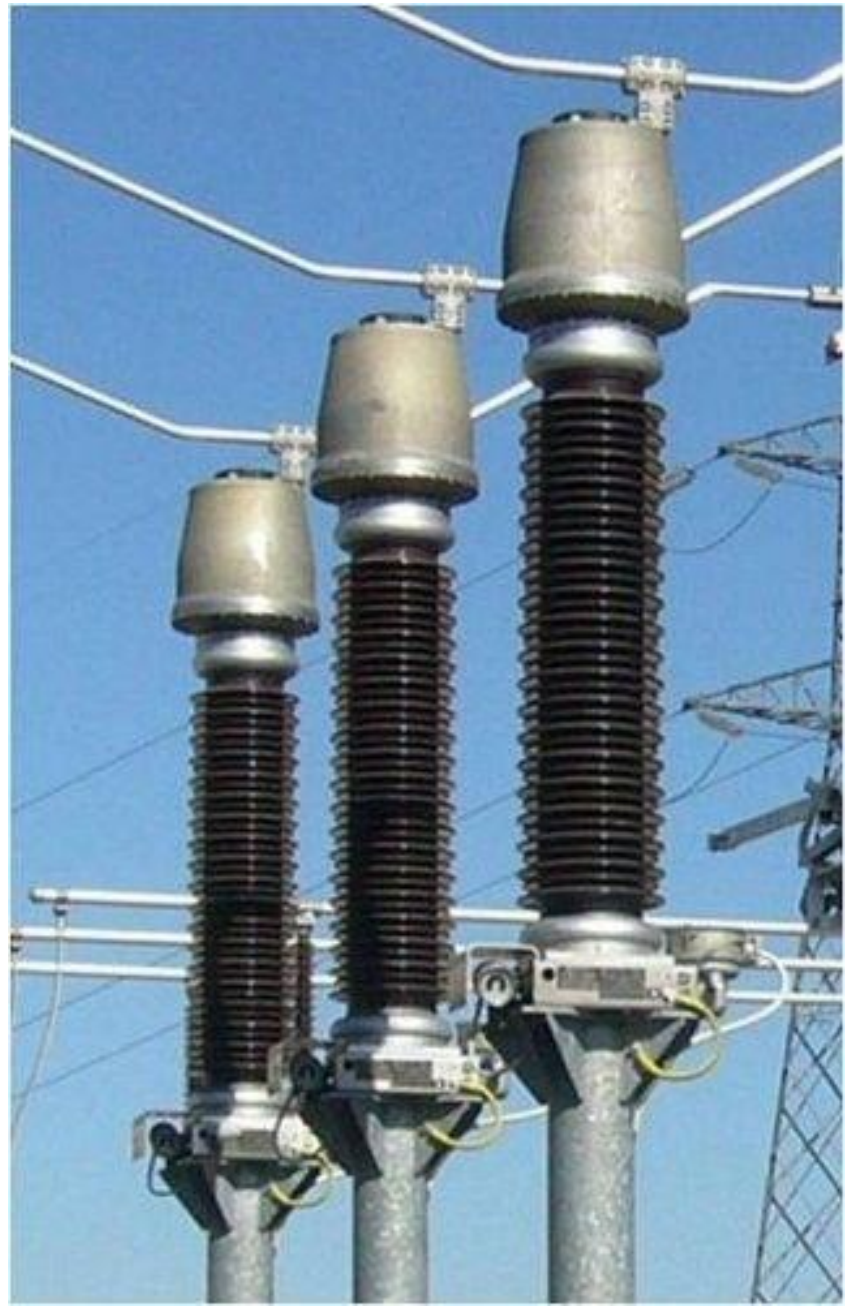

Figure 21: Voltage transformer in substation

Many protection relays require line to line voltage as an input. Figure 22 shows two VTs connected in an open Delta arrangement on the secondary which provides all three line to line voltages. Now the voltage transformer does not suffer the same problem of saturation as the CT. This is due to the fact that faults usually cause a voltage reduction not an increase. In the case of a system disturbance, the system voltage may rise however it is not sufficient to bring the VT to saturation. Compared to how CTs are affected to burden, VT affected by additional potential coils connected in parallel. Therefore the circuit impedance falls. Hence 
more current flows in both primary and secondary. The effect of increasing burden could eventually increase the PT's output current above its operating level and so introduce inaccuracies. On the other hand, figure 23 shows three VT configuration for line to neutral voltage.

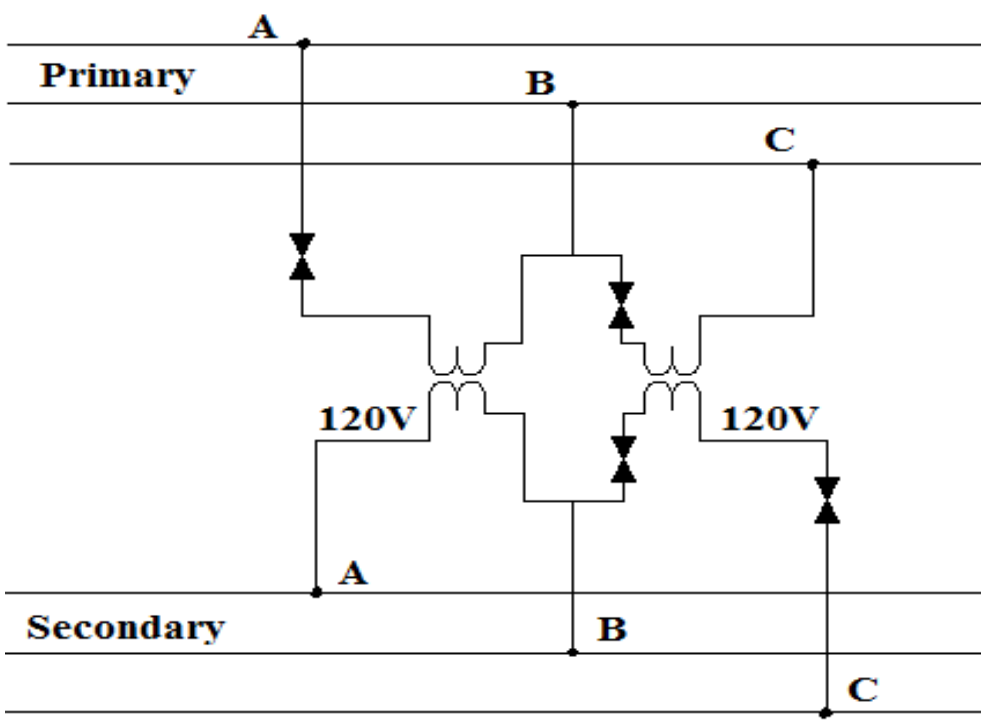

Figure 22: Open delta configuration for line to line voltage

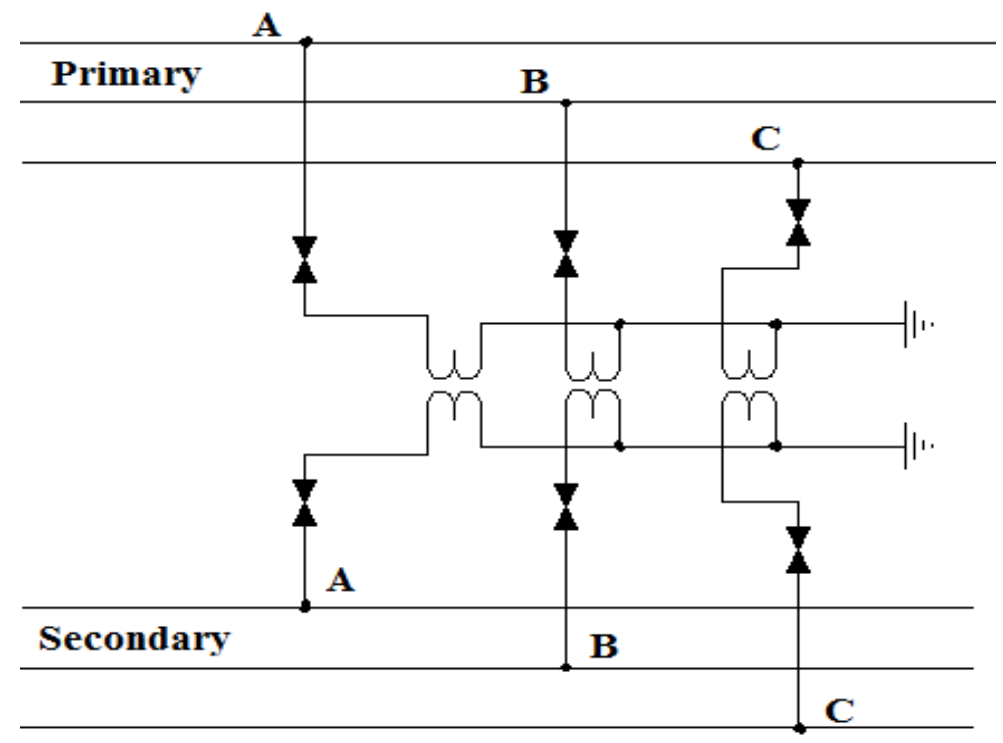

Figure 23: Three VT configuration for line to neutral voltage 


\subsection{Zones of Protection}

In a typical power system, there are equipment such as generators including their step up transformers, busses, step down transformers, transmission and distribution lines, and utilization equipment such as motors and static loads. In order to provide protection to these power system equipment the system is divided into various zones. Figure 24 shows various zones in the power system. The division of zones is created to discriminate the fault position [6]. Once the fault is located, the faulty part can easily be isolated and system can provide continuous power supply. For better explanation, Figure 24 shows typical power system configuration divided into 5 different zones and differentiated with various colors. Each equipment is protected and given a zone number. For example, zone 1 is for generator protection, zones 2 is for bus protection, zone 3 is for line protection, zones 4 as for transformer protection and zone 5 is feeder protection. Now all this equipment needs to be protected. However, type of protection used is generally different for each area.

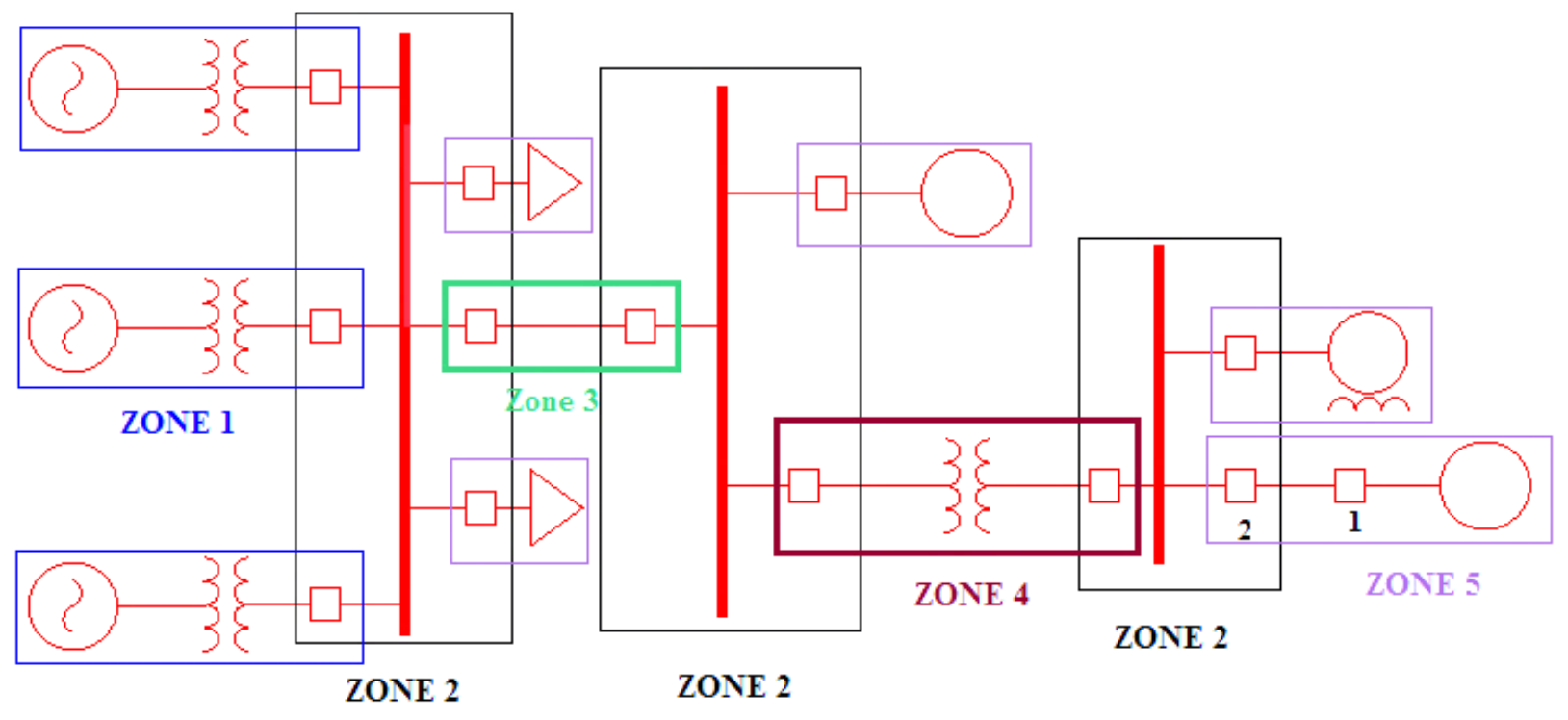

Figure 24: Power system protection zones

In, zone 1 is generator protection zone which includes its associated step up transformer. Any fault within this zone will trip the main generator breaker. This zone protects against the faults in generator itself, primary and secondary of the transformer and the breaker itself. 
The next area of the protection is bus zone. The buses normally have several incoming and outgoing connections. Any fault on bus requires that all breakers incoming and outgoing must be opened. In the figure 24 , it can be clearly seen that each bus zone overlaps other zones. So the generator breaker will operate either for a fault within generator zone or a fault in bus zone.

Zone 3 in the diagram is a transmission line zone and it overlaps with bus zone on either ends. Hence these breakers will open for a line fault and also for a fault on its respective bus. Moreover zone 4 is transformer protection zone. In this particular configuration, there is a step down transformer which reduces voltage down to the distribution level and feeds distribution bus. Therefore a transformer protection zone and it overlaps with bus zone on either side can be seen.

Finally, the distribution line feeds an induction motor in zone 5. In figure 24, zone 5, which is a feeder protection zone, overlaps with bus protection zone and has 2 circuit breakers. For this particular arrangement the first circuit breaker beside motor provides primary protection to the motor and circuit breaker 2 provides secondary or backup protection. Breaker 2 also overlaps with bus protection zone.

\subsection{Overcurrent Protection and Coordination}

The purpose of overcurrent protection is to detect abnormal conditions in the system and to isolate the faulty section by fast operation of protective devices to minimize damage and danger. In overcurrent coordination, protective devices are systematically coordinated in response to faults or overloads so that it will only remove the faulty section and minimize the equipment from getting out of service. In electrical power system protection coordination, all devices from load to source are organized in time-current study. The time current study is an evaluation of time each protective device takes to operate when current in the system increase to a certain level. This coordination is done so that the protective device nearest to the fault operates first. Following proper coordination will result in minimum disruption due to fault. The objective of overcurrent coordination is to determine the rating, setting and 
characteristics of overcurrent protective devices. Moreover, it is important to consider that minimum un-faulted section is interrupted when there is a fault in the system.

Overcurrent protection using fuse is the simplest form of all protecting devices. The fuses are installed in series with line. Figure 25 shows a fuse used for distribution line connection. Under normal operating condition, current passes through the fuse. However, when current exceeds the limitations, the contacts of the fuse start melting and thus create open circuit when fully melted. In time-current coordination fuse has two curves; one is minimum melting curve where fuse contacts starts melting and total clearing curve at which fuse contact are fully melted.

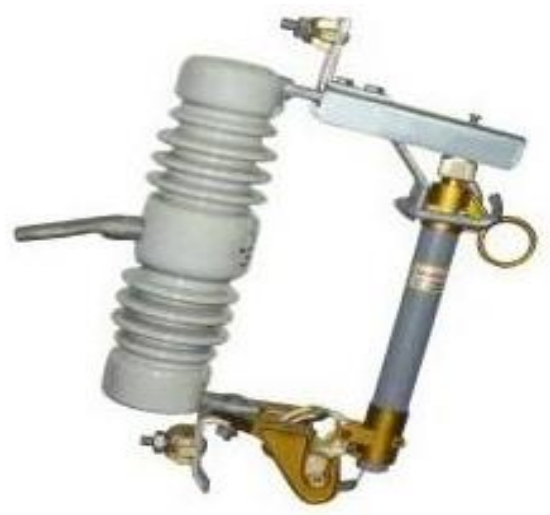

Figure 25: Fuse for distribution line

Another protective device used for overcurrent protection is a relay. In power system protection and coordination, operating speed of relays and discrimination of current and time setting are two major factors considered during design. These factors are explained using the figure 26 and figure 27 below.

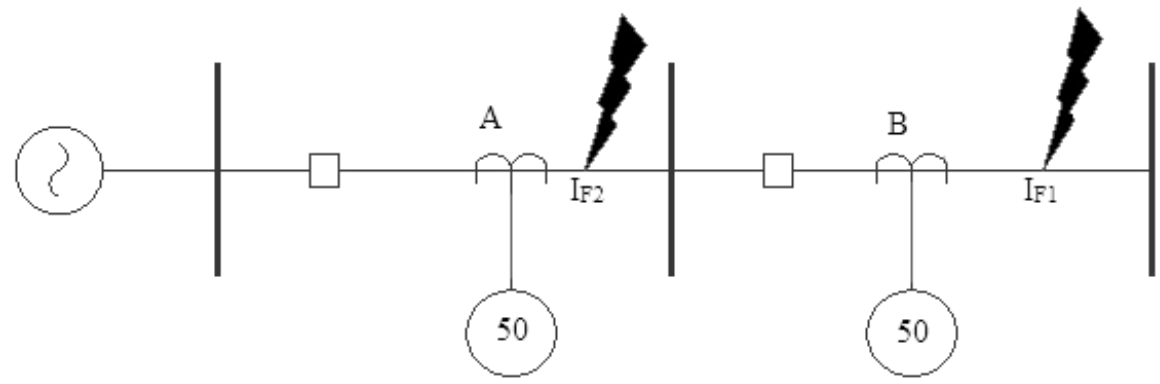

Figure 26: Protection and coordination using instantaneous relay 
Operating speed of the relay can be instantaneous, time delayed or inverse time. In most of the cases time delayed relay is used for proper coordination. In figure 26, there are two instantaneous relays A and B. In order to achieve coordination, relay A should operate when there is a fault at $\mathrm{I}_{\mathrm{F} 1}$ and relay $\mathrm{B}$ should operate when there is a fault at $\mathrm{I}_{\mathrm{F} 2}$. It can be achieved only by different current setting for both relays otherwise during fault both relays will operate. The fault current setting for both relays are calculated or simulated by creating fault near relay $\mathrm{A}$ and $\mathrm{B}$.

The characteristics of time delayed relays are shown in figure 27. The time delayed relay's operating time is independent of current. In protection coordination, relay time is calculated from load to source so relay closest to fault will have shortest operating time.

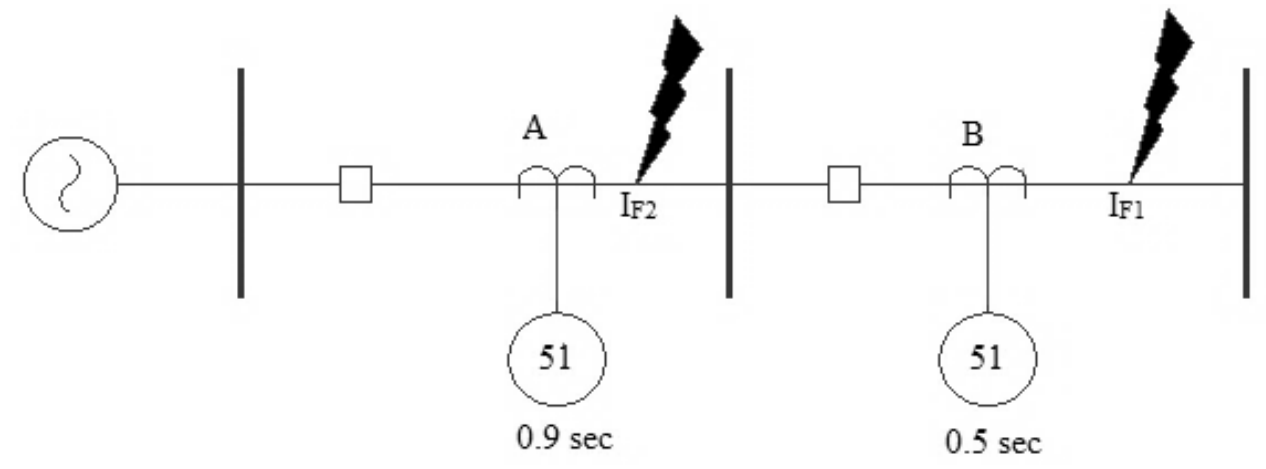

\section{Figure 27: Protection and coordination using time delayed relay operation}

The problem with this type of coordination is that the operating time at the source will be high. In figure 27 , it can be seen that both relays have operating time. If there is a fault at $\mathrm{I}_{\mathrm{F} 1}$, then the relay $\mathrm{B}$ will operate in 0.5 seconds. This method also provides backup protection in a sense that if relay close to $\mathrm{I}_{\mathrm{F} 1}$ doesn't operate in 0.5 seconds then other relay will operate in 0.9 seconds. Relay coordination can be achieved with current setting, time setting or current and time setting. In current setting, the current rating of each device is calculated or simulated and then applied. This is the case in instantaneous relay coordination. The time setting based coordination is shown in figure 27.

The inverse time overcurrent relays are subdivided into inverse definite minimum time (IDMT), inverse time, very inverse time and extremely inverse time. The relay operating time is based on fault current. As the fault current increases, relay will take action 
faster. Therefore, relay operation depends on the current and time settings achieved. The characteristics of these relays can be seen in figure 28. The pickup current is the minimum current that will cause the relay to initiate action to close contacts. Moreover, multiple of tap is multiple of pickup current. It shows how much time each relay will take to send trip signal to the protective device. For example, if pickup current is $100 \mathrm{~A}$ then at 10 multiples of pickup, the fault current will be 1000A. In that case, IDMT relay will operate in 0.2 seconds. However, inverse time relay will take $0.3 \mathrm{~s}$ and $0.375 \mathrm{~s}$ respectively, very inverse time relay will take $0.41 \mathrm{~s}$ and extremely inverse time relay will take approximately $0.5 \mathrm{~s}$ to operate.

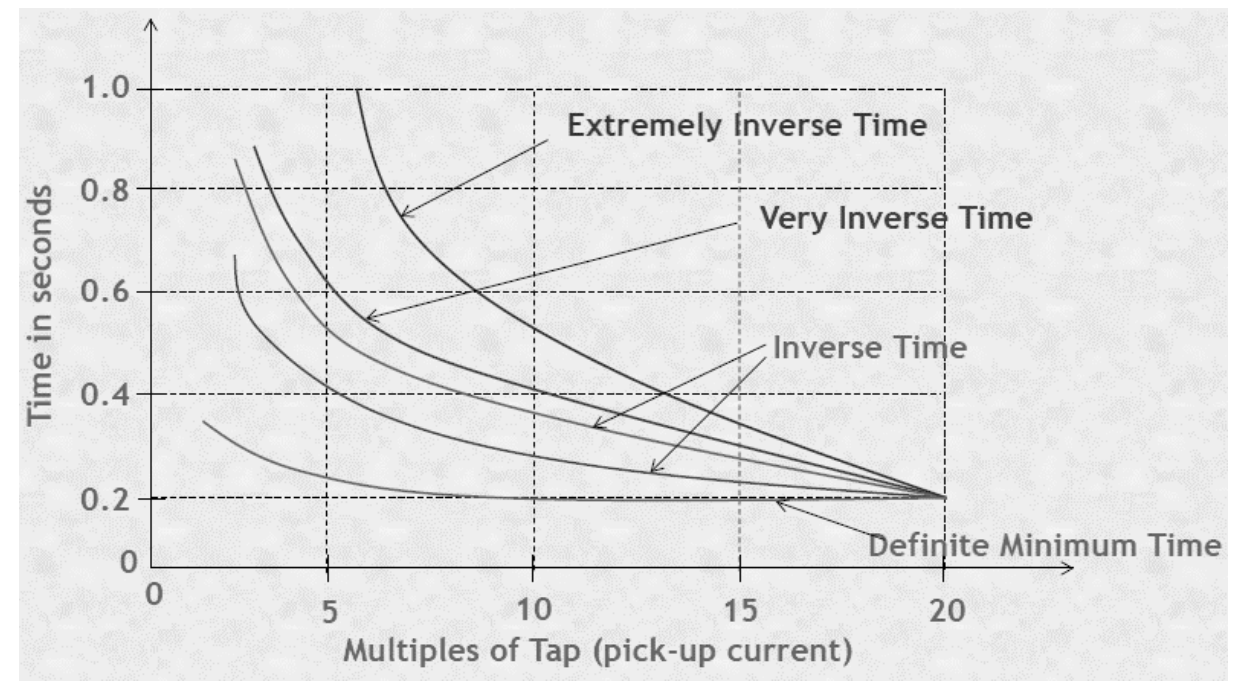

Figure 28: Types of inverse time relay characteristics

A recloser, similar to protective relay, does have capability to interrupt the circuit under faulty conditions. It is a self-controlled device which operates based on predetermined fault current level. The device can either operate manually if the controls are local, operates through SCADA (Supervisory Control And Data Acquisition) or through fixed operation. After pre-set sequential operation of opening and closing, the recloser is either resets, holds close position or locks out from operation.

Most important feature of the recloser is the flexibility in coordinating. The timecurrent characteristic of the recloser gives variety of operational choices which ranges from instantaneous tripping to time delays tripping. A common setting on recloser is when it senses the fault, it opens and then reclose for set amount of time. It will hold closed position 
for pre-set time and allow the protective device located downstream to operate. If a fault which originated the operation, a permanent fault, still exists then it will stay open thus isolating the faulty section [7]. Therefore it first operates as instantaneous tripping device and then as a time delayed operational device. Figure 29 shows the automatic circuit recloser connected on a distribution line.

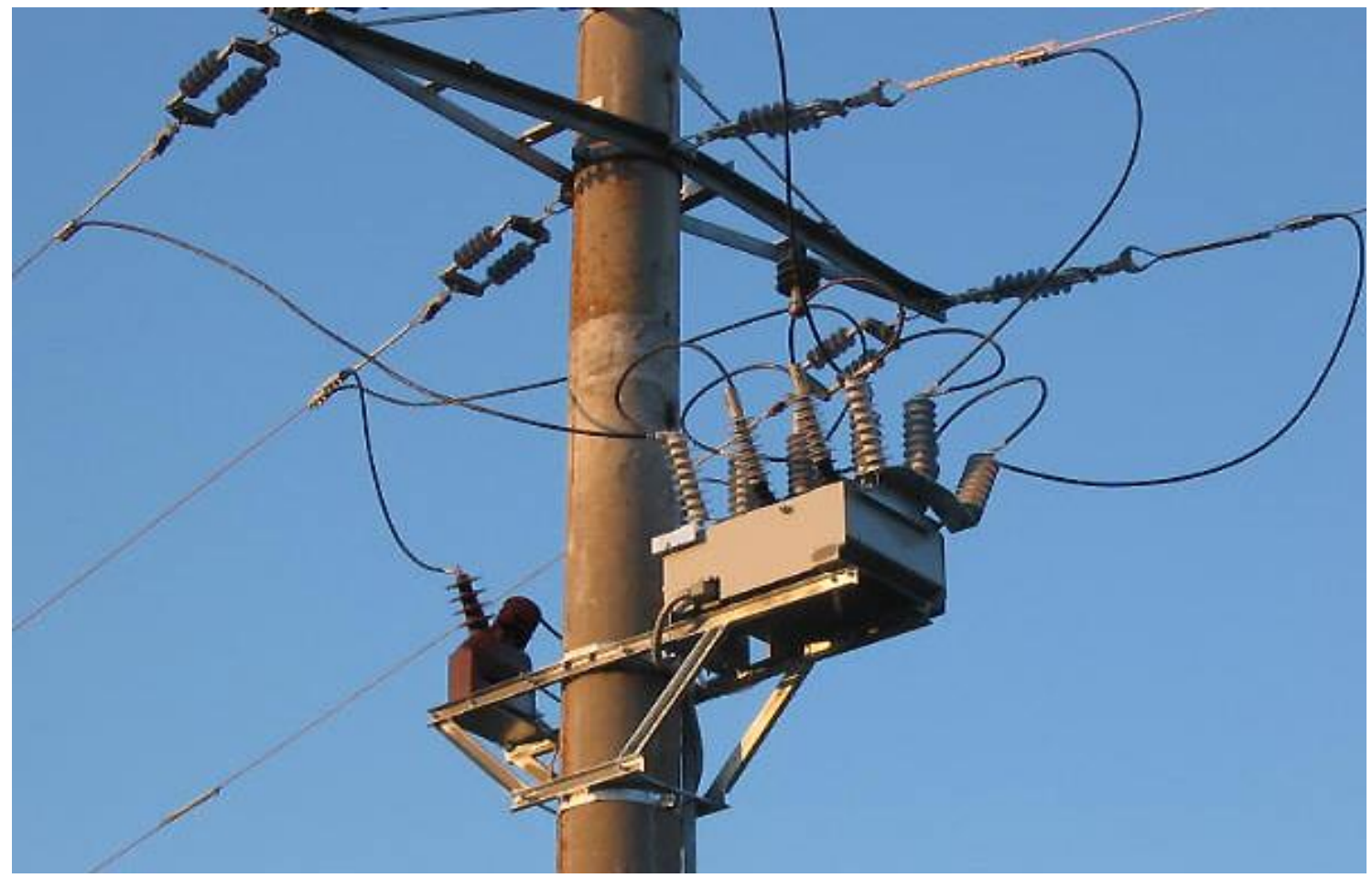

Figure 29: Automatic Circuit Reclosers

Summarizing the chapter, Instrument transformers, such as current transformer and voltage transformer, reduces current and voltage respectively to safer working level for monitoring purpose which causes the protection relays to be made small. Current transformer produces current proportional to primary in secondary. In order to eliminate undesirable operation, current transformer first magnetized by small amount of current. The current distortion induced in secondary of current transformer due to magnetization produces errors in result. This distortion leads to ratio error and phase angle error. Moreover, current transformer is also affected by core saturation. When current flow increased to certain level, the core becomes saturated and does not produce proportional flux and hence does not induce proportional current in secondary winding. Furthermore, the current transformer's accuracy 
is affected by burden. The accuracy decreases as number of relays connected to CT secondary increases. On the other hand, voltage transformer produces proportional voltage in secondary winding. Compared to current transformer, VT does not suffer from core saturation. Moreover, fault causes the voltage to reduce and transient in the system does not increase the voltage to a level of core saturation. For monitoring purpose when line to line voltage is needed, the VTs can be connected in delta configuration and when phase voltage is needed then VTs are connected in wye configuration.

In order to provide protection to power system equipment the system is divided into various zones. The division of zones is created to discriminate the fault position. Once the fault is located, the faulty part can easily be isolated and system can provide continuous power supply. Type of protection used for different equipment differs for each zone.

Overcurrent protection can be provided by either fuses, relays or reclosers. Fuses are simplest form of protection. On time current coordination diagram, there are two curves for fuses, minimum melting curve and total clearing curve. When current exceed limitation, fuse contacts start melting and creates open circuit. In protection and coordination using relays, operating speed and discrimination of current and time considered in design. Relays can be coordinated with time, current or both time and current. Recloser provides flexibility in coordinating. The settings on recloser allows it be operated as instantaneous and time delayed tripping device. When relay senses fault, it first operates on its instantaneous setting and then locks out if the fault is permanent. 


\section{Chapter 5 \\ Generation Protection}

In generation protection, protection system for generator, bus and transformer is discussed.

\subsection{Generator Protection}

Generator converts mechanical energy into electrical energy. Generators are built in extremely wide range of sizes depending upon the application and particular type of prime mover. The working principle of generator is based on electromagnetic induction. There are many other devices and auxiliary contacts connected to generator. Therefore they must be taken into account during generation protection design. Suppose an insulation failure occurred to the winding inside generator. In this case, it would not be sufficient just to trip out main breaker and disconnect unit from electrical system. The protection system of generator also needs to trip the stop valves and shut down the prime mover so as to prevent further damage. Since this report is to present generator electrical system protection, the prime mover problem and other mechanical failure will not be discussed. When a generator is tripped from system, its excitation system must also be de-energized by tripping the field breaker or equivalent. Figure 30 displays large industrial generator.

Typically generators are connected to the system in two common ways. In an industry where large amount of power supply is needed, small generator along with other generators is directly connected to a common bus through circuit breaker as shown in figure 31 . Generator feeds the power system and also feeds the station auxiliary contacts through station service transformer. 


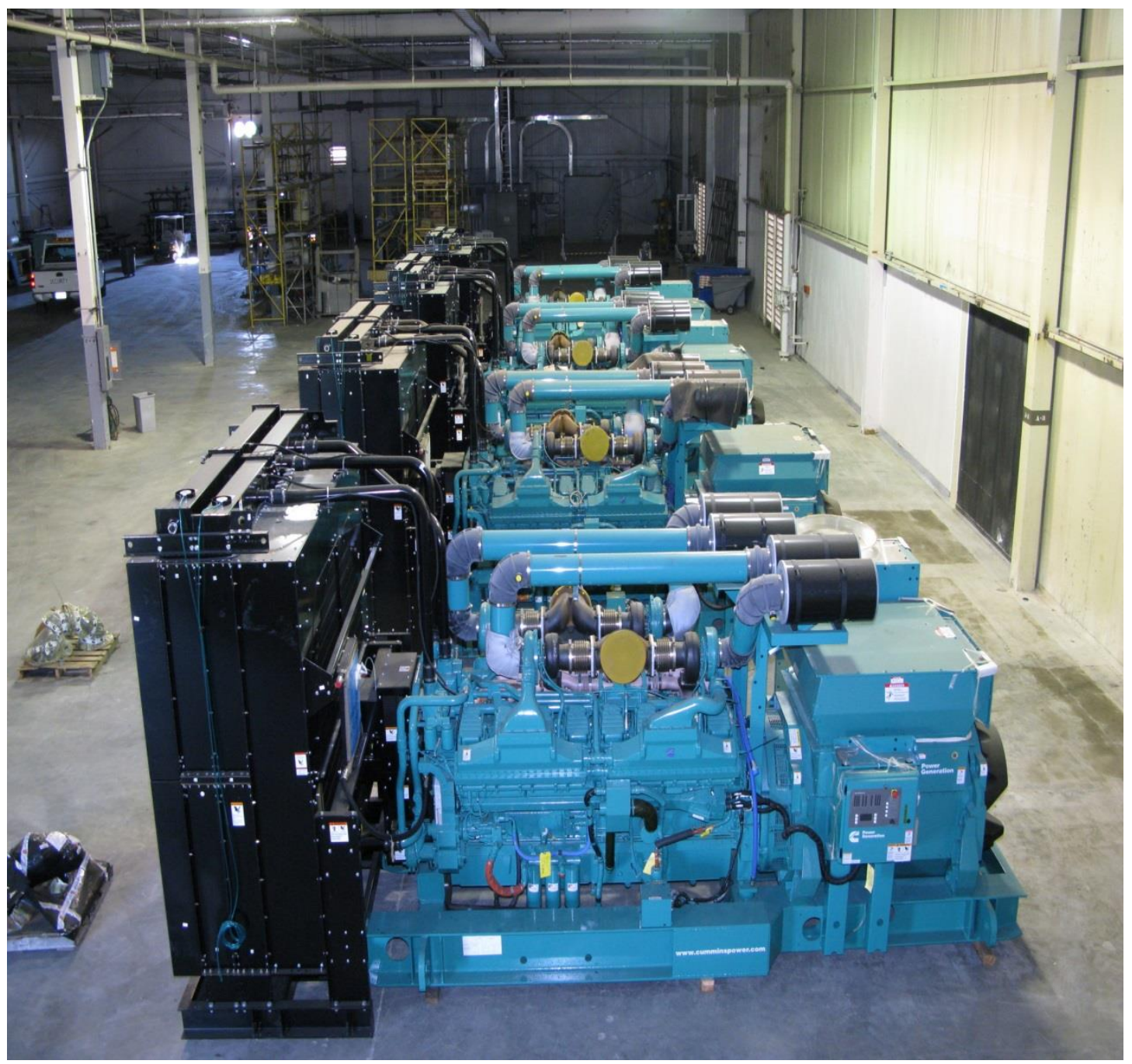

Figure 30: Large Industrial Generator

A fault occurring internally on one of the generator, as shown in figure 31, it should be detected by the protection system of that generator and this will cause it's specific breaker to be open and its own excitation system to de-energize. On the other hand, figure 32 shows the connection diagram of large generator. Generally large generators, voltage range from $13.8 \mathrm{kV}$ to $25 \mathrm{kV}$, are connected to a step up transformer and then the protection is provided by the circuit breaker. Installation of the circuit breaker, numbered 1 in the figure 32, on the secondary side interrupts lower current than primary. Any fault occurring internally to the generator will open this breaker and so isolate the transformer as well. 


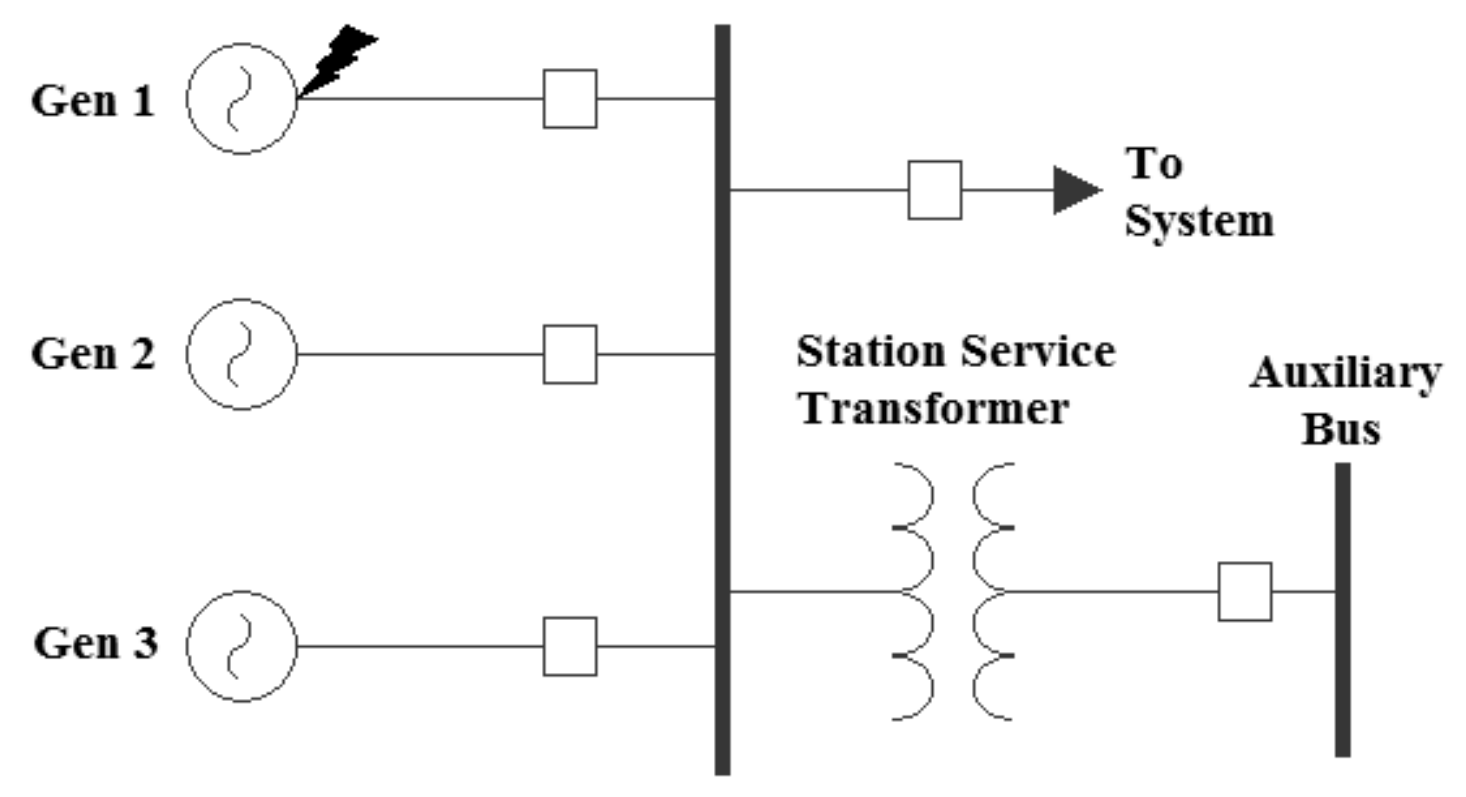

Figure 31: Small generator connection to common bus

In large generator arrangement, another transformer is connected to supply auxiliary power. This stations service transformer which is connected directly to generator terminals feeds the unit auxiliary. The unit auxiliary bus has an alternative feed from a general stations service transformer as the unit auxiliary need to be energized during start up. However, once the unit is synchronized and online, breaker 2 will be closed and general service breaker 3 opened. Now in this situation in the case of an internal fault developing inside the generator both the main circuit breaker and also the auxiliary circuit breaker must be opened so as to completely isolate the generator.

There are several types of problems associated with the generator such as bearing problem, lube oil problems, vibration problem, hydrogen cooling system problems, high winding temperature, prime mover failure or problems. Since these problems are mechanical in nature, discussion of these problems is out of scope of this report. 

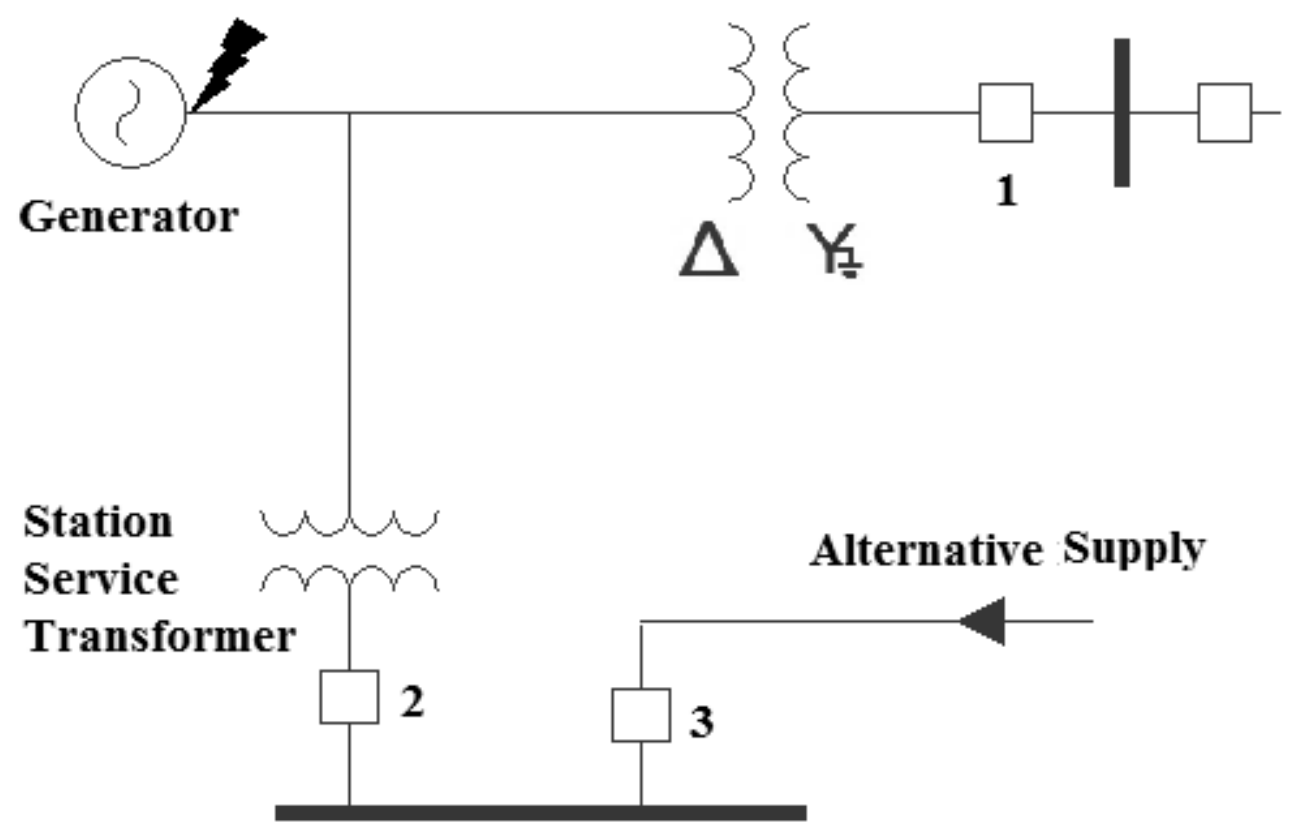

Auxiliary Bus

Figure 32: Large generator connection

Most internal problems with the generators are due to insulation failure in stator winding and field winding which results in phase to phase fault or phase to ground fault. Other possible abnormal conditions are excessive stator current which results in overheating of stator winding, overvoltage which may damage the insulation, under-frequency which may damage the turbine blades due to vibration and unbalanced currents in the generator stator which heats up rotor due to negative sequence components.

Figure 33 and figure 34 shows the pre-fault and after fault condition of the turbine generator. There are various reasons for this kind of fault. In the industrial application, this fault caused by the failure of protection devices such as frequency relay, turbine control and shutoff valves protection system. There are various types of fault and their protection scheme is discussed in next sub section. 


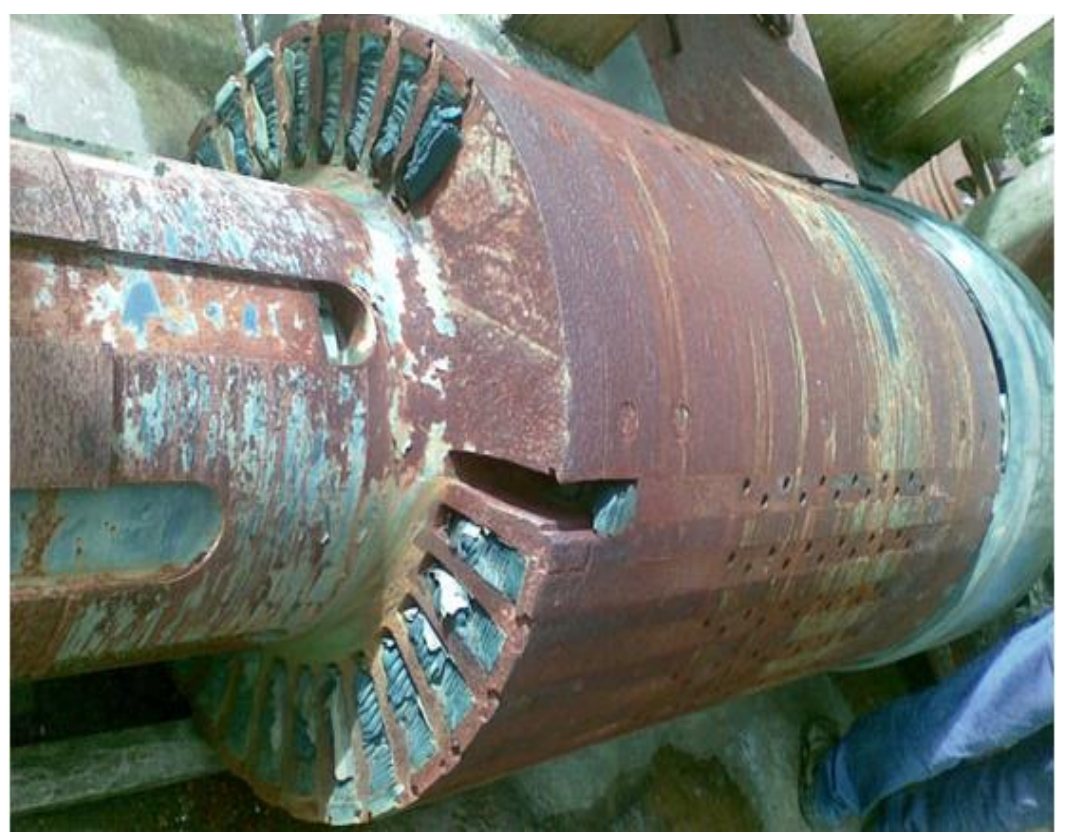

Figure 33: Turbine Generator before fault

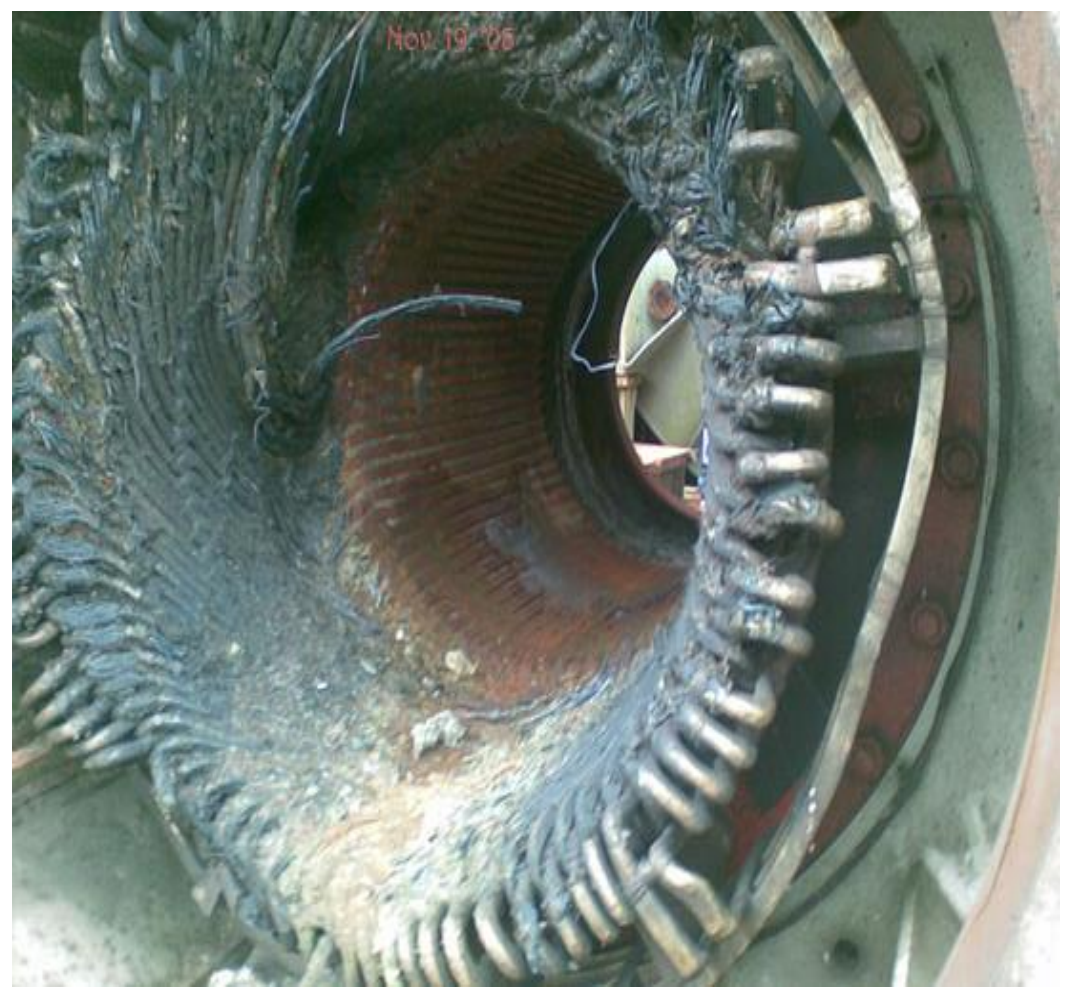

Figure 34: Turbine generator after fault 


\subsubsection{Generator Phase Faults}

Differential protection is used for protection against generator phase to phase faults. Figure 35 shows the differential protection scheme for Y-connected generator. As discussed before, under normal operating conditions when there is no fault or unbalance, no current will flow through the relay operating coil. However when there is an internal fault between winding $\mathrm{A}$ and $\mathrm{B}$ as shown in figure 35, there will be mismatch and operating coil for Phase A relay and phase B relay will operate. When the relay operates it will open the main circuit breaker, de-energize the field and initiate shutdown of the prime mover [10].

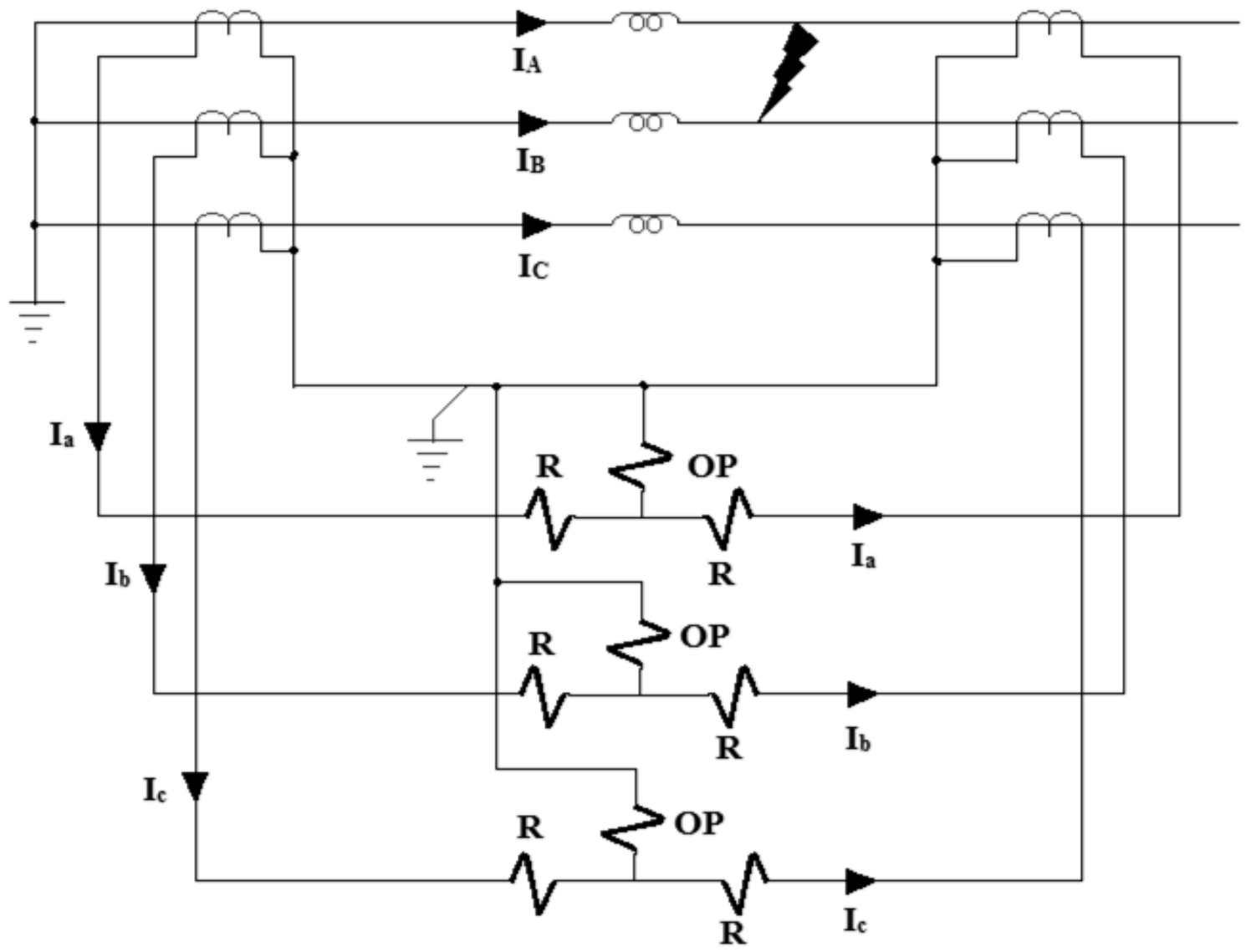

Figure 35: Differential protection scheme for the Y-connected generator

Figure 36 shows the differential protection for delta connected generator. In delta connected system, when there is no fault exist the sum of secondary currents $\mathrm{I}_{\mathrm{A}}, \mathrm{I}_{\mathrm{B}}, \mathrm{I}_{\mathrm{C}}$ is zero. Therefore no current flows in the neutral. If a fault does occur in the generator, there will be 
out of balance and current will flow through the neutral of the secondary and relay will operate.

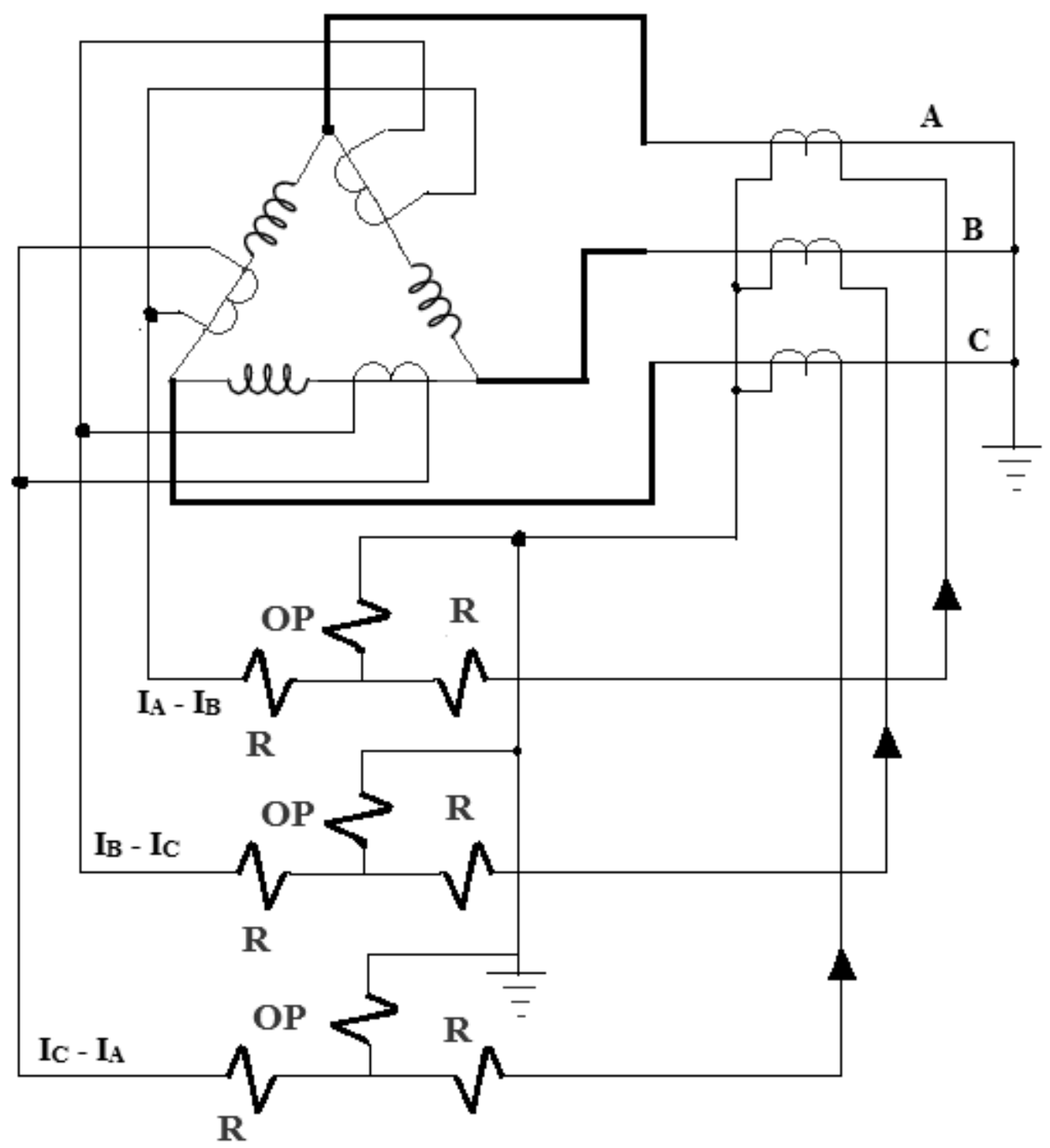

Figure 36: Differential protection scheme for the $\Delta$-connected generator

The single line diagram of the generator differential protection is shown in figure 37. The generator differential protection is provided by relay $87 \mathrm{G}$. In an event of a generator fault, the relay, $87 \mathrm{G}$, will operate and trip both main breaker and auxiliary breaker. As it shown in the figure 37 , the generator is directly connected to the transformer. Therefore in an 
event of transformer fault, the generator must also trip. The main transformer and station service transformer differential protection is provided by the relay named $87 \mathrm{~T}$ and $87 \mathrm{ST}$ respectively. Moreover, the differential protection for all three equipment, generator, transformer and station service transformer, is provided by linking all three equipment. In this case, operation of any one of these differential circuit will trip the main breaker and associated equipment. For a small generator arrangement, shown in figure 38, the generator is directly connected to the bus. The differential relay (87TG) is connected across the generator and the circuit includes the generator breaker.

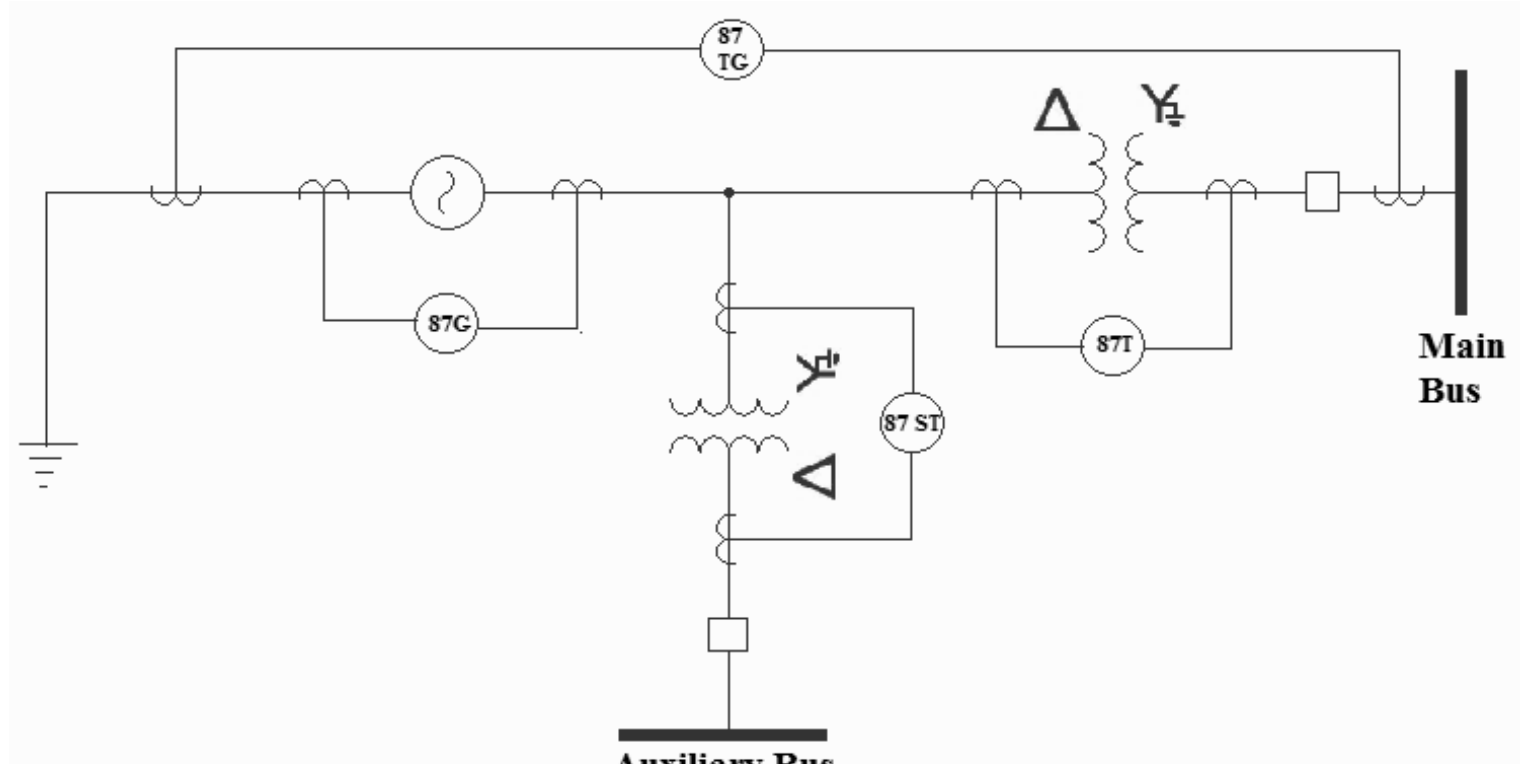

Figure 37: Single line diagram of generator protection scheme

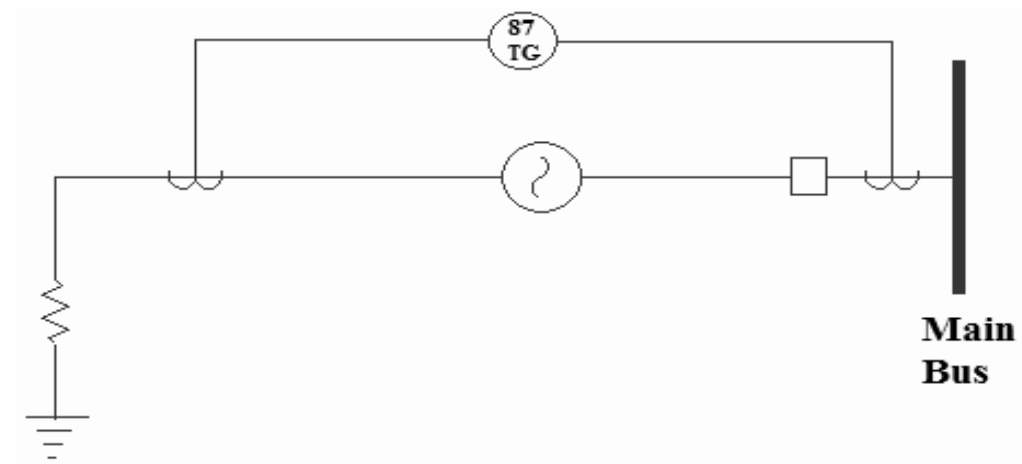

Figure 38: Protection scheme for generator directly connected to Bus 


\subsubsection{Generator Phase to Ground Faults}

Large generators are grounded through high impedance in order to limit the value of fault current to be under 10A. This limits the amount of internal damage that can be done to the generator. The configuration is shown in figure 39.

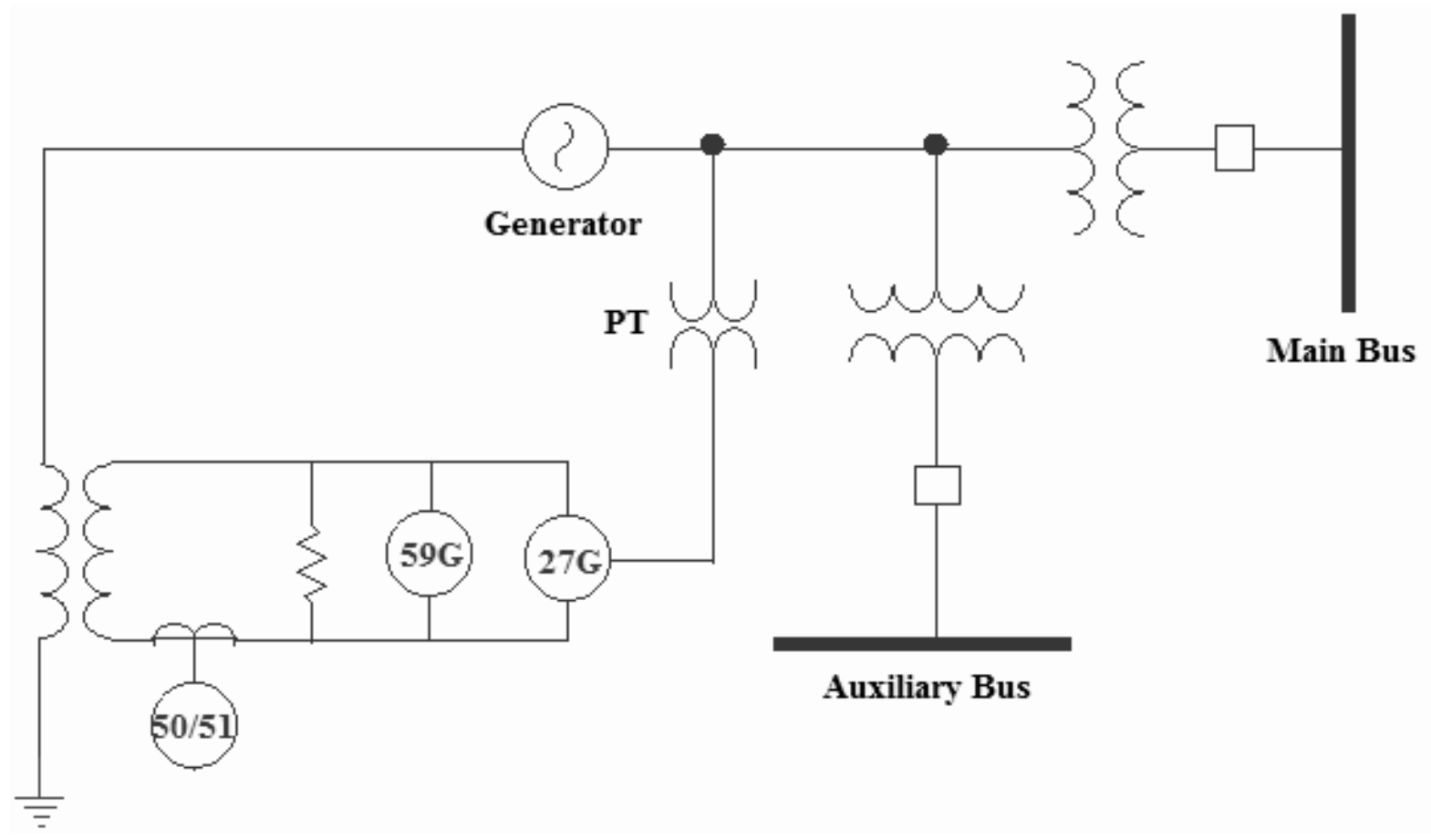

Figure 39: Generator ground fault protection

When there is a ground fault, the fault current will flow through ground to neutral of the generator. In order to measure the fault current, a current transformer is connected. This CT's secondary winding is connected to the time overcurrent ground relay which trips in case of fault.

Another protection scheme utilized for ground protection is using overvoltage ground relay generally set to pickup at 10 volts. Instead of a resistance the impedance in the neutral will be provided by a transformer secondary which is connected to the $59 \mathrm{G}$ relay as shown in figure 39. The ground resistor is connected in the secondary of the transformer to limit the fault current flowing through the neutral to 10A or less [11]. This relay provides protection to the generator, station service transformer, step up transformer and the interconnection of all these equipment. Moreover, in order to provide backup to the 59G relay, a CT is installed on 
the secondary side of the transformer as shown in the figure above. This CT is connected to either instantaneous overcurrent relay or time overcurrent relay or both.

Often during study, the generated sine wave is assumed to be perfect. However, this is not the case in practical situations. Due to design flaws or loading condition, generated sine wave is not as it is expected. In these cases there is possibility of presence of third harmonics in the system. Therefore, in order to avoid inadvertent tripping the ground fault detection relay must be isolated from these third harmonics. In these cases, an under voltage relay $27 \mathrm{G}$, which functions using third harmonics, is adapted. This relay is connected in parallel with overvoltage relay 59G. Moreover, $27 \mathrm{G}$ is tuned to respond to only third harmonic current and voltage. Under normal operating conditions when third harmonic voltage is present, relay $27 \mathrm{G}$ will not operate due to the fact that it is an under voltage relay. Conversely, when a ground fault occurs on the generator winding, the third harmonic voltage will be considerably reduced which will result in an operation of the relay [12].

The discussion above is for single generator system. However, in industrial generating plants there are several generators connected to the same bus and single common ground connection is provided as shown in figure 40. For simplicity and to avoid confusion, the fault on generator 1 has different direction. However, before fault condition, the current flowing in the secondary of the CT will be same for both generators. This configuration is economical and beneficial as when a particular generator is tripped or out of service then there is still ground connection for other generators. But this does provide a selectivity problem. If the ground fault occurs on generator 1, as shown in diagram below, the fault current will flow up the common neutral. However, an overcurrent or overvoltage relay fitted in the ground connection would not know which particular generator to trip. This problem can be solved by installing a ground differential relay on each unit. This relay has two operating coils. One coil is differential coil which is fed from the differential CT with the particular generator and other is neutral coil which is fed from common neutral of the CT [13]. In order to trip, the two currents must be in the same direction. 


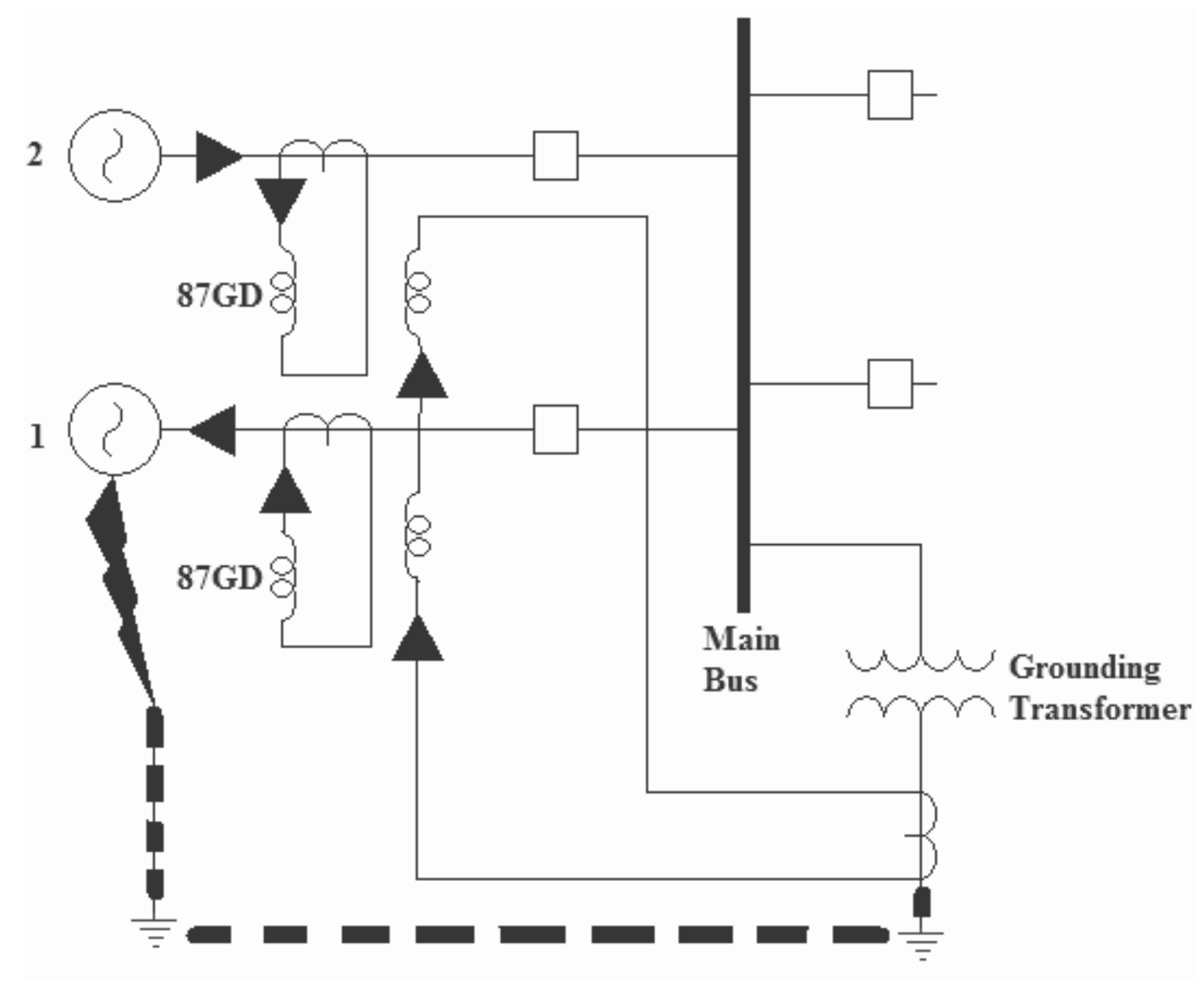

Figure 40: Ground differential protection for multiple generators

Now when there is a ground fault on winding of generator 1, current will flow in the common neutral and this will result in energizing the neutral coil in each ground differential relay. In second generator, the current flowing out of the generator will be out of balance due to the fault. However, the direction of the current flowing through CT differential coil and neutral coil is opposite. Thus it prevents the relay from operating. On the other hand, the generator which contains the fault has the current flowing into the generator to feed the fault. In this situation, the direction of the current flowing through the differential coil and neutral coil is in the same direction. So permits the relay to operate and trip the breaker removing the faulty generator from the system. 


\subsubsection{Generator Backup Protection}

Figure 41 shows different relays used for generator backup protection. In this configuration differential relay $87 \mathrm{G}$, overcurrent protection relay $51 \mathrm{G}$ and ground differential protection relay $87 \mathrm{GD}$ can be seen as primary protection. Importance and explanation of these relay is discussed in previous subsection. For backup protection, a CT located on the generator output conductors supplies secondary current for several different relays. In the figure below, a negative sequence relay (46), a voltage restraint overcurrent relay (51V), a directional power relay (32) and a field relay (40) can be seen. In addition to the current as an input, few of these relays are provided with voltage from potential transformer.

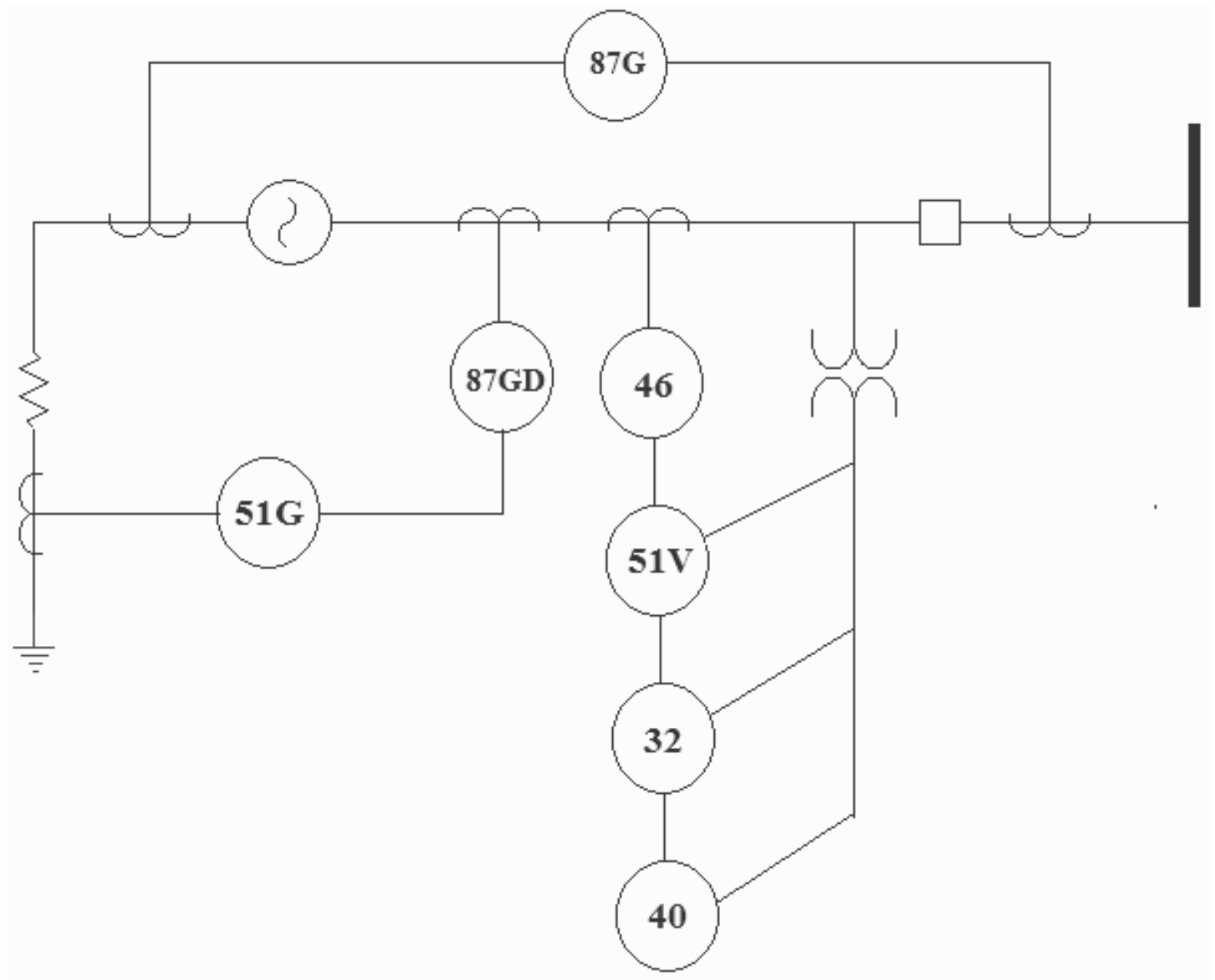

Figure 41: Generator backup protection 
Negative current or voltage opposes generator rotation and consequent breaking effect causes overheating of the rotor. The primary function of the negative sequence relay is to prevent over heating of the generator rotor in case of prolonged out of balance operation. Negative sequence current is present when the phase currents are out of balance due to either phase to phase system fault or generator fault which is cleared by their respective primary protection. However, if the primary protection fails to operate then the negative sequence relay will register the continued presence of the negative components and trip the generator. Hence the negative sequence relay act as a backup protection.

Another backup protection is provided by the time overcurrent relay with voltage restraint $(51 \mathrm{~V})$. In the case of internal fault to generator, this relay acts as a backup to the generator differential relay $87 \mathrm{G}$. The reason for using voltage controlled overcurrent relay to avoid operation due to overcurrent when there is an external fault (fault outside of differential protection zone of the generator). Therefore when the voltage is normal on the system the voltage restraint element prevents operation of the time overcurrent relay. As a result when an internal fault occurs on generator, the terminal voltage falls and it falls below pre-set value of normal voltage then the voltage restraint is lifted and the relay will operate in case of overcurrent.

Another backup relay typically installed on small generators is the reverse power relay. This relay will operate when power flows into the generator attempting to drive it as a motor. A typical example can be during load reduction. The load is not the same throughout the day. There are times of the day when the demand is at the peak. However when load is reduced, during night time, the turbines steam control valves shut off inadvertently during load reduction. In this situation the turbine is no longer driving the generator but the generator is still synchronized to the power system. So it draws current in an attempt to drive the turbine. This situation can cause serious overheating and damage to the turbine lowpressure blades.

One of the major concerned of the generator is loss of field excitation. In this condition, the generator is still connected to the power system and still delivering real power because it is still being driven by its prime mover. However it will no longer supply reactive 
power. On the contrary, it will draw reactive power from the system in order to maintain excitation. The generator will continue running and producing power as an induction generator with low power factor [14]. However this will probably lead to low voltage at the generator terminals and more importantly serious overheating will occur in the stator. If the field cannot be restored promptly the unit should be shut down. Normally protection relays are installed to detect reduction or loss of excitation. These relays may be used for alarm purposes but more often they initiate tripping of the unit.

Loss of field relays work by measuring current in the excitation circuit. When it falls below a preset level the relay will operate after a time delay. Another method of determining the loss of field is by measuring reactive power on generator high side terminals. When the generator is drawing reactive power it means that it is operating as induction unit.

In summary, Generator converts mechanical energy into electrical energy. A fault occurring on generator should be detected by its protection system. It should cause the main breaker to open, de-energize excitation system and shutdown prime mover. Protection against generator phase faults can be achieved by differential protection. Under normal operating conditions and condition of fault outside the differential protection zone, there is no current flowing through operating coil. However, for an internal fault, there will be mismatch and current will flow in operating coil and cause it to trip the breaker.

Large generators are grounded through high impedance in order to reduce ground fault current to be under $10 \mathrm{~A}$ to limit the internal damage to generator. Another protection scheme which is utilized is use of overvoltage ground relay. Moreover, protection against distorted sine wave can be provided by use of under-voltage relay which functions using third harmonics. This relay will operate when voltage is considerably reduced due to ground fault.

In industrial plants where multiple generators are connected to same bus and single ground connection is provided, protection is provided by ground differential protection. When there is a ground fault detected, current direction in neutral coil and CT differential coil is same. Therefore the ground differential relay will operate removing the faulty breaker from the system. 
Generator backup protection is provided by negative sequence relay, time overcurrent relay with voltage restraint, reverse power relay and loss of field relay. Negative sequence current and voltage opposes the generator rotation and overheat the rotor. Therefore negative sequence relay will trip if prolonged out of balance is detected. Moreover, when there is a fault, generator terminal voltage falls which results in lifting voltage restraint from overcurrent relay and allows it to operate. Reverse power relay operate when power flows into the generator attempting to drive it as motor. Furthermore, under loss of field excitation, the generator draws reactive power from system in order to maintain excitation. The generator will continue producing power at lower power factor and work as induction generator.

\subsection{Bus Protection}

The bus is a very important part of power system as it must be used at every junction point of lines and feeders. Normally there are number of lines coming into the bus and feeding out of the bus. Fault at the bus may be due objects or animals or birds bridging either bus and insulator or two busbars. Moreover, bus fault might also be due to lightning flashover on a bus situated outside in open environment. When there is a fault at bus then it should be removed as quickly as possible because of the potential damage that can happen. Figure 42 shows busbar condition after fault due to bridging of two buses.

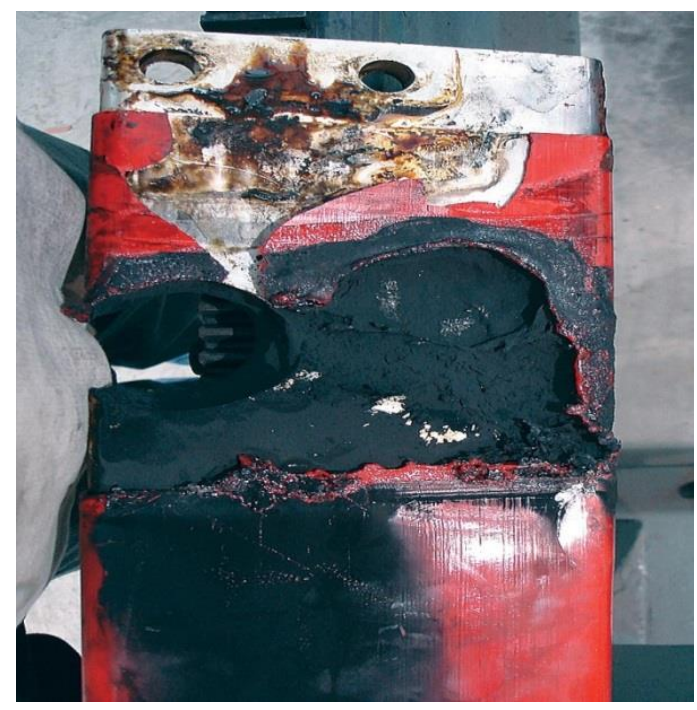

Figure 42: Bus fault 
Figure 43 shows a simple single bus arrangement where 2 generators are feeding the bus and 2 transmission lines feeding out of the bus. In normal operating conditions, current coming into the bus equals current going out of the bus. Same principle works when there is a fault outside of bus. But when there is a ground fault at the bus, not only the generators feed the fault. But the current flow in the transmission line reverses and it provides current to the fault.

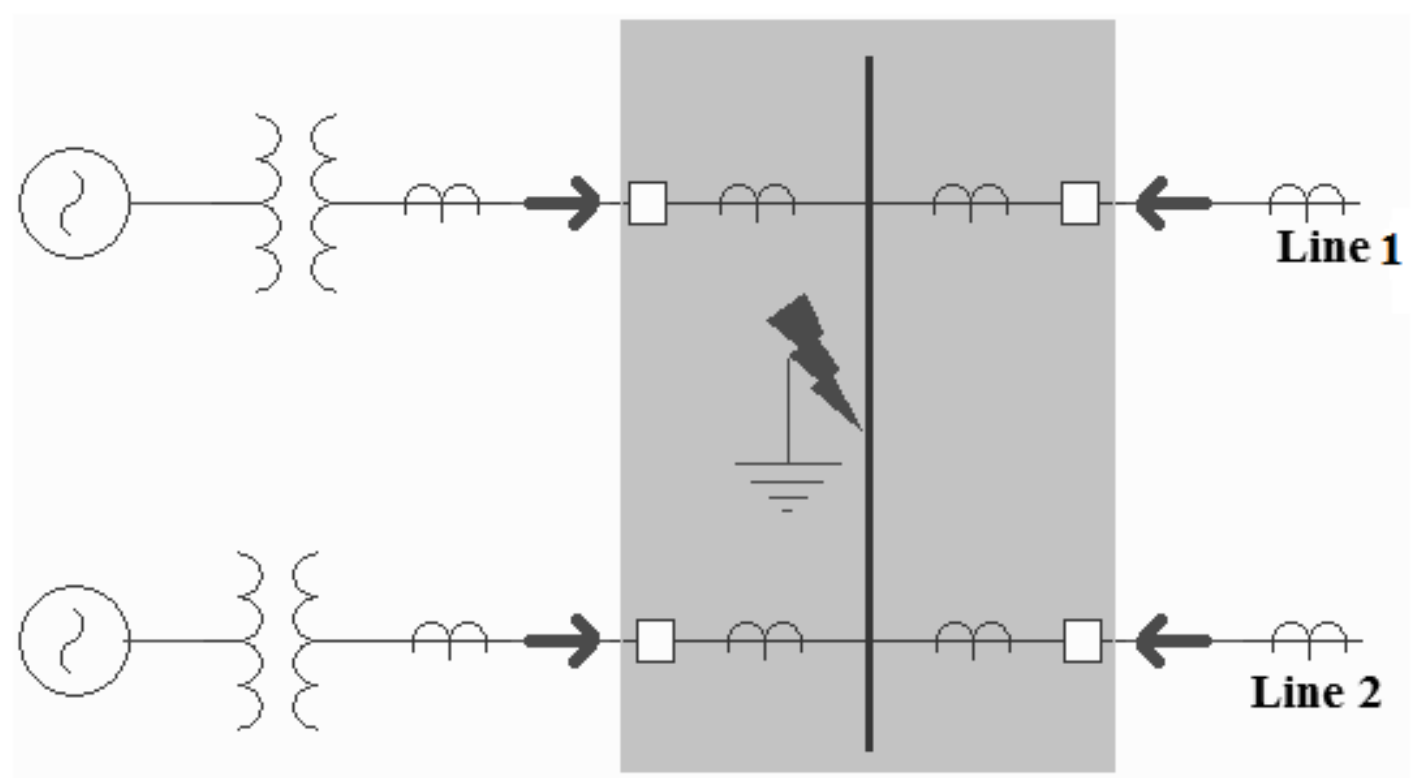

Figure 43: Single bus configuration with ground fault at the bus

Different types of bus protection schemes and their pros and cons are explained in next subsection.

\subsubsection{Types of Bus Arrangements}

\subsubsection{Single Bus Scheme}

Single bus scheme is shown in figure 44. For this particular system, if the circuit breaker opens due to a fault or maintenance then the system will be without power because of the loss of availability of generators. Hence adequate protection must be applied. This type of configuration has lowest cost and requires small land area compared to other schemes [15]. However, this arrangement has the lowest reliability. 


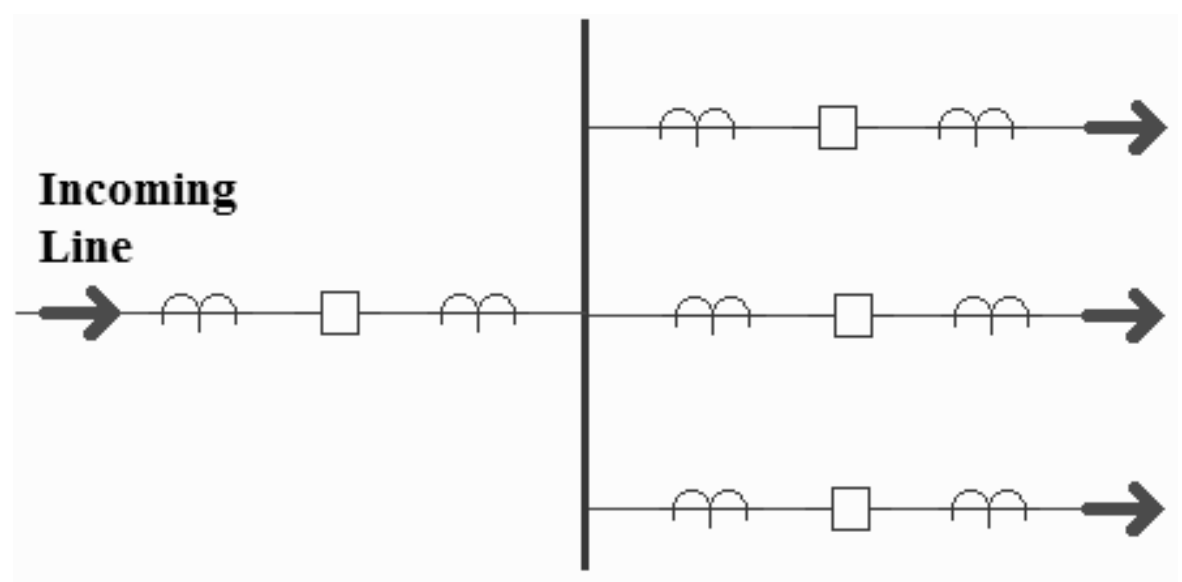

Figure 44: Single bus scheme

\subsubsection{Sectionalized Bus Scheme}

Sectionalized bus scheme shown in figure 45 is an extension of single bus protection scheme. In an attempt to improve reliability two buses are connected with tie breaker. Therefore, in an event when there is a fault or when the circuit breaker needs to be removed for maintenance, entire station will not be out of power. However, this scheme has higher cost compared to single bus scheme because of the number of circuit breaker installed. In this arrangement, tie-breaker will normally be closed for system reliability. As it is shown in figure 45 , if there is a fault in line $\mathrm{A}, \mathrm{F}_{\mathrm{C}}$, then circuit breaker above the fault will be open. In this case, bus A will be fed from other incoming line through tie breaker. In case of fault $\mathrm{F}_{\mathrm{D}}$, bus B can be fed from incoming line A. In both cases, proper directional relay technique can be used to avoid other line feeding the fault. However, when there is a fault at bus $\mathrm{A}, \mathrm{F}_{\mathrm{A}}$, connected circuit breakers including the tie breaker will operate. This would isolate the faulty bus from operation. Though bus B will still operate in normal condition. Moreover, since there is only one circuit breaker in each line feeding the load, the line has to be put out of service during maintenance or during fault at load. 


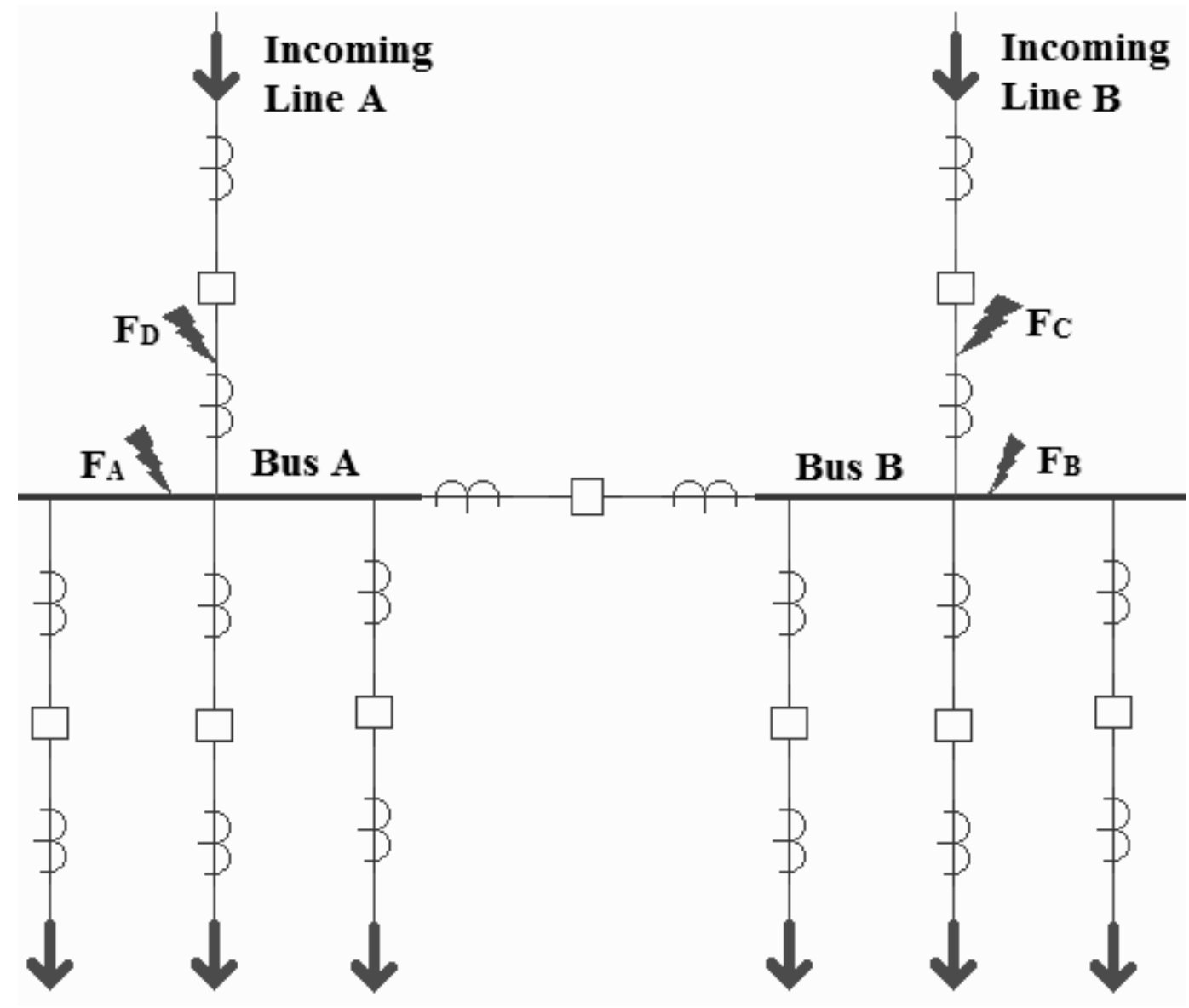

Figure 45: Sectionalized bus scheme

\subsubsection{Main and Transfer Bus Scheme}

Figure 46 shows the main and transfer bus scheme. In this arrangement, line can be fed either by main bus or through transfer bus. Suppose circuit breaker 1 in figure 46 needs to be isolated for maintenance. The disconnect switch of line 1 will be connected to transfer bus. Moreover, disconnect switch of the tie breaker closes as well providing path for that line. In this case, tie breaker would operate as the breaker for line 1 . This could be done with any of the line. As a result, adding one extra breaker will provide backup for all other line in connected system. In this system, main bus is protected by differential protection but there is no adequate protection for transfer bus. The protection and relaying may get complicated for this system. Moreover, if there is a fault at the main bus then it will impact on entire substation. 


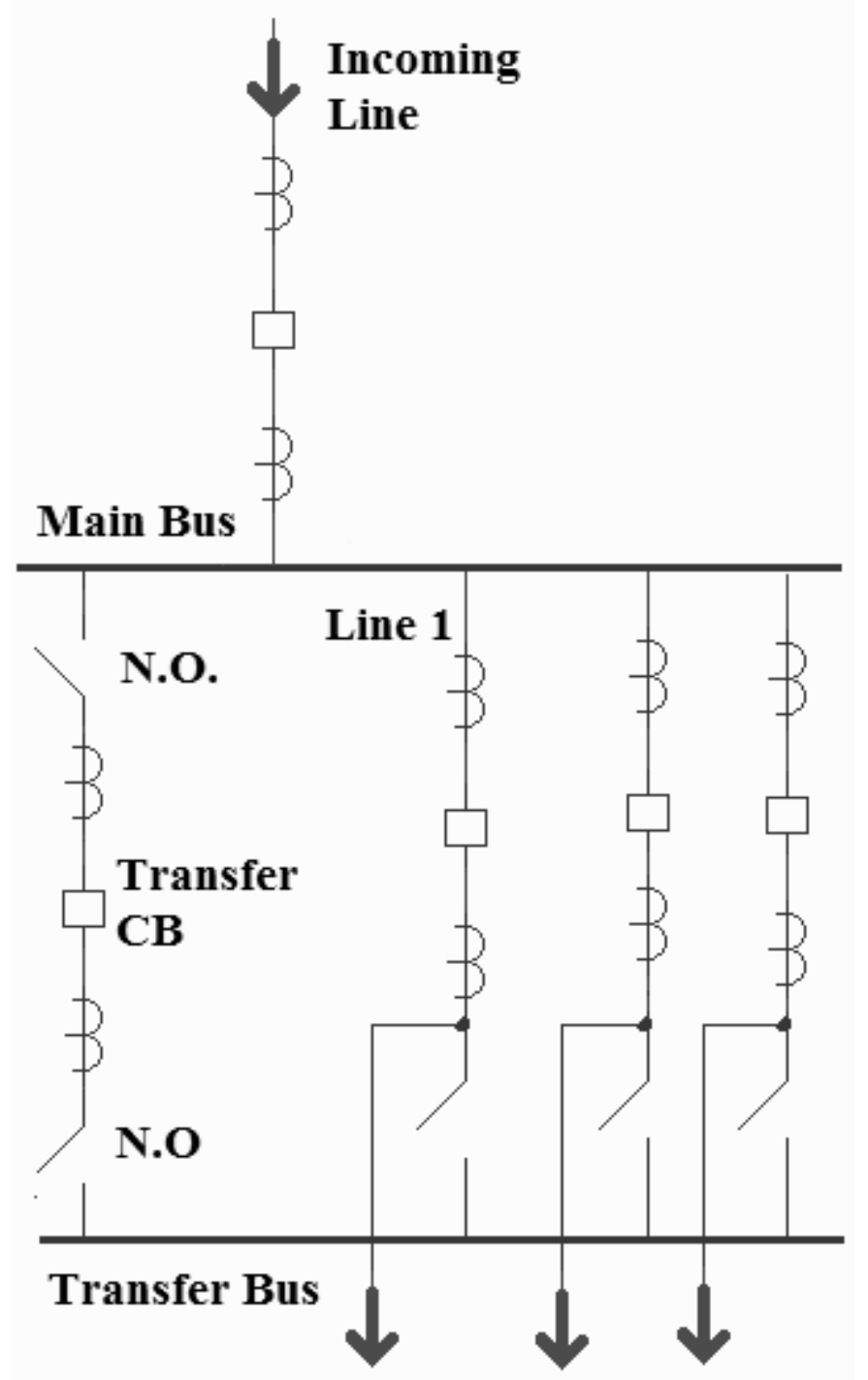

Figure 46: Main and transfer bus scheme

\subsubsection{Ring bus scheme}

In ring bus scheme shown in figure 47,4 circuits are connected in a ring which is broken into 4 sections by 4 circuit breakers. Each line is associated with 2 circuit breakers. Which means a fault on any line will cause the directly connected circuit breaker to trip. However, rest of the three lines will still be in service. Any circuit breaker can be taken out for maintenance without affecting the supply of any lines. 


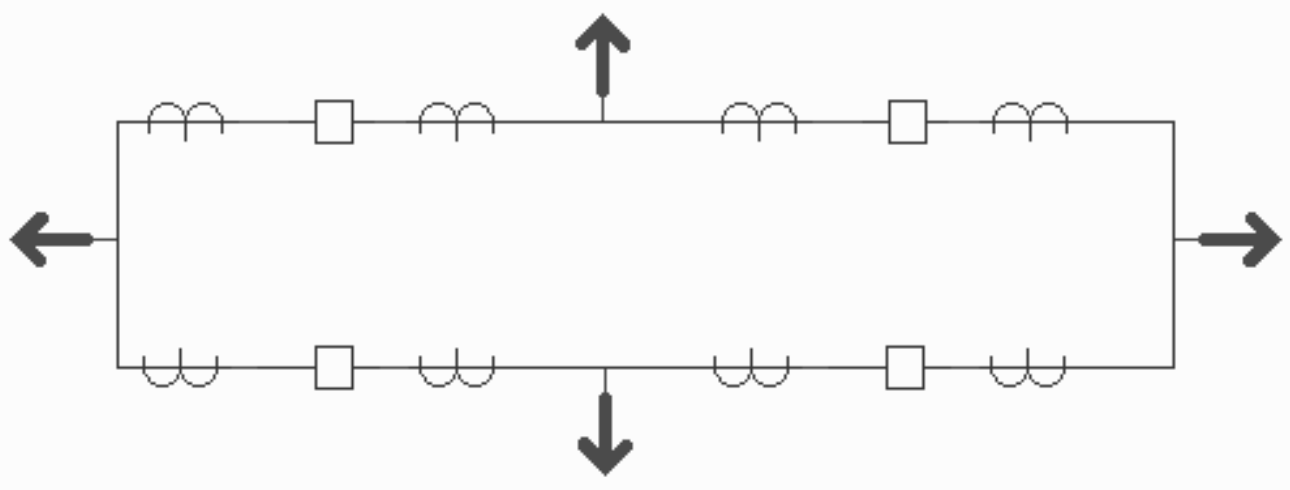

Figure 47: Ring bus scheme

\subsubsection{Breaker and a half scheme}

In this scheme shown in figure 48, each circuit has its own breaker and another breaker which is shared with another circuit. In normal operating conditions the shared breaker is closed. This scheme provides better reliability. In a situation when there is a fault at Bus 1, breakers connected to bus 1 will trip. In this situation, line can be fed from Bus 2 since the shared breaker is close. Moreover, any breaker can be removed for maintenance without system disruption. 


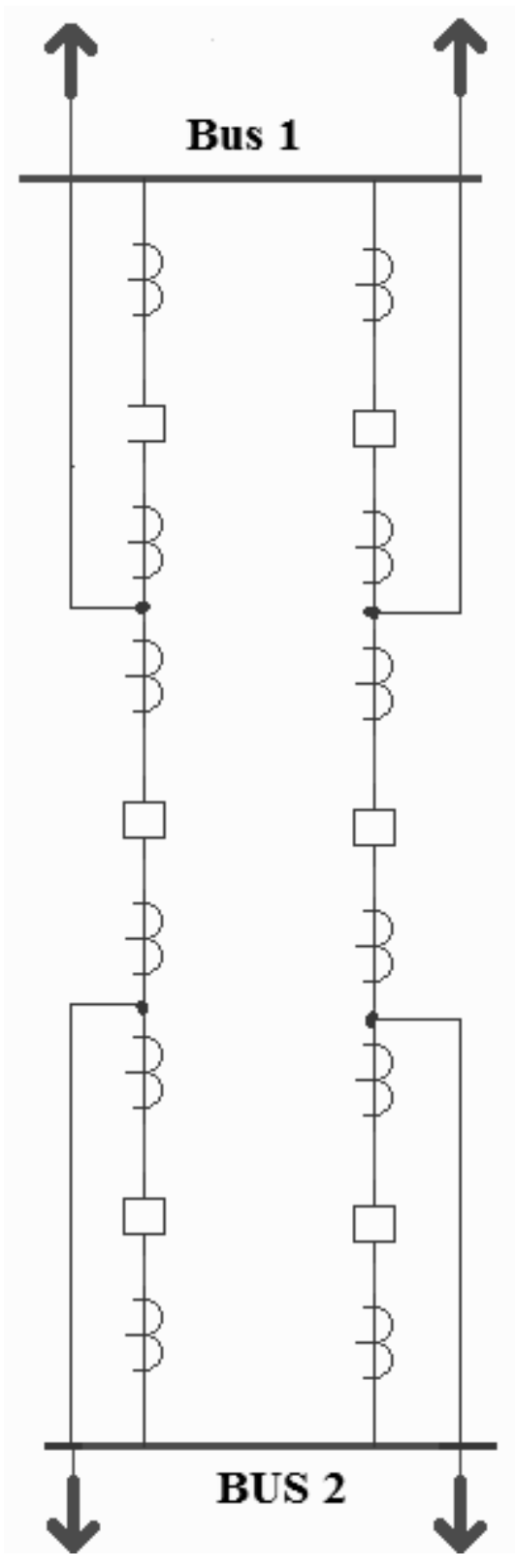

Figure 48: Breaker and a half scheme

\subsubsection{Double bus double breaker scheme}

In double bus double breaker scheme shown in figure 49, each incoming line has two circuit breakers, which allows it to be immediately connected to either bus 1 or bus 2 . Each bus has its own zone of protection. Now suppose there is a fault on bus A. In this case all the breakers connected to bus A will trip and immediately close breakers to connect these 
circuits to bus B. This scheme has very high reliability and flexibility in operation. Moreover, any of the breaker or bus can be taken out for service without disrupting the service. Most importantly, in case of bus fault, there is no interruption to the service. The cost of double bus double breaker scheme is very high since each circuit need two breakers.

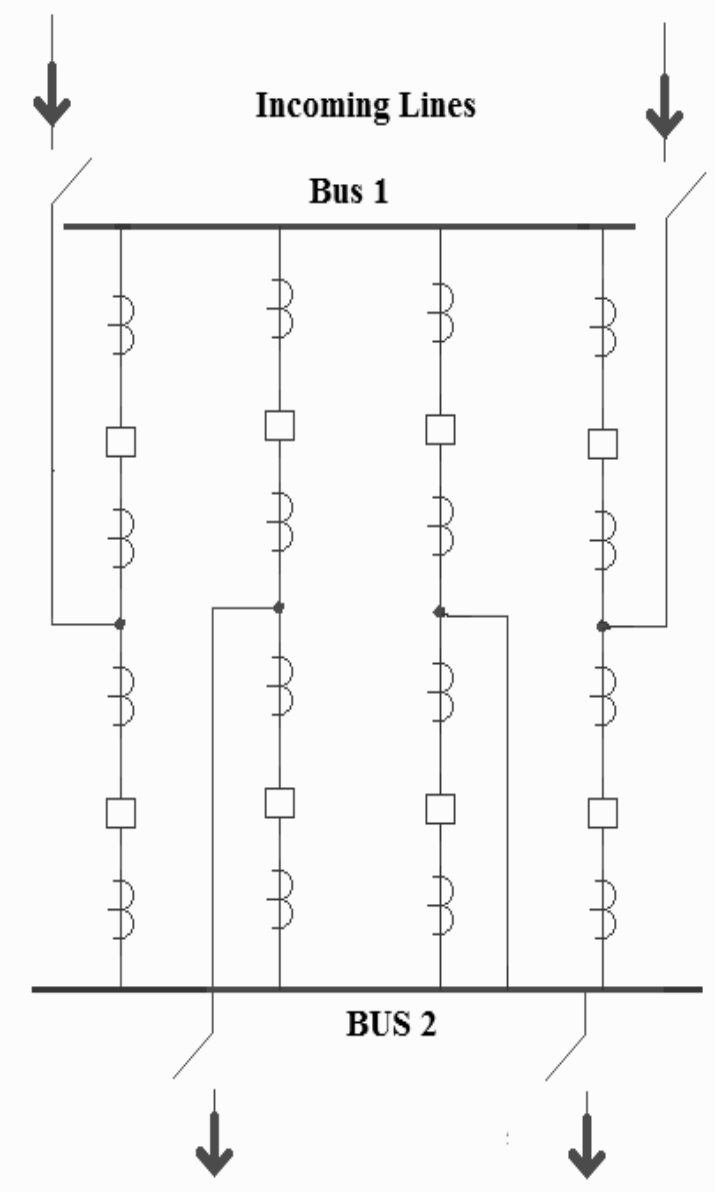

Figure 49: Double bus double breaker scheme

\subsubsection{Bus differential protection}

Figure 50 illustrates an example for the explanation of bus differential protection. There are total 6 circuits, 3 incoming with 400A each and outgoing lines have currents 500A, 400A and 300A respectively. Assuming all CTs have ratio of 100:1, the secondary current for each CT can be easily calculate and shown in the figure. In normal operating condition 
total current coming in equals total current going out. Therefore CT will not operate as loads are balanced.

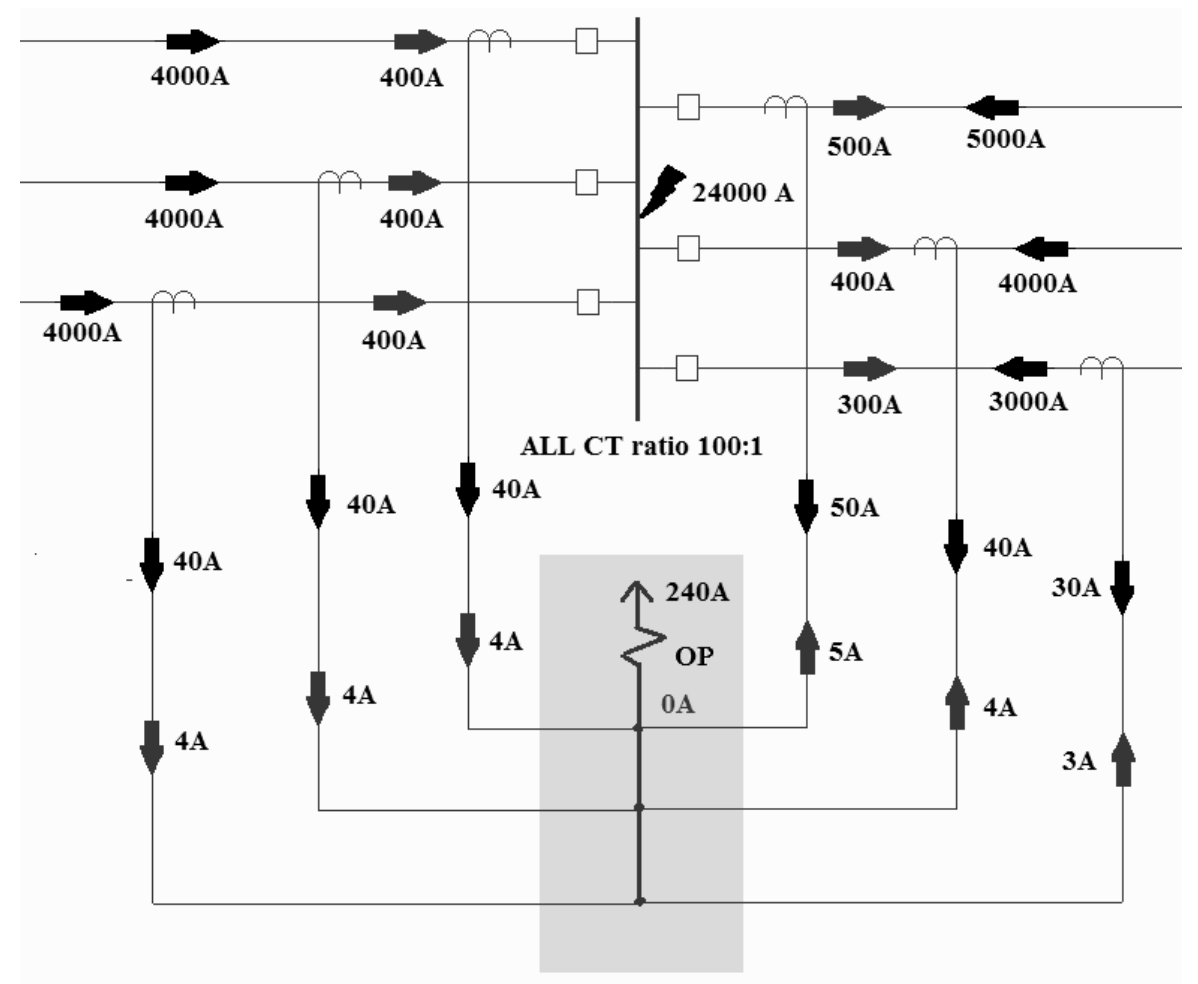

Figure 50: Bus Differential Protection with internal fault

Now suppose a fault occurs on the bus with magnitude of 24000 amperes which is shown in figure 50. In this case, all six lines feeds current into bus to supply fault current depending upon the reactance of each line from its respective source. For illustration purpose, assume the current feeding into bus is as shown in figure above. The secondary side of CT has fault current feeding into relay is also shown in the diagram. Since the currents are coming in from both sides, total current will add up and 240A current will flow through the operating coil. Therefore relay will trip. This will operate and trip all bus breakers. This is the result expected for an internal fault. Now consider the case of an external fault as shown in figure 51 where the fault current is same as previous case. Three incoming line to bus feeds 4000A each and for outgoing lines, line 2 and 3 feeds 4000A and 3000 respectively. Therefore total of 19000A current is fed into the fault by these lines and also line 1 feeds 5000A. 


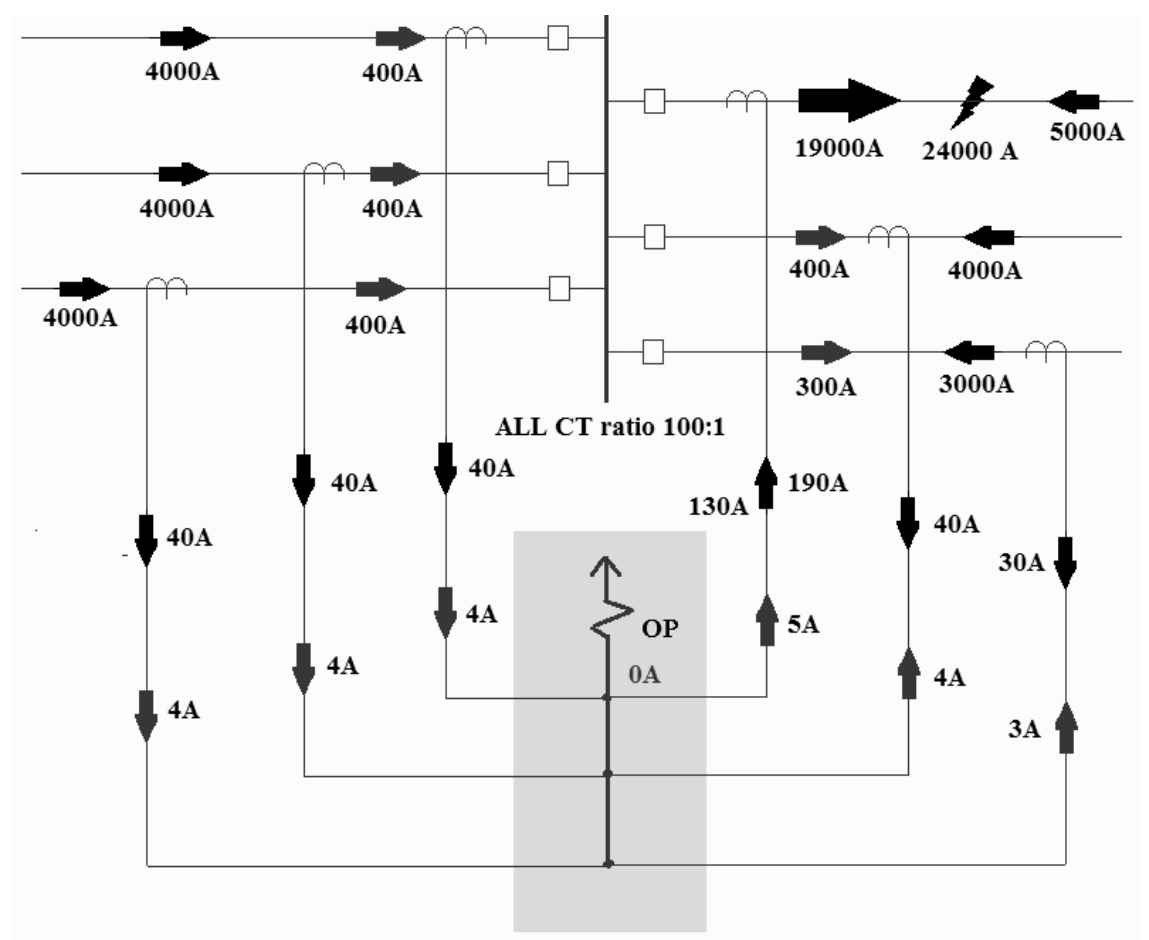

Figure 51: Bus differential protection with external fault

In the CT secondary, current flow is shown in the figure above. Total current coming into the restraint coil of relay is $190 \mathrm{~A}$ and exactly same amount of current is going out of the relay. Therefore zero current would pass through the relay and it will not operate. This is an expected result for an external fault. But in practical situations, it will not react as expected.

As it is discussed before, the amount of magnetic flux circulating in core is proportional to current in primary winding. As current increases, flux increases. However, core becomes saturated at a certain point and flux will not increase in proportion to primary winding [16]. Therefore, primary to secondary current relationship will not be true in that case. As a result, an error will generate which affects relay measurement. The standard classification of $\mathrm{CT}$ allows $10 \%$ error for current flow up to 20 times the rated current. However, level of current in the CT secondary feeding the faulty line is 38 times (190A) its rating which is very high than the standard limit of 20 times to retain accuracy. As a result the current transformer core will saturate [17].

Moreover, due to distortion occurring in first few cycles will cause the current to be low. Suppose the current is $130 \mathrm{~A}$ in this case. The current mismatch will be 60A. Therefore 
$60 \mathrm{~A}$ current will be passing through the operating coil. Therefore the relay will operate. In order to allow high speed tripping and avoid miss-operation due to distortion, one of the solution is to set the percentage differential by calculating differential using equation below.

$$
\% \text { Differential }=\frac{\text { Operating coil current }}{\text { Restraint coil current }}
$$

Equation (3)

The current through operating coil is $60 \mathrm{~A}$. Moreover, 250A restraint current is flowing in one direction and 70A restraint in the other direction. Therefore the restraint coil current is $180 \mathrm{~A}$. The percentage differential calculation in this case is $33 \%$. Another solution to the same problem is the use of different restrain coil for each phase as shown in figure 52 .

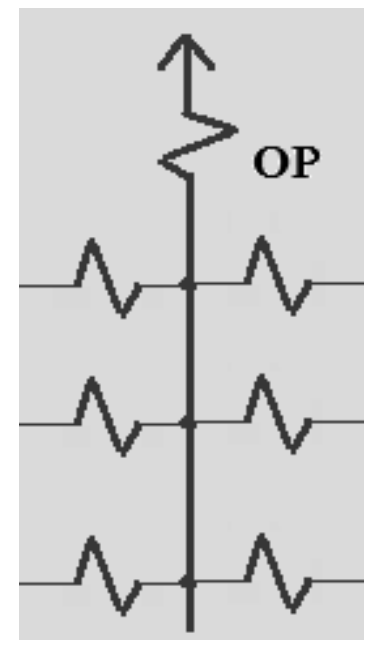

\section{Figure 52: Bus differential relay with multiple restraint coils}

Summarizing the chapter, bus is an important component of power system as it must be used at every junction point and the damage that can occur is devastating because of availability of fault current. In normal operating condition, current enters the bus equals the current going out of the bus. Moreover, same principle works for faults outside of bus. There are various bus arrangement schemes discussed in this chapter.

Differential protection provides better protection for bus faults. Due to the available short circuit current, current transformer core saturation must be kept into account when designing the protection scheme. Moreover, one operating coil per phase is recommended for better operation and avoid faulty operation. Up to $10 \%$ error is allowed for current flow up to 20 times the rated current. 


\subsection{Transformer Protection}

There are different types of transformers such as two winding transformers, three winding transformers, auto transformers etc. A power transformer is shown in figure 53. Winding connection can be either wye (Y) or Delta $(\Delta)$ to get desired voltage levels and phase relationship. A Y- $\Delta$ or $\Delta$-Y arrangements are made for the transformer so that the high side voltage leads low side voltage by $30^{\circ}$. For transformer protection, the type of protection scheme used depends upon the size and importance of transformer in power system. Transformer must be protected against internal faults, which occurs as a result of insulation failure which creates short circuit path between phases and often to the grounded iron core, and through faults in which heavy fault current flowing can cause serious damage to windings and even burn the core itself. Differential protection provides best protection against internal faults and through faults can be cleared by other protective devices. However if the fault fails to clear, then it can place severe overload on transformer. Heavy fault current flowing in the secondary winding will produce a corresponding relatively heavy current flow through the primary.

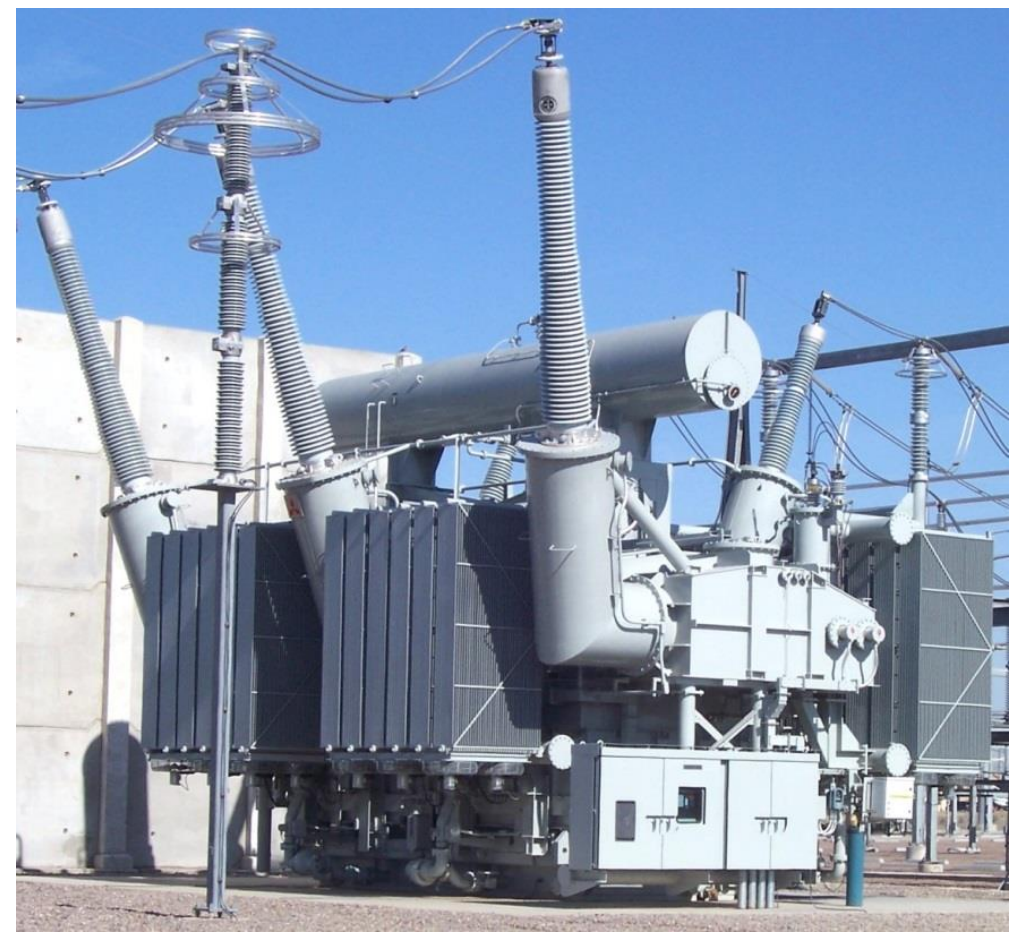

Figure 53: Power transformer 
As shown in figure 54, for a $\Delta$ primary and $\mathrm{Y}$ secondary connection of the transformer, if a three-phase short-circuit occurs downstream of the secondary, heavy fault current will flow through all three phases of the primary winding.
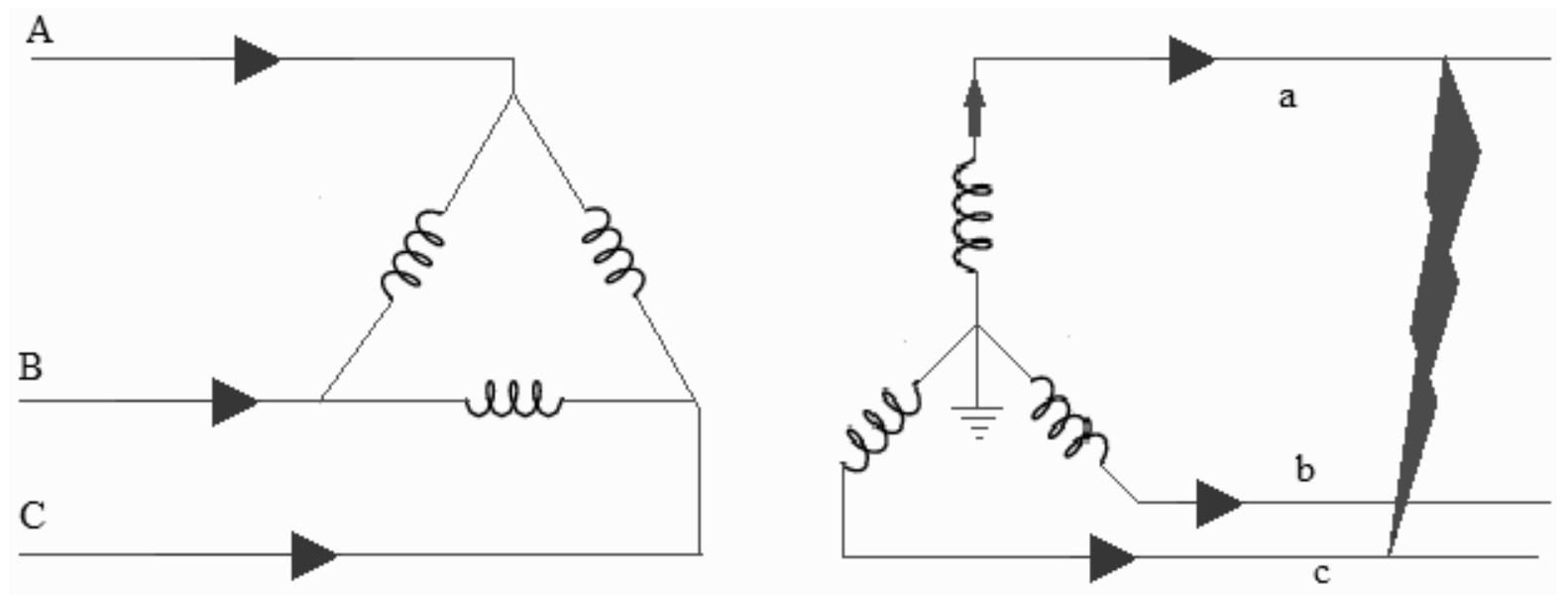

Figure 54: Delta - wye connection with 3 phase fault

In the case of a phase 2 phase fault on secondary, in figure 55, between lines $\mathrm{B} \& \mathrm{C}$ then heavy fault current will circulate in the secondary $b$ and $c$ phase windings. Likewise heavy current will flow through the associated windings on primary and this will be in addition to load current which is still being supplied.
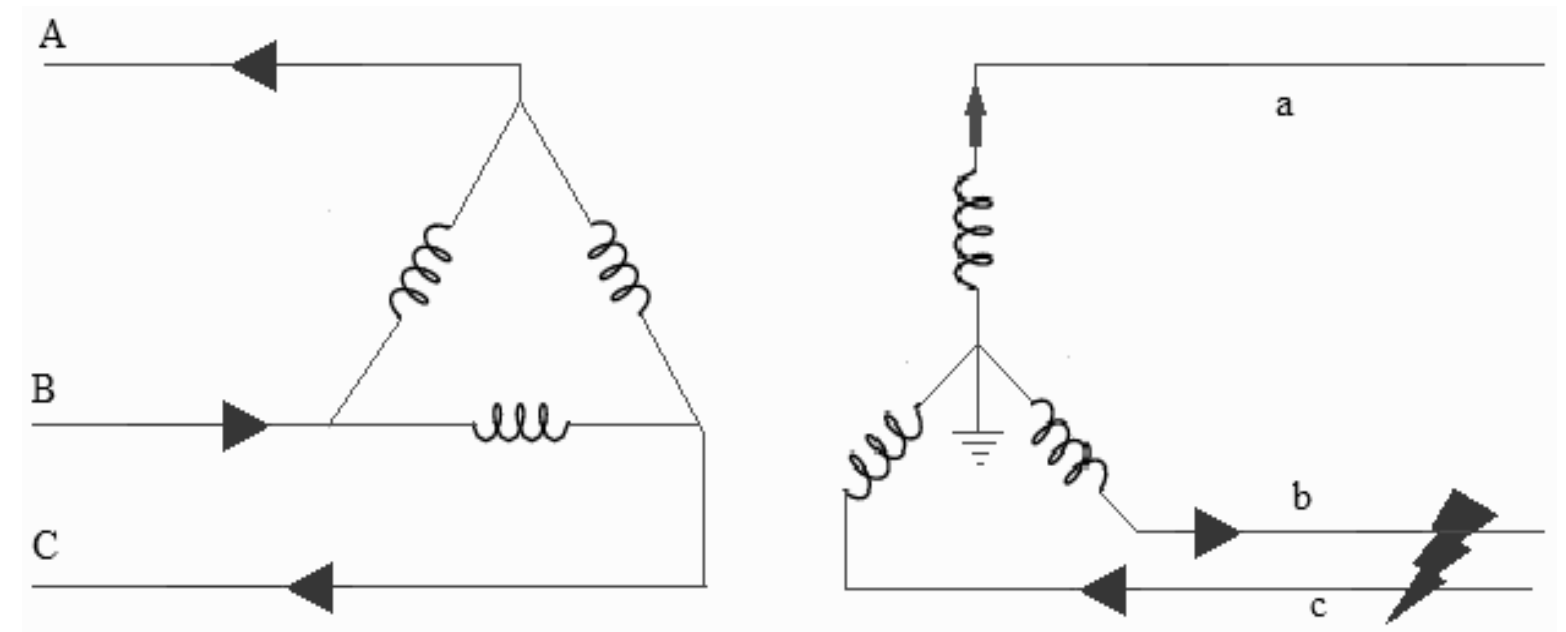

Figure 55: Delta - wye with phase to phase fault

Where there is a ground fault, shown in figure 56 on line A, additional current must flow through the associated phase on the primary. The result of this high fault current passing 
through the transformer can cause mechanical and the thermal damage. The high current causes physical movement of the winding and this in turn can cause rapid breakdown of the insulation. Similarly the insulation will deteriorate rapidly due to the high temperature resulting from high overcurrent.
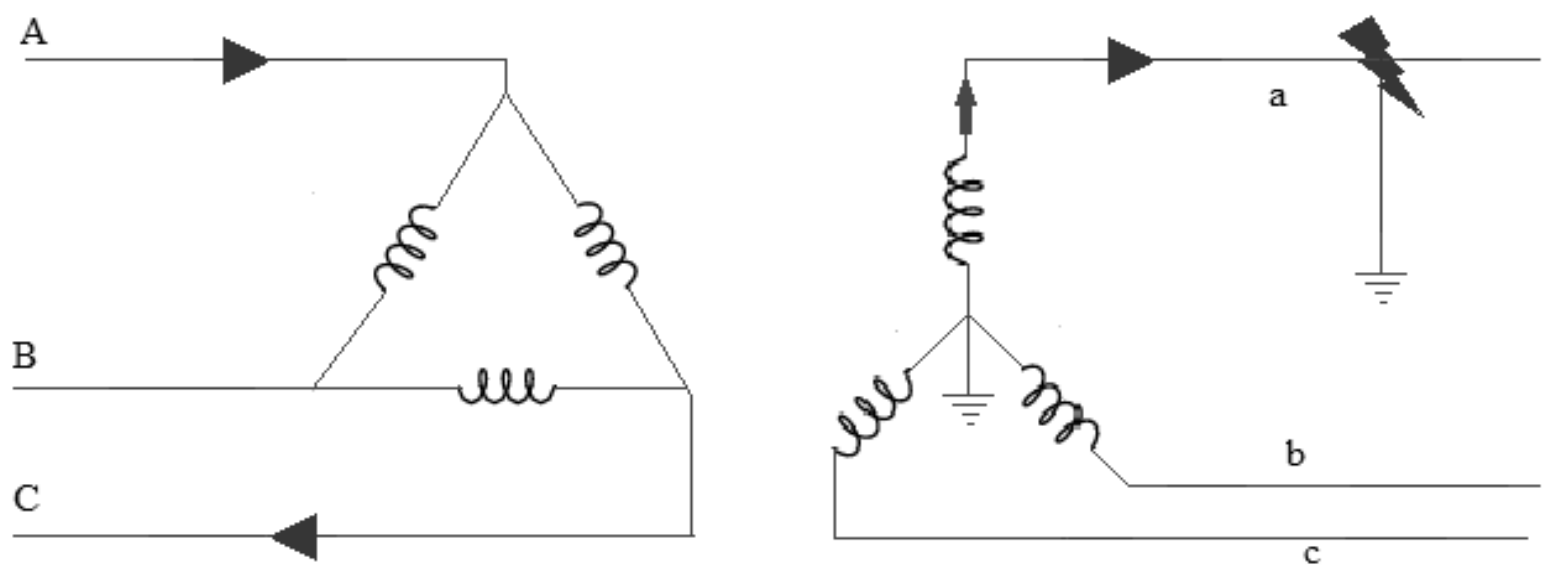

Figure 56: Delta - wye with line to ground fault

Table 2 shows Four classes of transformers which are categorized by size and for each category a curve is provided showing the thermal limit for transformers in that category.

Table 2: Transformer Categories

\begin{tabular}{|c|c|c|}
\hline Category & Single Phase (kVA) & Three Phase (kVA) \\
\hline I & $5-500$ & $15-500$ \\
\hline II & $501-1667$ & $501-5000$ \\
\hline III & $1668-10000$ & $5001-30000$ \\
\hline IV & Above 10000 & Above 30000 \\
\hline
\end{tabular}

Table 3 indicates the allowable time of operation for different values of overload. For example with three times the normal rated current this transformer can operate for 300 seconds that is five minutes before damage will occur. 
Table 3: Transformer short-time thermal overload capability

\begin{tabular}{|c|c|}
\hline Time & Times rated current \\
\hline $2 \mathrm{~s}$ & 25.0 \\
\hline $10 \mathrm{~s}$ & 11.3 \\
\hline $30 \mathrm{~s}$ & 6.3 \\
\hline $60 \mathrm{~s}$ & 4.75 \\
\hline $5 \mathrm{~min}$ & 3.0 \\
\hline 30 min & 2.0 \\
\hline Figure 57 shows the thermal overloading capability curve for category
\end{tabular}

Figure 57 shows the thermal overloading capability curve for category III transformer. This curve may also be used for coordinating for backup protection. As it can be seen in the figure below, as the current decreases the amount of time the relay takes operate decreases.

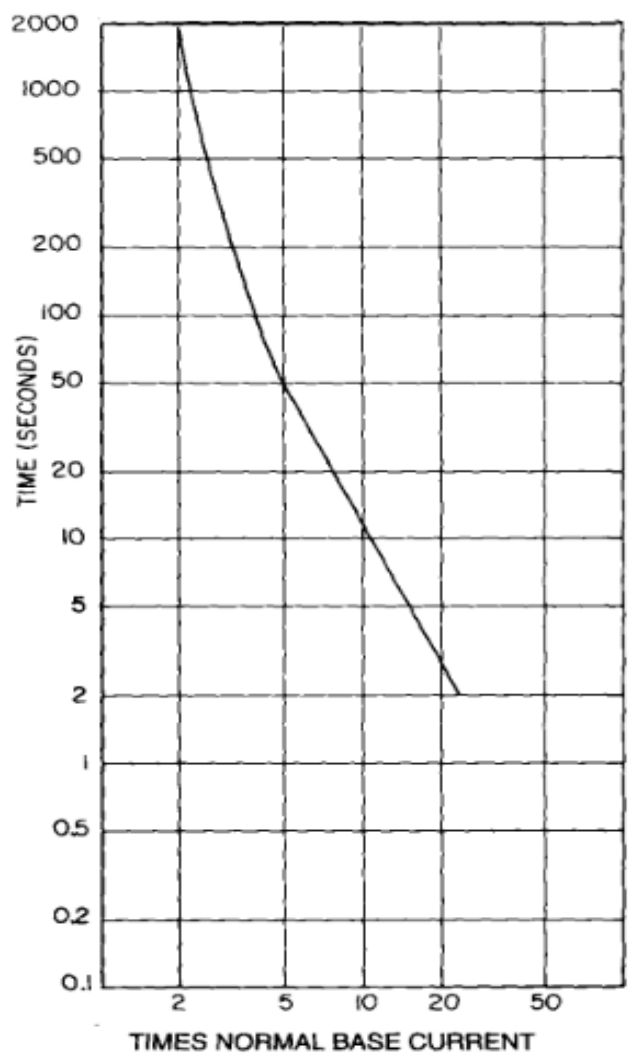

Figure 57: Category III transformer (5 - 30 MVA) 
If the overcurrent is at 10 times normal then the allowable operating time is only about 12 seconds. In order to prevent this, the first line of protection would be the operation of protection devices downstream in the low voltage system. In fact the low voltage protection will probably be set to operate on a curve shown above and trip the feeder breaker. As it can be seen, for 30 times rated current the feeder protection will trip in two seconds. This is long before the thermal limit of the transformer is reached. However backup must be provided to protect the transformer in the event the downstream feeder protection fails to operate this is usually in the form of overcurrent protection on the primary side of the transformer. In figure 58 single phase fault on transformer winding is shown.

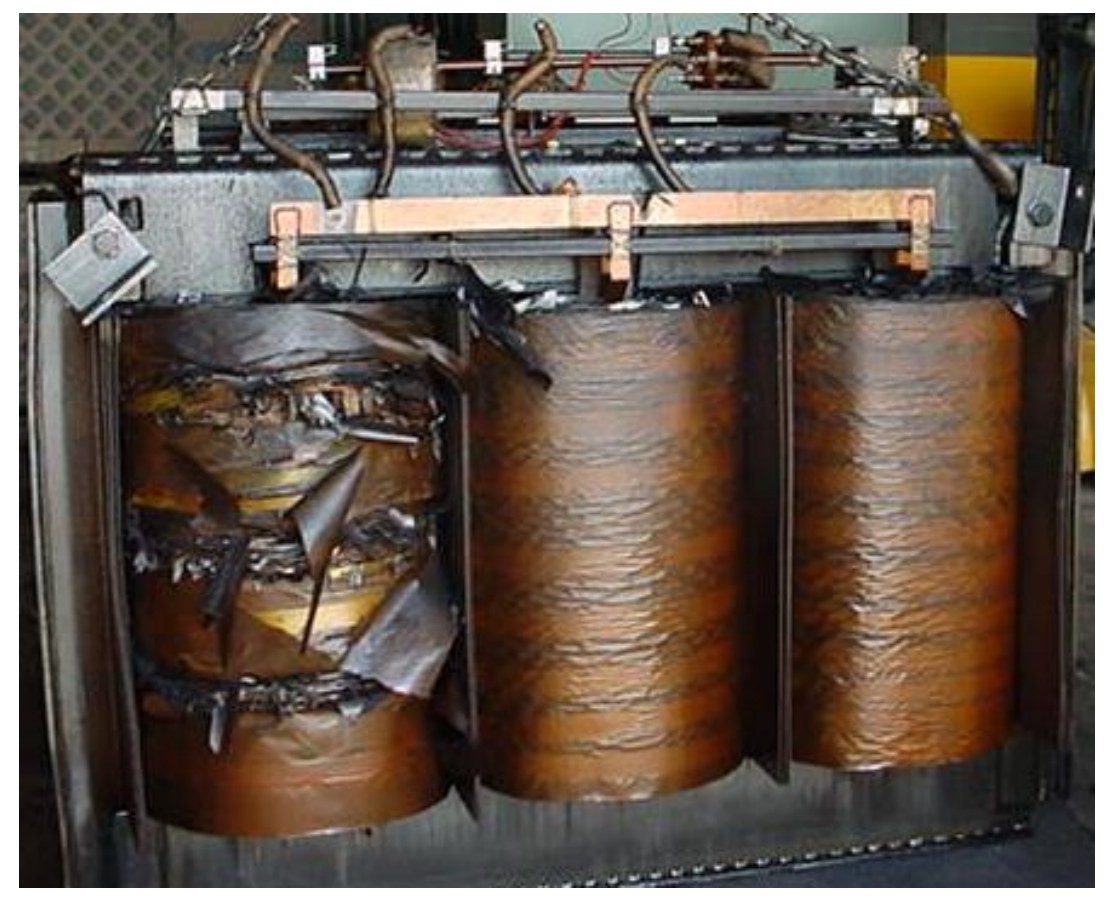

Figure 58: Fault on transformer winding

\subsubsection{Differential Protection on 2 winding transformer}

When applying differential protection to transformers certain factors that must be taken into consideration are the magnetizing inrush current, phase shift in Y (WYE) $-\Delta$ (DELTA) connected transformers, phasing of CT connections, selection of CT taps and the effects of transformer taps [21]. Figure 59 shows simple form of differential protection on transformer. 


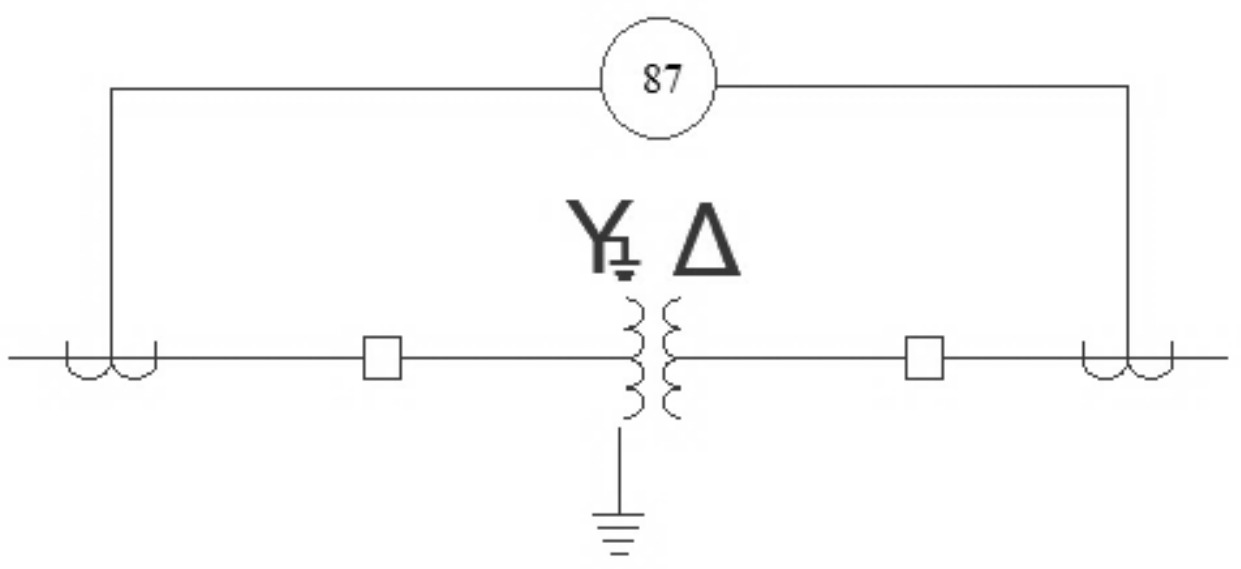

Figure 59: Differential protection scheme

The inrush current is due to the initial energizing of the transformer. The large inrush current is high in second harmonics and this factor is used to provide a harmonic restraint to differential relays which are used for transformer protection [22]. The harmonic restraint unit filters out the second harmonic and uses it to restrain operation of the relay. After few cycles the inrush current is reduced and the second harmonic current disappears so allowing the relay to operate as normal.

Moreover, the differential protection must compensate for any shift in phase across transformer which can be achieved by proper connection to the CT secondary. If transformer is connected Delta on both primary and the secondary sides then Wye connected CTs are used on both sides as there is no 30 degree shift to correct. Figure 60 shows delta - delta configuration of transformer with wye configuration CTs on both sides. 


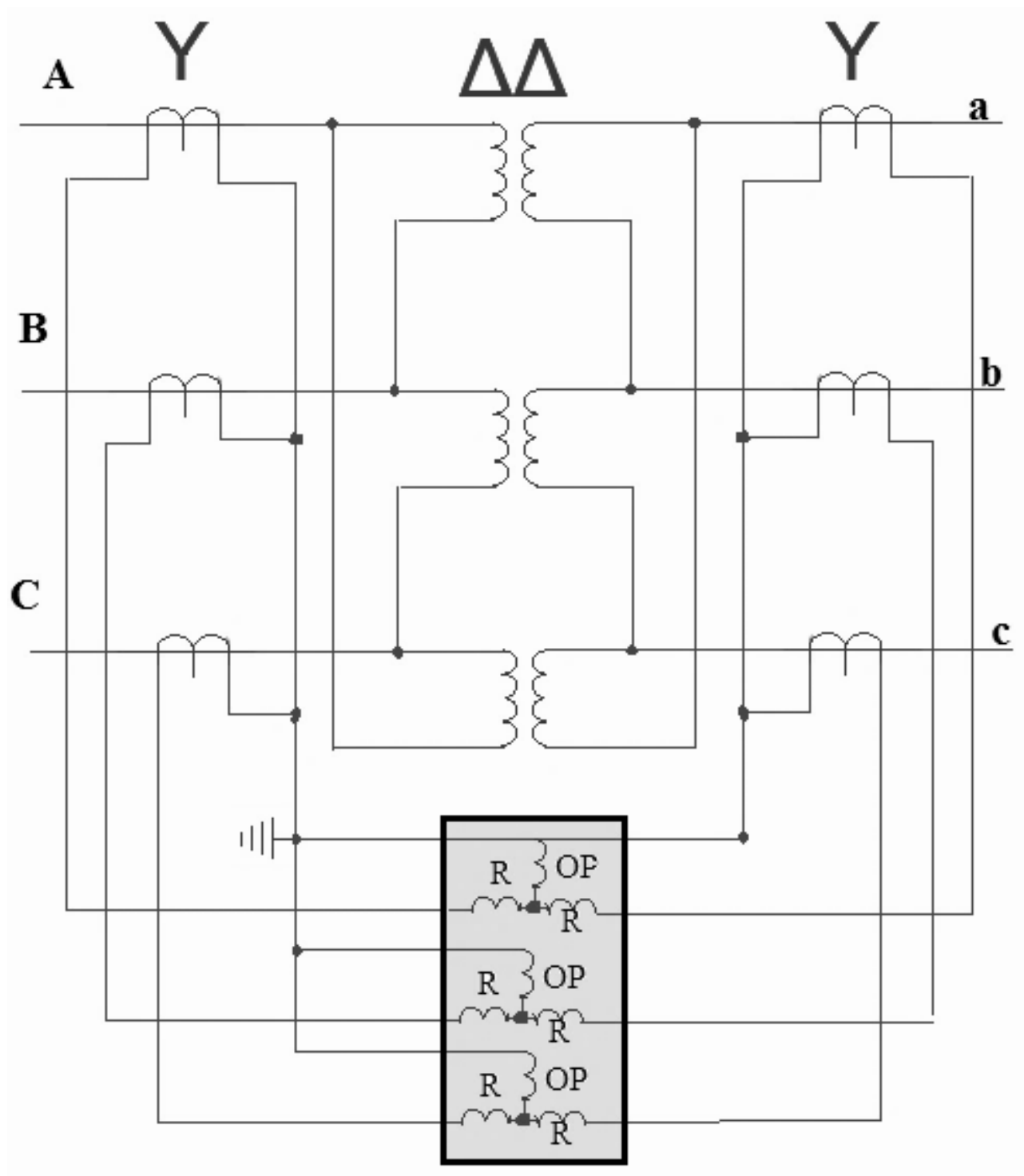

Figure 60: Delta - Delta connection configuration

Figure 61 shows Y-Y connection of transformer with delta connected CTs on both sides. When transformer connection is grounded Wye on both primary and secondary, then CTs are connected in Delta on both sides. The reason for this is because in wye CT connections, zero sequence current may flow in the relay causing unwanted tripping on through faults and delta CT connections are safer as they eliminate zero sequence current from the relay. 


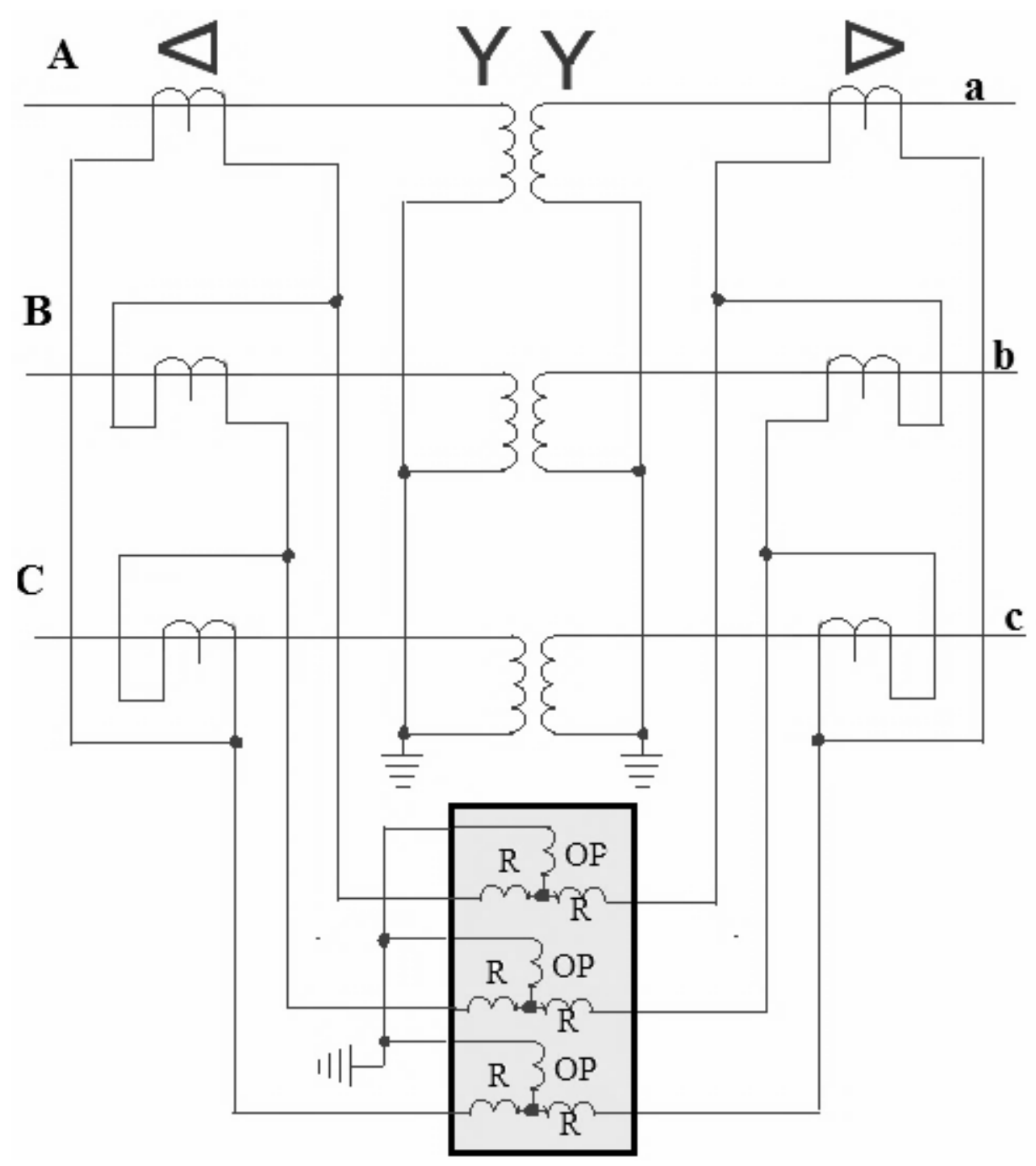

Figure 61: Wye - wye connection configuration

Figure 62 shows delta primary to wye secondary connection of transformer. The high voltage side operates at $138 \mathrm{kV}$ line to line while the secondary side is at $69 \mathrm{kV}$ line to line. Neutral of wye connected secondary is grounded therefore the CTs on this side of transformer should be connected in Delta to avoid issues due to zero sequence current. Similarly, CT connection on primary side should be connected in wye as to correct for the 30 degree difference across the transformer. 


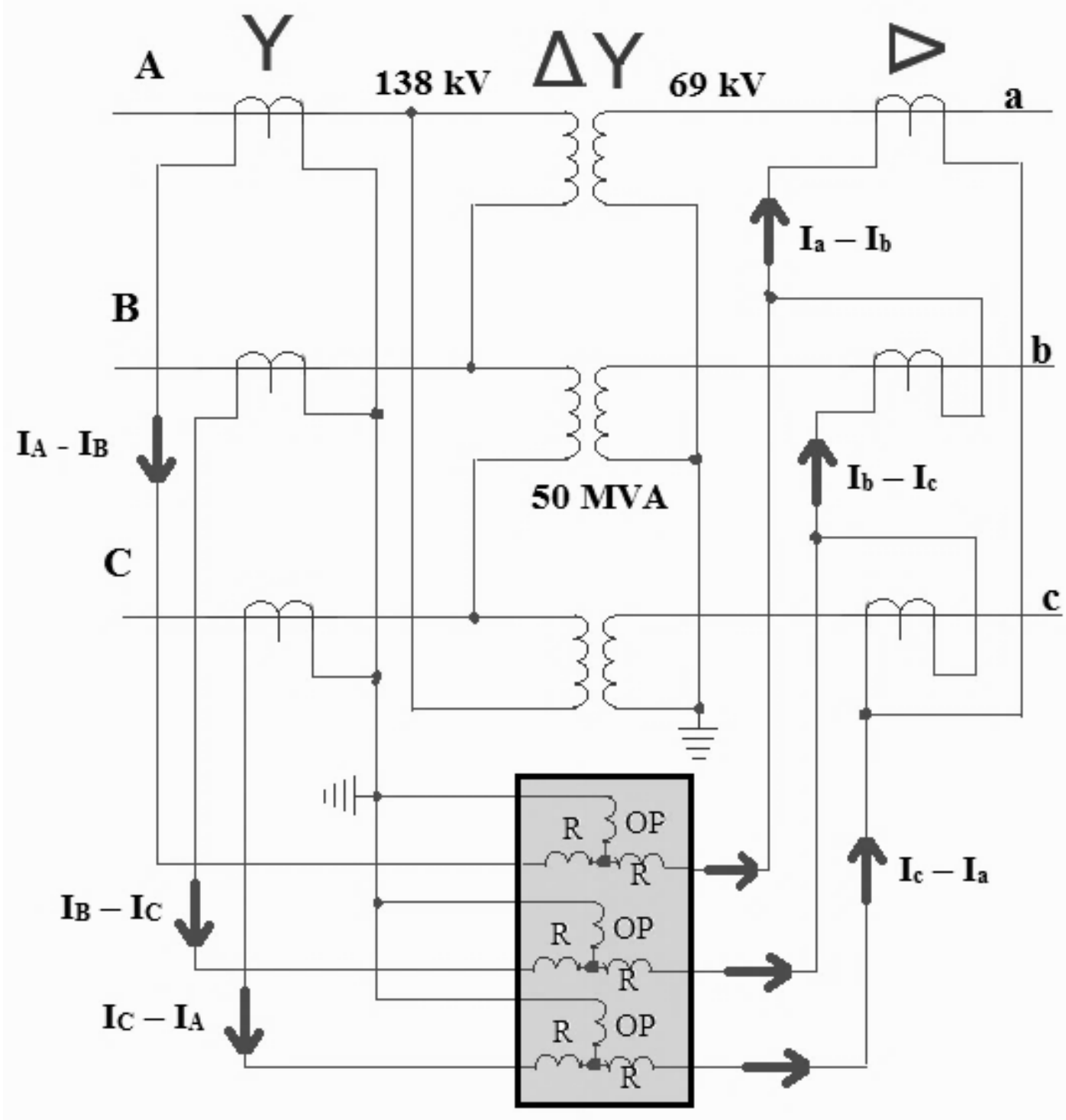

Figure 62: Delta - Wye connection configuration

Most importantly CT ratios must be selected to allow for the different secondary currents resulting from wye or Delta Connection. As shown in figure 62, the phase currents in primary winding are $I_{A}, I_{B}, I_{C}$ and the line current in line $A$ is $I_{A}-I_{B}$, in line $B$ is $I_{B}-I_{C}$ and in line $\mathrm{C}$ is $\mathrm{I}_{\mathrm{C}}-\mathrm{I}_{\mathrm{A}}$.

Now with load current assumed to be 0 suppose an internal ground fault occurs in phase $\mathrm{C}$ with a delta - wye transformer. This will cause increased current flow in primary phases $\mathrm{B} \& \mathrm{C}$ as shown. This in turn causes increases current flow in relays $\mathrm{B} \& \mathrm{C}$. With radial 
system there is no back feed so there is no current flow in all secondary CTs. Thus there is an imbalance in current flow in relays $\mathrm{B} \& \mathrm{C}$ and both will operate. For an external fault currents balances on both sides of the relay and no operation takes place

In addition to $\mathrm{CT}$ phasing, the $\mathrm{CT}$ ratio tap Settings in the differential relay must also be considered. In order to reduce the mismatch in the $\mathrm{CT}$ characteristic, the $\mathrm{CT}$ ratio tap Settings could be adjusted [21]. This mismatch can be evaluated by comparing the difference in the ratio of high side current $\left(\mathrm{I}_{\mathrm{H}}\right)$ to low side current $\left(\mathrm{I}_{\mathrm{L}}\right)$ against the ratio of high side tap setting $\left(\mathrm{T}_{\mathrm{H}}\right)$ to the low side tab setting $\left(\mathrm{T}_{\mathrm{L}}\right)$ as shown in the equation below.

$$
\% \text { Mismatch }=\frac{\frac{I_{H}}{I_{L}}-\frac{T_{H}}{T_{L}}}{\frac{T_{H}}{T_{L}}} * 100 \%
$$

Figure 63 shows an example of calculating the mismatch for differential protection scheme for transformer. For 50 MVA transformer, delta connected primary has voltage 138 $\mathrm{kV}$ line to line and wye connected secondary voltage is $69 \mathrm{kV}$ line to line. Current for both primary and secondary can be calculated by equation given below

$$
I=\frac{S_{x f r m}}{\sqrt{3} * V_{L L}}
$$

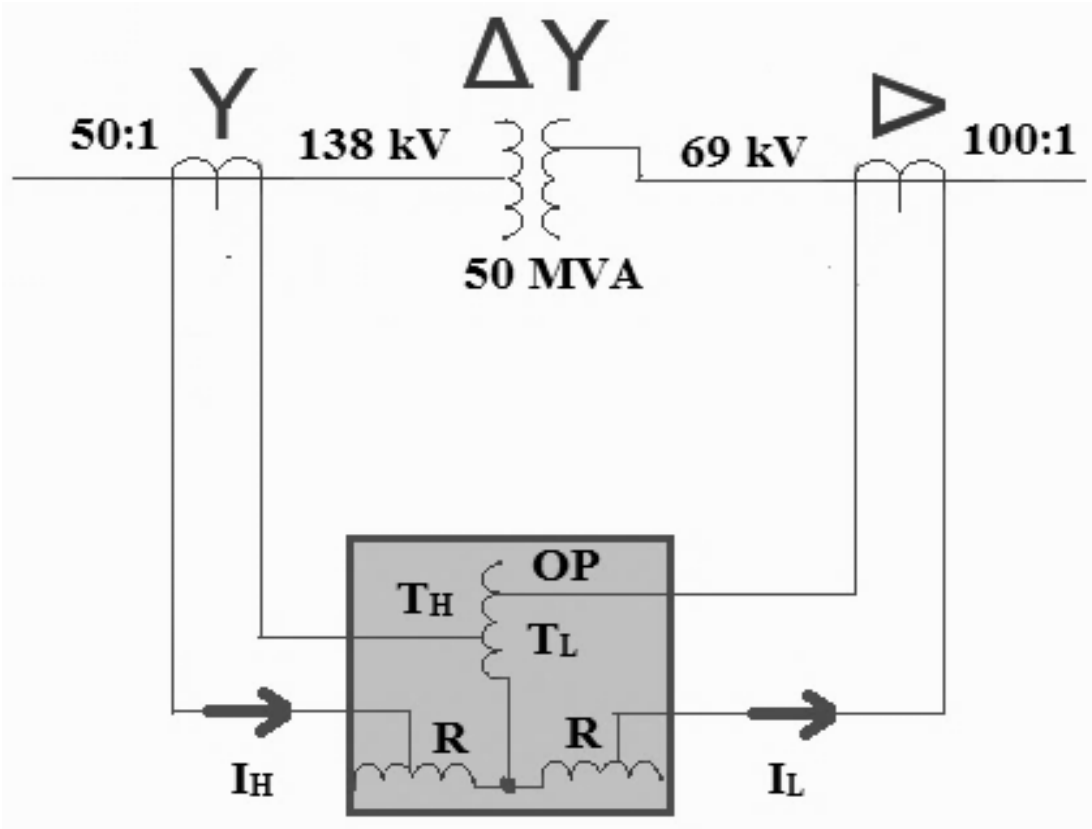

Figure 63: Differential protection of transformer example 
For primary CT the ratio can be 50:1 then current through primary side restraint winding of the differential relay is $4.18 \mathrm{~A}$. Since voltage is half of the primary side, the ratio of secondary CT is 100:1. Secondary side current through the restraining coil is also 4.18. Since the secondary side CT is connected in delta, the current in secondary restraint coil is equal to $(4.18 * \sqrt{3})$ which equals $7.25 \mathrm{~A}$. The ratio between these two $\mathrm{I}_{\mathrm{H}}$ divided by $\mathrm{I}_{\mathrm{L}}$ is 0.577 . For calculation purpose, assuming primary side tap setting is 5 and secondary side tap ratio is 9 . Then the mismatch can be calculated as,

$$
\% \text { Mismatch }=\frac{\frac{4.18}{7.25}-\frac{5}{9}}{\frac{5}{9}} * 100 \%=3.9 \%
$$

Now table 4 shows different scenarios of tap settings and voltage of current transformer and power transformer and the mismatch is calculated in MATLAB.

Table 4: Different scenario for mismatch

\begin{tabular}{|c|c|c|c|c|c|c|c|c|}
\hline \multicolumn{2}{|c|}{ Primary Side } & \multicolumn{2}{c|}{ Secondary side } & \multicolumn{2}{c|}{$\begin{array}{c}\text { CT current to } \\
\text { Differential relay }\end{array}$} & \multicolumn{2}{c|}{ CT tap setting } & $\begin{array}{c}\text { Mismatch } \\
\%\end{array}$ \\
\hline $\begin{array}{c}\text { Voltage } \\
(\mathrm{kV})\end{array}$ & Current & $\begin{array}{c}\text { Voltage } \\
(\mathrm{kV})\end{array}$ & Current & Primary & Secondary & Primary & Secondary & \\
\hline 138 & 209.18 & 69 & 418.37 & 4.18 & 7.25 & 5 & 9 & 3.923 \\
\hline 138 & 209.18 & 69 & 418.37 & 4.18 & 7.25 & 5 & 8 & -7.63 \\
\hline 138 & 209.18 & 69 & 418.37 & 4.18 & 7.25 & 4 & 9 & 29.9 \\
\hline 138 & 209.18 & 75.9 & 380.34 & 4.18 & 6.59 & 5 & 9 & 14.31 \\
\hline 151.8 & 190.17 & 69 & 418.37 & 3.80 & 7.25 & 5 & 9 & -5.53 \\
\hline
\end{tabular}

The CT ratios should be selected to keep this mismatch to the absolute minimum but at the same time the current on the CT secondary should not exceed the current ratings of either the CT or the relay restraint coils.

\subsubsection{Differential Protection on 3 winding transformer}

Transformer protection in 3 winding transformer works in same manner as two winding transformer. Three winding transformer configuration is shown in figure 64. 


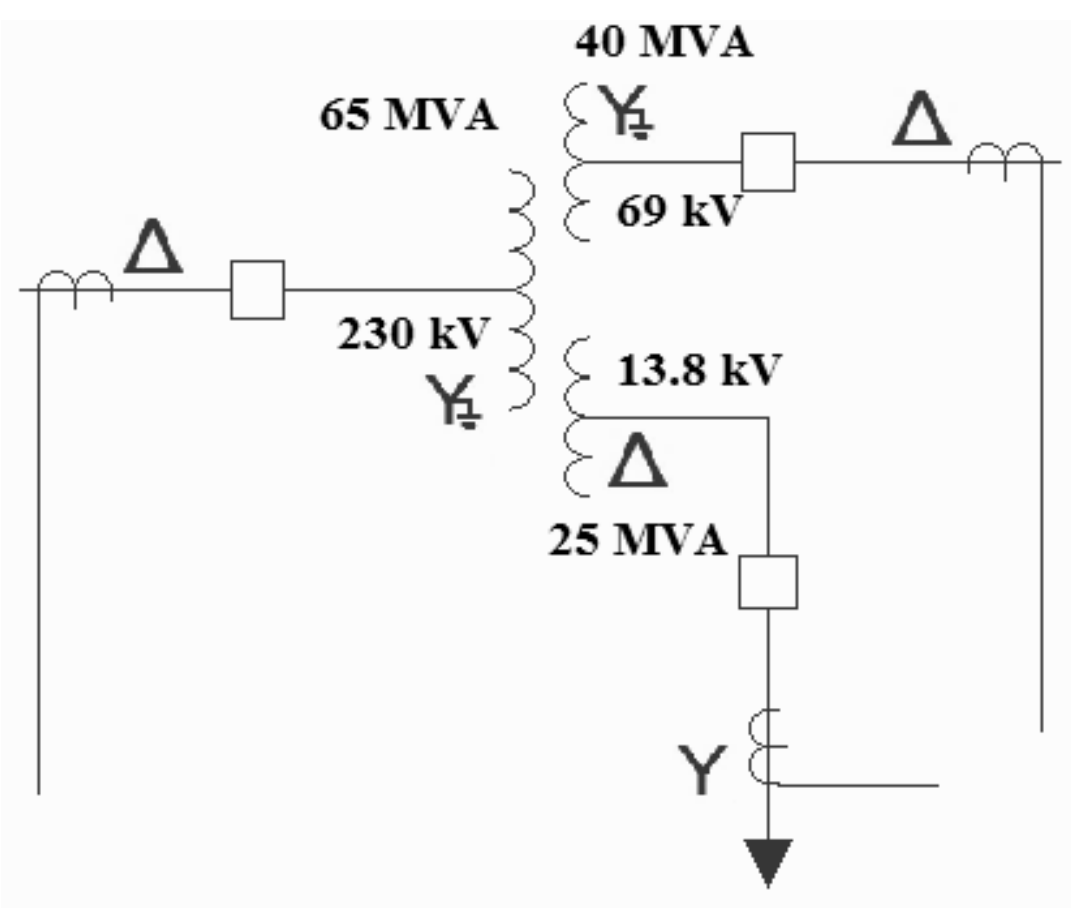

Figure 64: Three winding transformer configuration

Three winding transformer as it can be seen in figure above, primary and secondary winding connected in wye configuration with voltage level of $230 \mathrm{kV}$ and $69 \mathrm{kV}$ respectively. However the tertiary winding is connected in delta configuration with voltage level of $13.8 \mathrm{kV}$. As it is discussed before, primary and secondary CTs are connected in delta configuration to avoid zero sequence current which may flow in relay causing unwanted tripping on faults outside the differential protection zone and delta CT connections are safer as they eliminate zero sequence current from the relay. Moreover, current transformer connected in tertiary winding is delta configuration so that high side voltage leads low side voltage by $30^{\circ}$.

Figure 65 shows currents leaving and entering in primary, secondary, tertiary and differential relay. In balanced operating condition and in condition of fault outside of the zone, these three sets of currents cancel and no current will flow through the operating coil. Therefore current flowing through the operating coil is 0 and the differential relay will not trip. However, if an internal fault occurs inside the transformer then out of balance currents 
flow in the operating coil and relay will trip. With three winding transformer, selecting correct CT taps and calculating mismatch is similar to two winding transformer.

For illustration, consider 40 MVA passing through both primary and secondary winding. Using MATLAB, current through primary and secondary winding of transformer and current transformer secondary currents are calculated. Assuming the ratio in current transformer primary as 30:1, in secondary as 80:1 and the tap setting for high voltage side is 5 and low voltage side 7 the calculations are shown in table 5.

Table 5: Mismatch calculation for differential relay protection

\begin{tabular}{|c|c|c|c|c|c|c|c|c|}
\hline \multicolumn{2}{|c|}{ Primary Side } & \multicolumn{2}{|c|}{ Secondary side } & \multicolumn{2}{|c|}{$\begin{array}{c}\text { CT current to } \\
\text { Differential relay }\end{array}$} & \multicolumn{2}{|c|}{ CT tap setting } & $\begin{array}{c}\text { Mismatch } \\
\%\end{array}$ \\
\hline $\begin{array}{c}\text { Voltage } \\
(\mathrm{kV})\end{array}$ & $\begin{array}{c}\text { Current } \\
\text { A }\end{array}$ & $\begin{array}{c}\text { Voltage } \\
(\mathrm{kV})\end{array}$ & $\begin{array}{c}\text { Current } \\
\text { A }\end{array}$ & $\begin{array}{c}\text { Primary } \\
\text { A }\end{array}$ & $\begin{array}{c}\text { Secondary } \\
\text { A }\end{array}$ & $\begin{array}{c}\text { Primary } \\
\text { A }\end{array}$ & $\begin{array}{c}\text { Secondary } \\
\text { A }\end{array}$ & \\
\hline 230 & 100.4 & 69 & 334.7 & 5.8 & 7.25 & 5 & 7 & 12 \\
\hline 230 & 62.76 & 13.8 & 1045.9 & 3.62 & 13.07 & 5 & 7 & -61.20 \\
\hline
\end{tabular}

Now from the result shown in the table, $12 \%$ mismatch is within the relay restrain settings. However, the mismatch in other configuration is too high for good reliability even when using the whole range of taps. In cases like this use of auxiliary CTs in the main CT secondary circuit is recommended. 


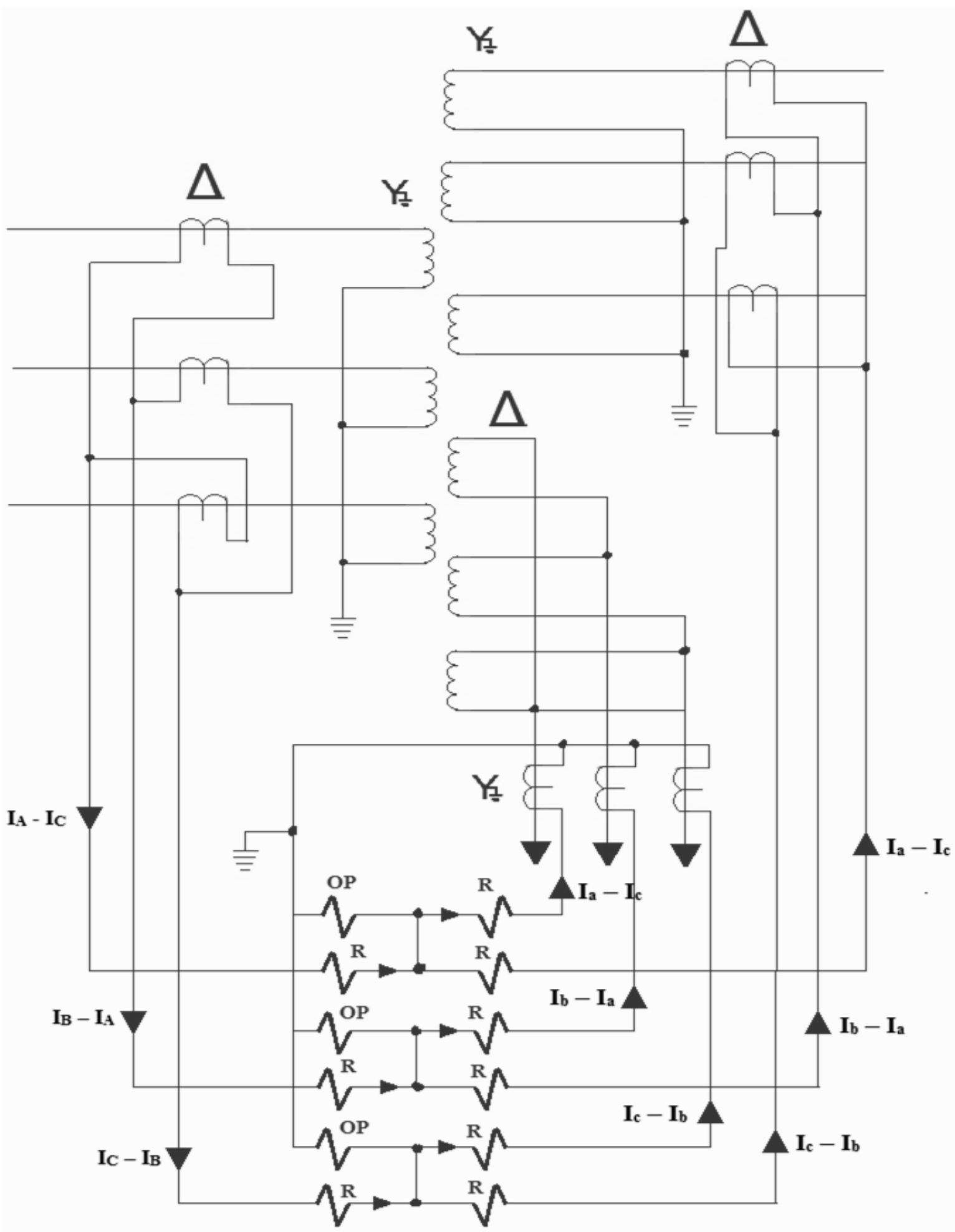

Figure 65: 3 winding configuration of transformer 


\subsubsection{Ground Fault Protection}

Normal differential protection scheme will protect for ground faults as well as phase to phase faults. This is because the relay is sensitive to unbalance caused by ground fault as distinct from direct measurement of ground fault current. However, in some cases, a ground differential relay ( $87 \mathrm{GD})$ is connected the measure and operate on zero sequence ground fault current. The typical application of this is shown in figure 66.

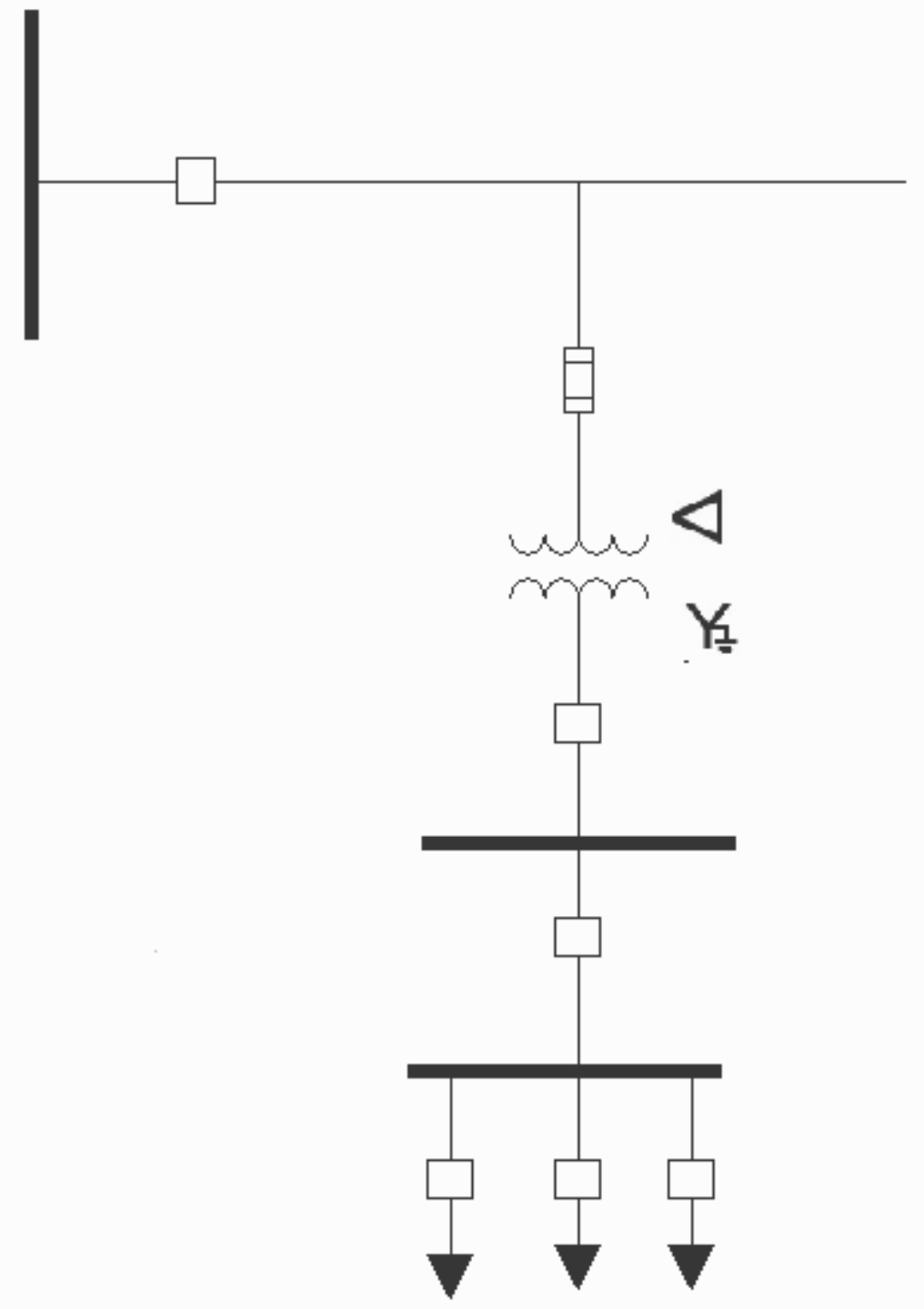

Figure 66: System configuration for illustration of ground fault protection 
The distribution substation transformer where high voltage side is connected in Delta which is protected by fuses and there are no CTs available. The secondary side of transformer feeds through a breaker into the substation bus from which various feeders are tapped off. Secondary side of the transformer is wye connected and grounded through a resistor. Three phase diagram of this system is shown in figure 67 which shows how the ground differential relay is connected. If there is no ground fault present then no current flows in the secondary of the CTs. If an external fault occurs on line $\mathrm{C}$ then zero sequence current will flow through current transformer secondary to the relay. However, this will be counterbalanced by the same value of current flowing from neutral of CT therefore no current will flow through relay operating coil as shown in figure 67.

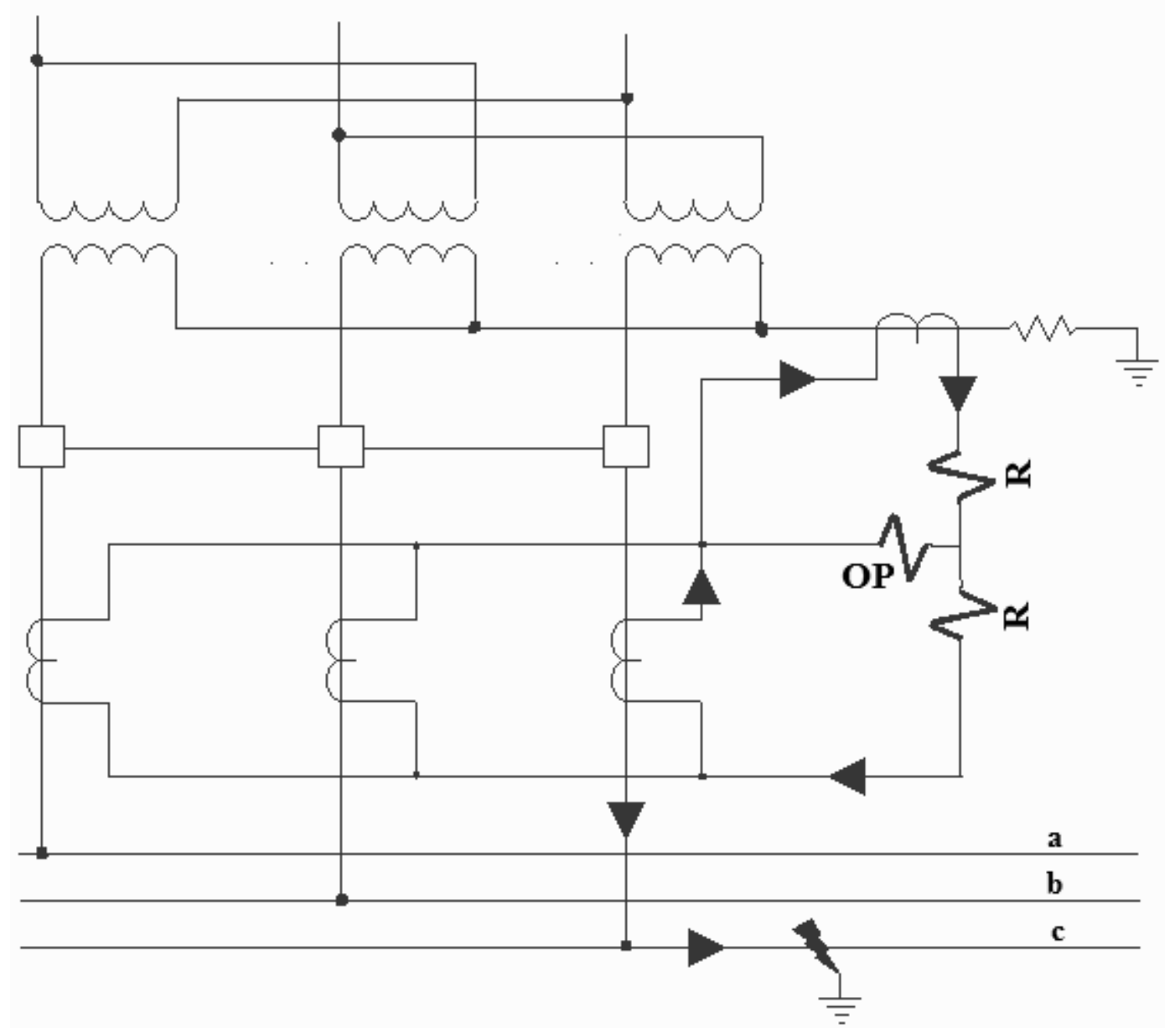

Figure 67: Ground differential relay protection scheme with external fault 
However, if there is an internal ground fault in one of the transformer winding as shown in figure 68, current in that $\mathrm{CT}$ will reverse and added to that from the neutral $\mathrm{CT}$. this current will flow through the differential relay and it will operate.

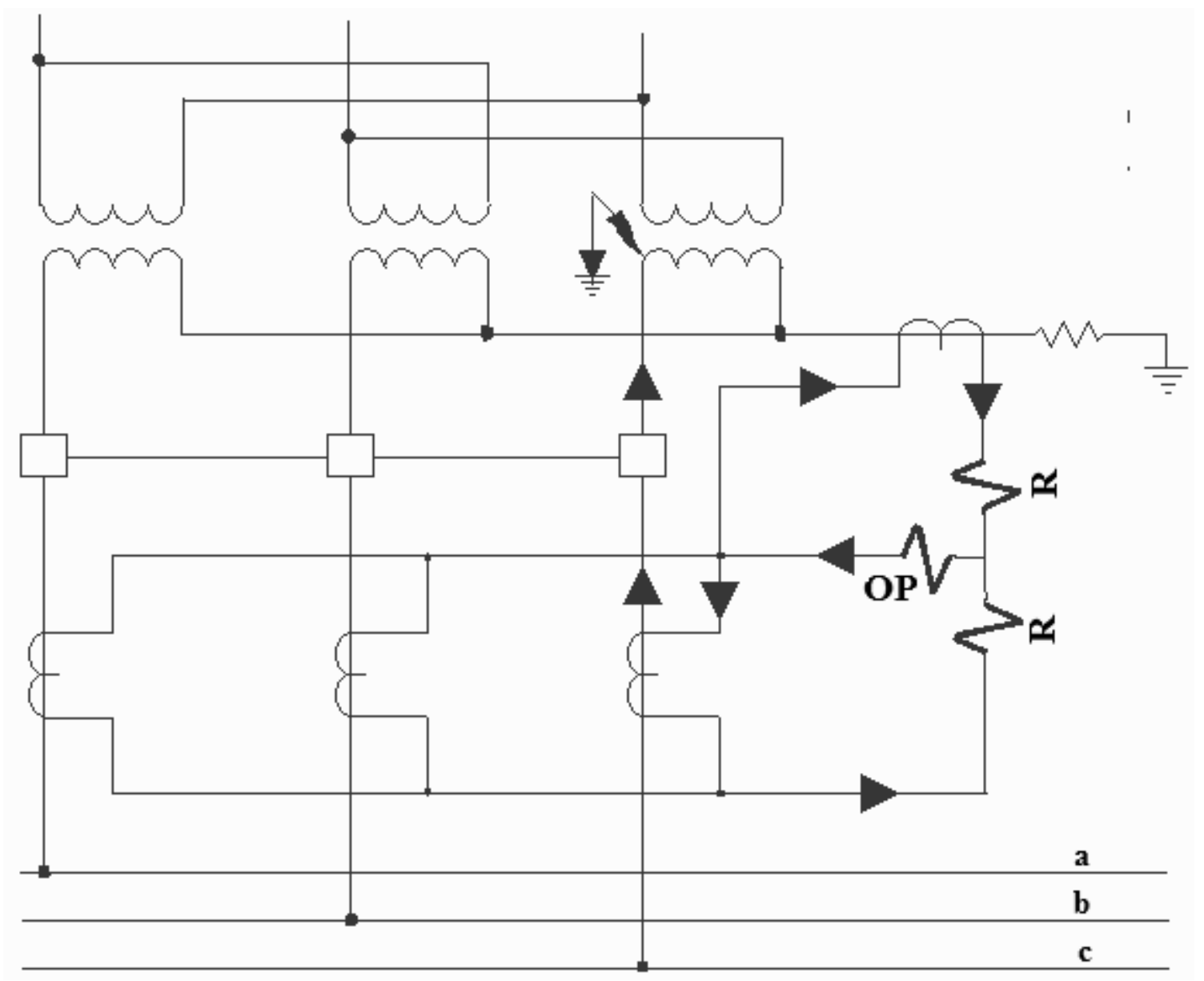

Figure 68: Ground differential relay protection scheme with internal fault

With this arrangement, quite often time overcurrent ground relay $(51 \mathrm{G})$ is installed in neutral. This act as backup protection for transformer ground differential and ground faults out on feeders. As it is shown in figure 66, primary high voltage fuses may not clear a low level fault on secondary winding because they are usually sized to protect against heavy short circuit currents in primary. Operation of the backup ground protection relays will initiate tripping of first breaker upstream of the fuses in order to isolate the primary winding by providing a communication channel between ground relay and breaker. 


\subsubsection{General Protection Scheme of Transformer}

Figure 69 shows general protection scheme which includes relay protection described above as well as few other relay protection. Thermal protection is provided by relay 49 . Thermal relays are oil temperature and winding temperature. This relay detects overheating of oil or winding hot spots which may have occurred as a result of continuous overload or perhaps an internal fault. On the other hand, relay 63 operates on gas pressure or gas accumulation. Gas pressure relay operates if a sudden rise in gas pressure occurs inside the tank. Relay 49 and 63 are usually used for alarm indication since setting it for a trip command will result in loss of power in a temporary fault. These relays are very sensitive and detect the fault in transformer before it develops severe enough to operate differential protection [22]. Suppose if heat is generated in the oil by an electric arc. In this case the thermal protection relay will sense sudden rise in oil temperature and send an alarm signal. Moreover, if the gas is produced due to the arc then gas pressure relay will sense it and send an alarm signal in control room.

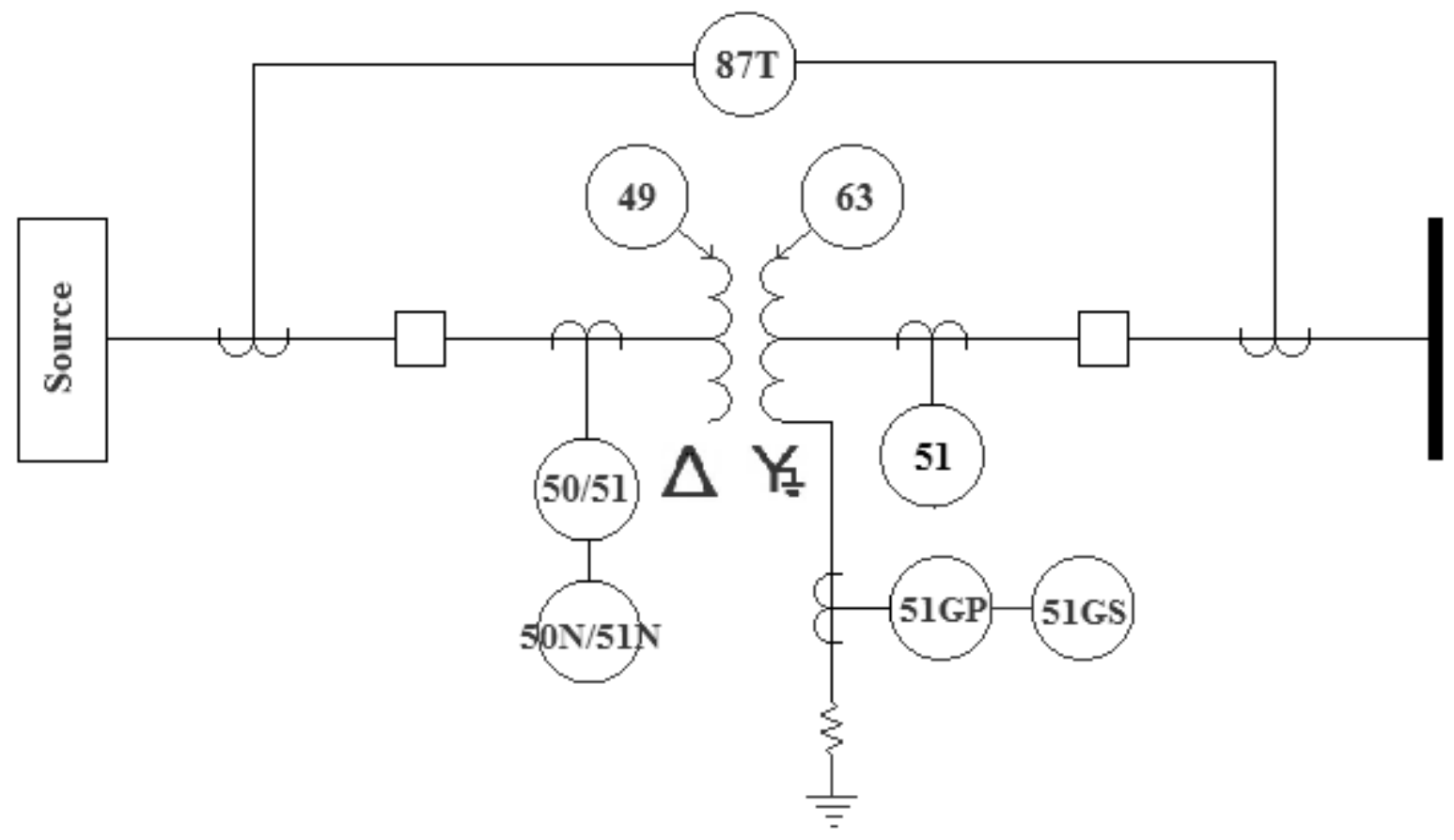

Figure 69: Other protection schemes 
Differential protection is a preferred method of protecting transformers against internal phase to phase faults or phase to ground faults. It is connected right across transformer including primary and secondary breakers. There are several other protective relays used as shown in figure above. The overcurrent ground relay $51 \mathrm{G}$, which is connected in the grounded neutral of transformer secondary, is wired to trip primary breaker and serves as backup for a ground fault on the secondary bus and feeders. Often second ground relay is provided to operate secondary breaker and this is set with a longer time setting so as to allow the primary ground relay time to clear first. Overcurrent relays are often installed as backup in primary and secondary circuits. The overcurrent relay 51 will act as a backup for fault on the secondary bus or feeder.

Summarizing the discussion in this chapter, winding connection can be wye (Y) or Delta $(\Delta)$ to get desired voltage levels and phase relationship. A Y - $\Delta$ or $\Delta$-Y arrangements are made for the transformer so that the high side voltage leads low side voltage by $30^{\circ}$. When transformer winding connection is wye on both side then CT connection should be delta to avoid unwanted tripping due to zero sequence currents. Moreover, if transformer winding connection is delta on both sides then Wye connected CTs are used on both sides as there is no 30 degree shift to correct. While applying differential protection to transformer, magnetizing inrush current, phase shift in $\mathrm{Y}-\Delta$ connected transformers, phasing of CT connections, selection of CT taps and the effects of transformer taps should be considered.

In ground fault protection, if an external fault occurs on line then zero sequence current will flow through current transformer secondary to the relay. But this current is counterbalanced by current flowing from neutral of transformer. Therefore relay will not operate. However, for an internal fault, fault current in ground relay and current from neutral will be added and flow through the operating coil. Therefore differential relay will operate. Transformer thermal protection is provided by relay 49 which initiate an alarm if there is rise in oil temperature and winding temperature due to internal fault. Moreover, relay 63 will operate if gas pressure is increased. 


\section{Chapter 6 \\ Transmission and Distribution Line Protection}

Line protection can be differentiated in two categories; Transmission line and distribution line. A transmission line connects the generating station to substations. However, a distribution line feeds customers. The lines can be either delta connected or wye connected where the neutral connected along the same support structure. Loads across three phases are often out of balance so that some current normally flows along the neutral. Neutral is usually connected to ground of the source transformer and additionally by connection to grounding straps which rundown intermittent polls in the ground. There are different types of fault occurs on transmission lines. These faults are discussed earlier in subsection of chapter 1. An example of a transmission line is shown figure 70 .

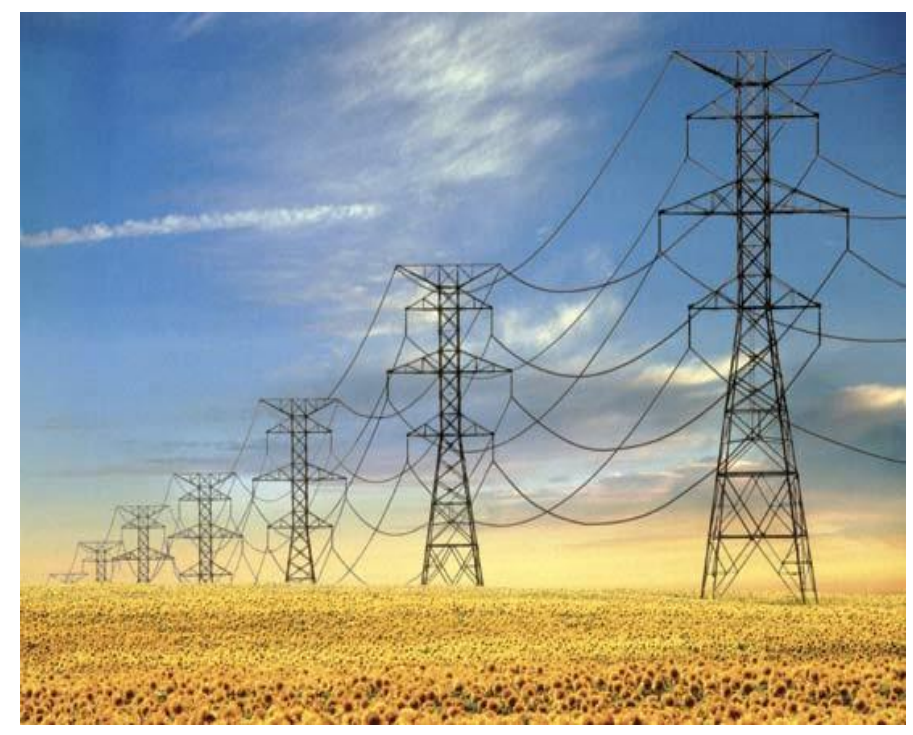

Figure 70: Transmission line

The protection scheme chosen for line depends upon the installation of line. For example, providing protection is fairly simple on radial distribution line than a transmission line which forms part of a complex network. Moreover, outage on transmission line may cause interruption of power to many customers than outage of a single distribution line. Therefore backup protection is important if primary protection fails to clear the fault. In all 
situations the objective is to provide protection which is sensitive, selective and reliable. In figure 71, transmission line fall is seen. This can be result of structure failure or natural disaster. However, in terms of fault condition, this will lead to three phase shorted to ground which will cause excessive current to flow through the circuit. Therefore, protection scheme must be chosen to protect the system against these faults.

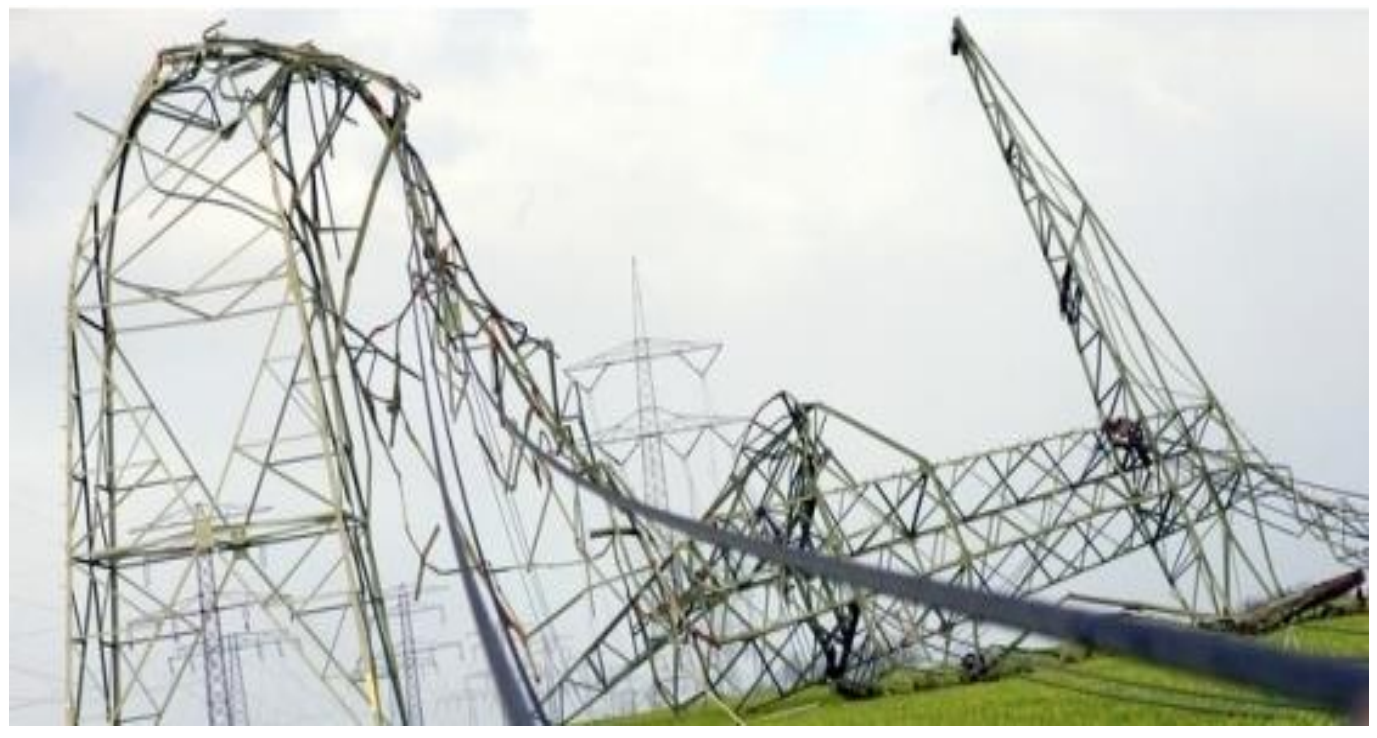

Figure 71: Transmission line structure failure

\subsection{Overcurrent protection on radial system}

Figure 72 shows radial connection of distribution line. In some cases a line directly feeds to the industrial customers. However, voltage has to be stepped down further to feed the residential customers. Line is supplied from source on one end only and loads are tapped off to feed customers all along the route. Even under fault conditions, current flow in radial lines is in one direction only [18]. For heavy industries where large amount of power supply needs to be provided, sub-transmission line is connected radially to supply one distribution substation only. 


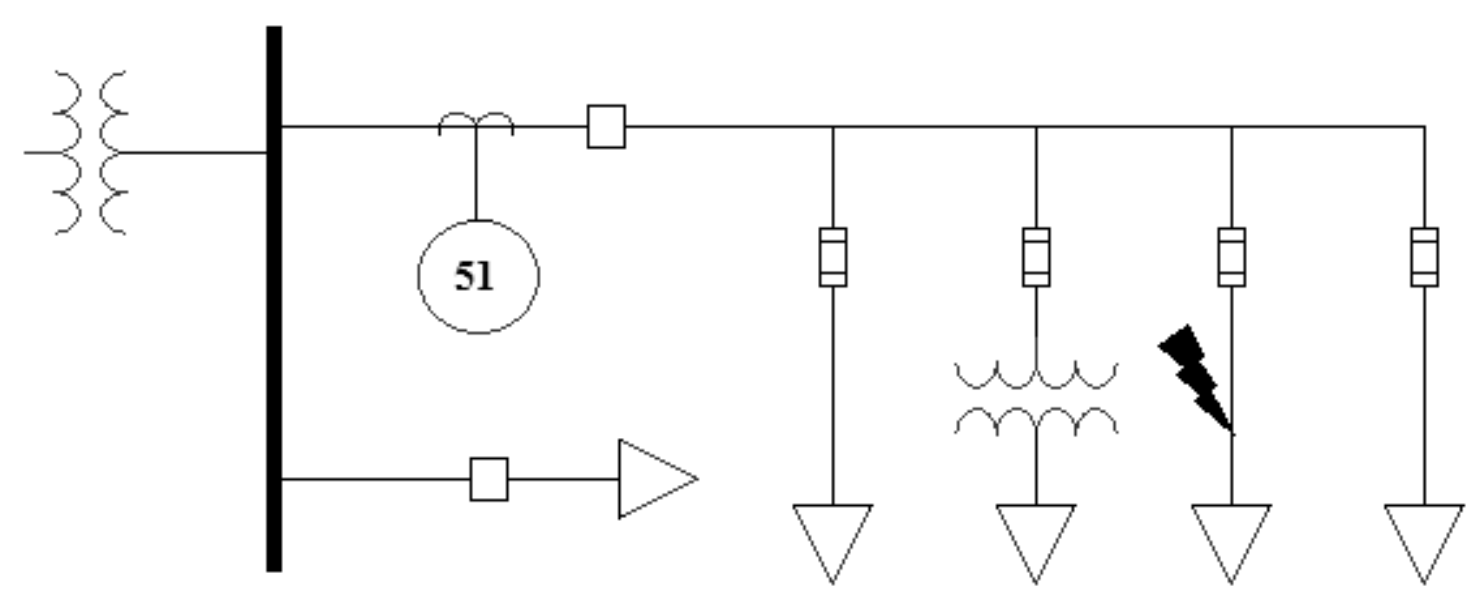

Figure 72: Distribution line radially connected

Overcurrent relays are widely used for protection throughout the distribution system and in many sub transmission systems. The time overcurrent relay is very suitable for the protection of radial lines where the fault current flows in one direction only. In radial system configuration, connection of inverse time overcurrent relay's inverse time characteristic allows faults downstream to be cleared by local protective fuse before relay has time to operate. This prevents the relay from opening breaker so avoiding interruption of all customers on that line. On the other hand, if the local protection fails to operate then time overcurrent relay would eventually timeout and opens breakers to clear the fault. Thus it acts as remote backup to the downstream local protection. As it can be seen in figure 72 , operation of remote backup protection causes an outage too many customers than local protection. If the inverse time overcurrent relay fails to operate then there is no other protection provided. In setting the time overcurrent relay, pickup value which is the point at which relay starts to operate and time dial setting which defines the time of operation for different values of fault current must be adjusted.

In order to set the time dial of relay, it is necessary to know the anticipated value of fault current for a fault close to breaker and for a fault at far end of the line also. As it is mentioned before, the level of fault current flowing to feed a short circuit at far end of the line will be less than for a fault close to the breaker. This is because of the impedance of the 
line between two points. Another factor which may affect the level of fault current is the amount of fault capacity available at the source.

Figure 73 shows a radial system, which has several load centers, is fed by single source of power supply. All the protective devices, the fuses, the recloser and the breaker overcurrent protection, need to be coordinated to protect the transformer from damage due to overload and to provide selectivity in isolating the faulty circuit only. For a fault, $\mathrm{F}_{1}$, on load end as shown in figure 73, will cause recloser to open on its instantaneous setting. It will then reclose after short time interval. The recloser will open again after specified time interval and will lockout if the fault is permanent. However, before that lock out time the local fuse will operate to isolate the faulty circuit so the recloser remains closed.

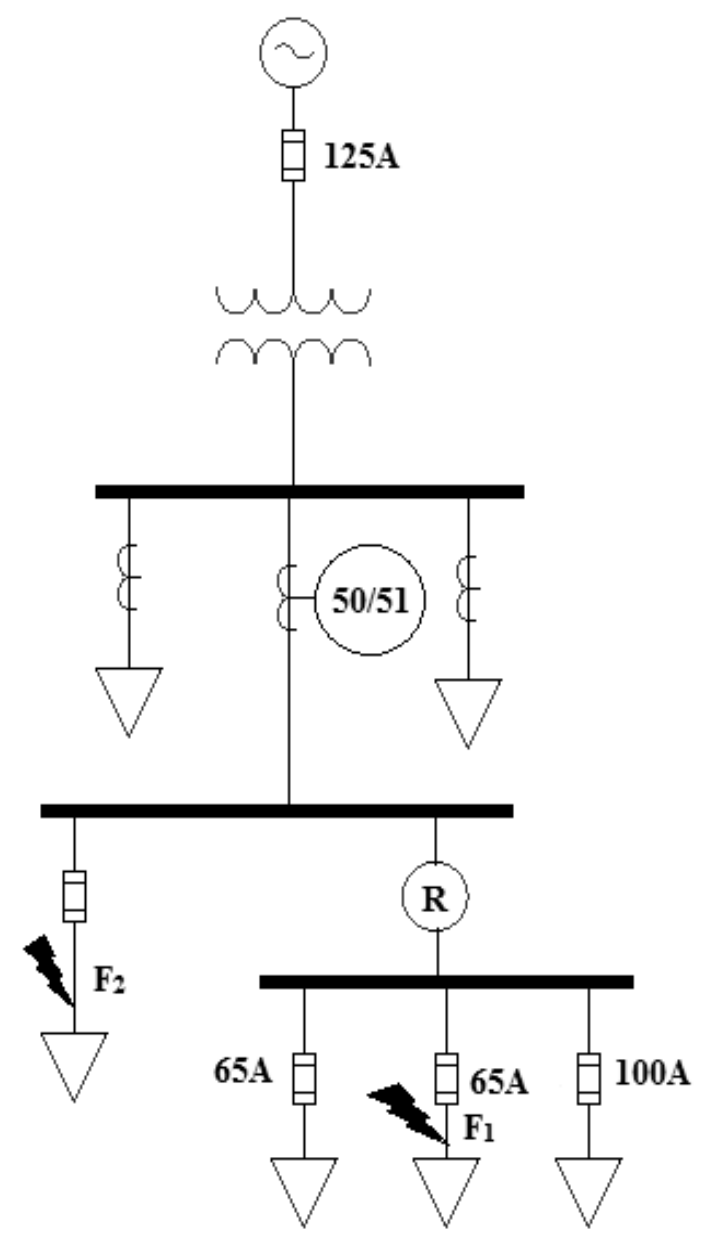

Figure 73: radially connected distribution system 
If there is a fault, $\mathrm{F}_{2}$, on other branch as shown in figure 73 , then it will cause the instantaneous overcurrent relay to open the feeder breaker. After a time delay reclosing relay will close the breaker again. Once breaker has opened for this fault, the instantaneous relay will be prevented from operation until a specified time interval. Similar to other branch, if the fault is permanent then the fuse will operate to clear the circuit.

There is yet another protection of $125 \mathrm{~A}$ fuse in the circuit if these protection devices fail to operate. However, this fuse melting time should be over other protective devices because if this fuse operates before other protective devices then all the loads will be without power.

As it is discussed earlier, ground fault can be cause by lightning strike or an object coming into contact with live line. Since lines are fully exposed in atmosphere, chance of fault occurrence is very high. Therefore adequate protection must be provided to overcome this situation. The most common form of protection against ground fault on a line is by using time overcurrent relays. Ground overcurrent relay is usually connected as shown in figure 74.

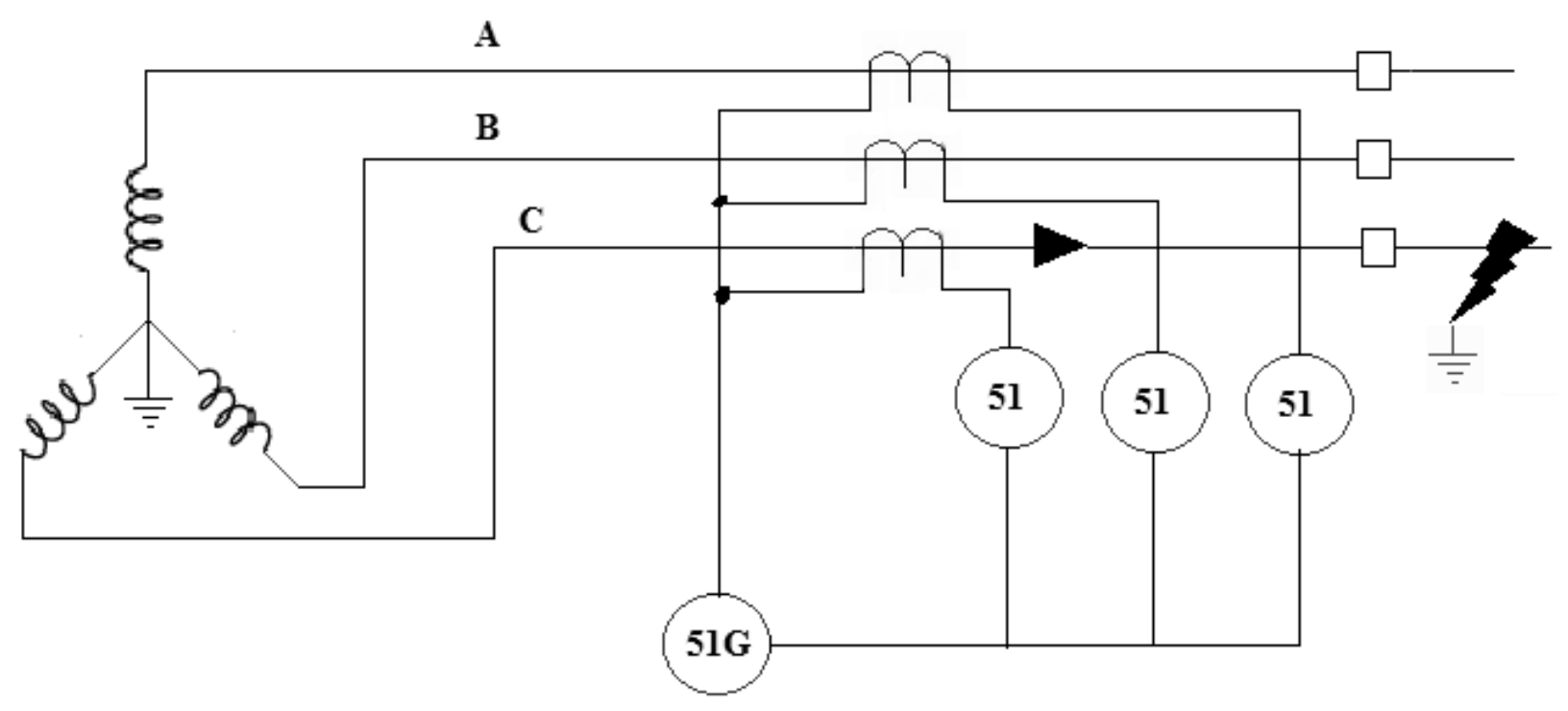

Figure 74: Protection against ground fault protection in the radial line

If a ground fault occurs on one of the three phase lines, high current will flow along the line to feed the fault. CTs are wye connected therefore the difference in current flow along three phases will be registered by overcurrent relay which is connected in the common 
neutral [19]. In setting the pickup for this relay the type of circuit in which it is installed must be kept in mind. For example if this is a radial distribution line then it is probable that there is a certain amount of unbalanced load during normal operation resulting in current flow through the neutral. Therefore relay pickup must be set above this value.

\subsection{Overcurrent Protection of Loop System}

In power industry, a more common connection is loop configuration. Figure 75 shows the sub-transmission line connected in loop configuration. In some cases, there is only one source of supply connected to line. However, in order to increase reliability, there are other supplying sources connected in loop as well. In case of a fault as shown in figure 75, the faulty section can be isolated by opening respective breakers. Rest of the system continues delivering power to other loads.

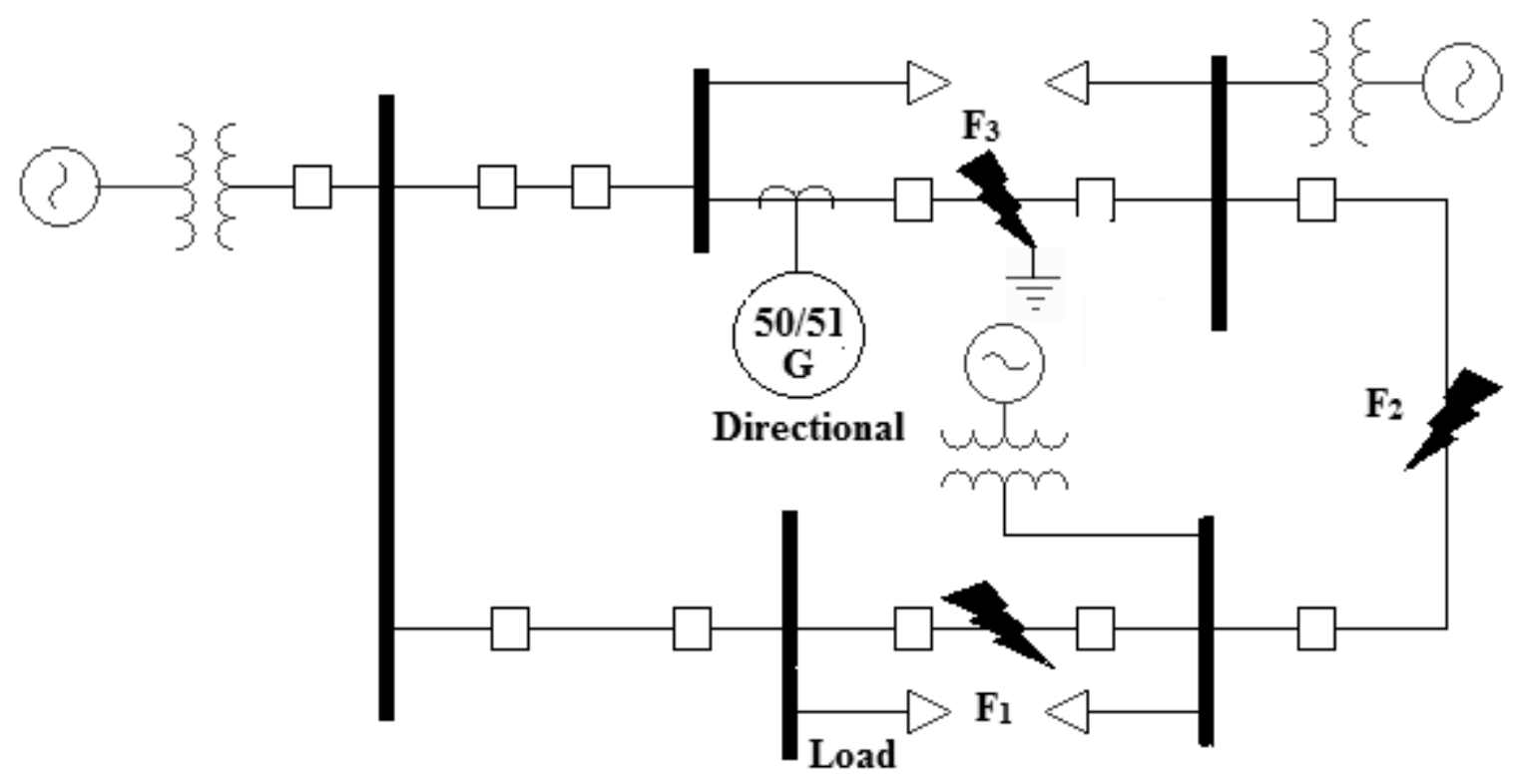

Figure 75: Sub-transmission line with loop system

Sub-transmission lines provide links between high voltage bulk transmission system and various distribution stations. High-voltage transmission lines usually cover long distances bringing power from remote generating sources to the areas of load demand. Highvoltage transmission lines are also used to interconnect with other power systems for both, supply energy and import energy, when needed. Transmission lines normally form part of a 
complex network which interconnects many lines and buses and also includes several sources of power generation at different locations. As with loop system, current in any particular line can flow in either direction according to the configuration and loading of the system. This adds to complication of providing adequate protection.

In a loop system, breakers are located at both ends of each section of a line feeding into various buses [18]. As shown in figure 75, if a fault occurs, $F_{2}$, then current will flow in clockwise direction from source to fault in upper section of the loop and in a counter clockwise direction in bottom section of the loop. In this case both breakers associated with fault will trip and provide isolation from fault. However, if fault occurs at $F_{1}$ then current will flow in clockwise direction to the fault. However, current will flow in opposite direction to the fault in bottom section of loop. Therefore directional relay protection must be provided to overcome this problem.

There are multiple sources connected to each other through transmission line providing more reliability to the system for continuous power supply. Therefore the problem of coordination becomes very complicated because of maximum and minimum loading conditions. One problem with this type of configuration is that during high load demand, many generators and parallel circuits are feeding into the system. This will provide high fault capacity and low impedance. Conversely, during a light load period some of the generators and circuits may be disconnected so it will have lower fault capacity [19]. As a result during light load, level of fault current at any particular location may be lower than at peak time. When setting the time dial, minimum level of fault current at the end of the line is considered which should not be allowed to flow for extended period of time to avoid damage. When the loading condition is very low, some generators need to be disconnected which changes the direction and magnitude of flow of fault current. Another type of protection which is utilized in industry is the voltage restrained overcurrent relay which is set to operate when voltage in the system falls below a set range. If there is a fault close to source, the voltage falls drastically. When voltage falls below set range then the voltage restraint is lifted and overcurrent relay is permitted to operate. 
In a loop system or complex transmission system, ground overcurrent relays are normally controlled by directional units. The relay will be allowed to operate when ground fault current is flowing into the line but the directional element will block tripping if the fault current is flowing out of the line into the next section which is a correct operation but the reminder of the system should operate and only breaker associated to that sections should open.

\subsection{Distance Relay Protection}

On most high voltage lines particularly interconnected transmission system, the preferred method of protection is by the installation of distance relay. The basic application a distance relay is discussed earlier. Distance relay measures voltage and current entering the line and from this it calculates the impedance downstream. This is the total impedance including that of the other transmission lines and the circuits and the system load. Figure 76 shows the configuration of distance relay on transmission line.

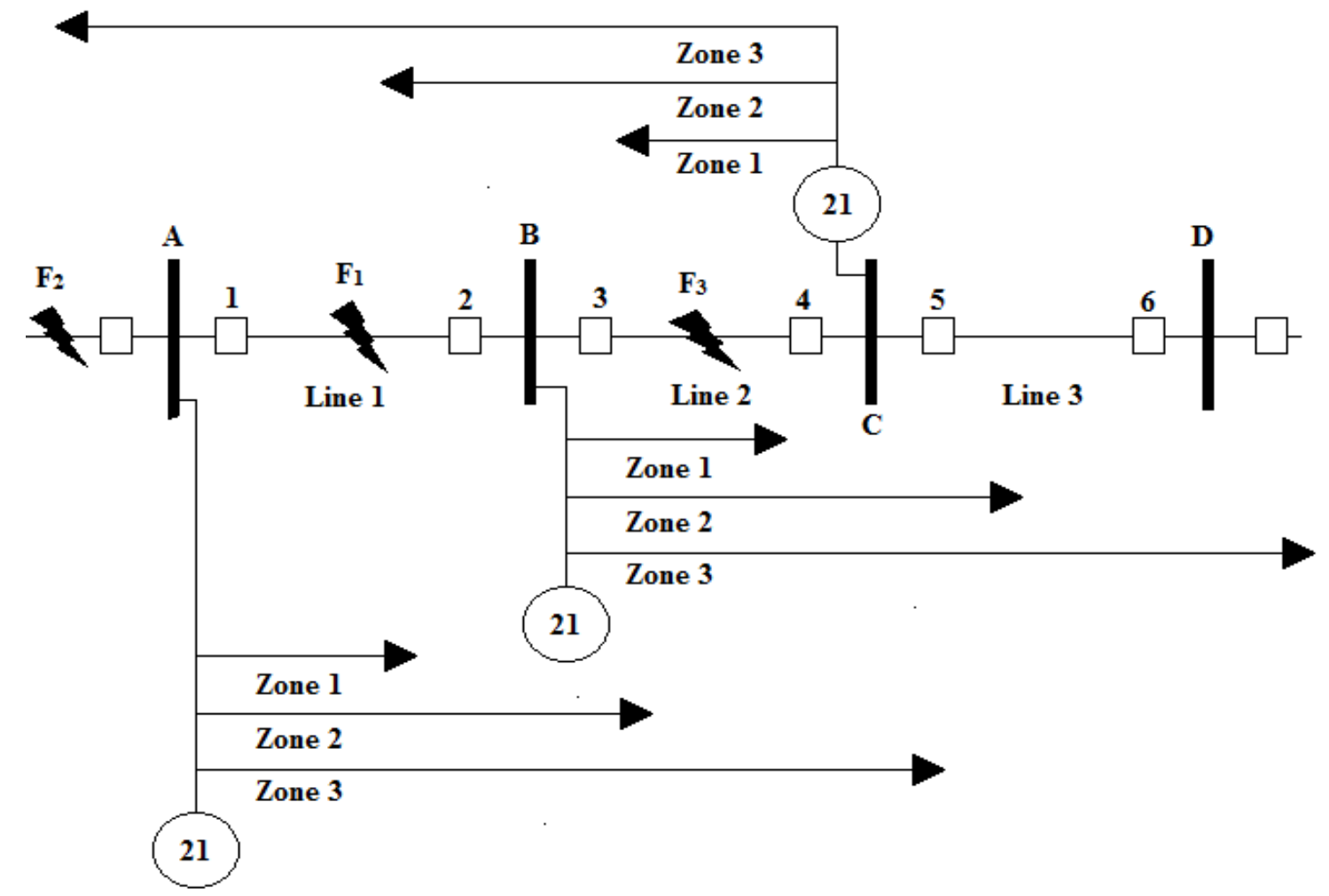

Figure 76: Distance relay protection on transmission line 
This comprehensive figure which includes multiple distance relays is explained thoroughly. At the bus A location, a distance relay is installed to trip breaker 1 and also to protect transmission line 1 between buses $A$ and $B$. If a fault occurs halfway along line 1 as shown in figure above, then the total impedance measured by relay will fall dramatically and this will cause the relay to operate. An important characteristic of the distance relay is that it operates independent of voltage fluctuations [20]. For example if voltage falls then current will fall correspondingly the impedance measured remains the same. Suppose there is a fault outside line 1 which is shown as $\mathrm{F}_{2}$ then distance relay will not operate on fault outside its protection zone because the impedance is outside of protected impedance zone. However, the characteristics can be offset to allow tripping upstream if desired. Distance relay on bus A should not trip for faults on transmission line 2 which is between buses B and C without any setting of zone 2. Therefore actual operation of distance relay for zone 1 is set to operate up about $70-80 \%$ of line to allow preciseness in relay functioning.

Relay is also equipped with second element of zone 2 which is set to cover a longer distance. It will operate for a fault occurring along line 1 and into the first 20 or 30 percent line 2. This is set with a time delay so as to allow the zone 1 element to operate first. However for a fault within line 1 , if the zone 1 element fails to operate for any reason then the zone 2 element will pick up and operate. It will also operate for a fault for the remaining 20 percent of line 1 and it will operate for a fault in the first part of line 2 . Therefore it provides backup protection to zone 1 . However the time delay should allow the local protection at bus B to operate first in order to protect line two. The coordination diagram shows zone 2 stretching from bus A and into line two. Similarly the relay is equipped with the third zone of protection which stretches into line 3 . This is set with longer time delay than zone 2. Bus B will have a similar distance relay installed to operate breaker 3 and protect line 2 and again on succeeding buses. Therefore distance relay protection is provided for each bus and it will trip breakers 1,3 and 5 in case of a fault.

Moreover, breakers 2, 4, and 6 will have distance relay protection in opposite direction. For example, a distance relay will be installed at bus $\mathrm{C}$ to measure voltage and current entering transmission line 2 through breaker 4 . The zone settings will be similar to 
those which has already been discussed but in opposite direction. Now for example, if a fault occurs 50 percent along transmission line 2 then first zone of distance relay at $\mathrm{C}$ would trip out breaker 4 without time delay. At the same time distance relay at bus B would trip breaker 3 without time delay so clearing the fault. If the fault occurred close to breaker 3 that is within the first 10 percent of line 2, breaker 3 would trip with no time delay and breaker 4 of zone 2 would trip after a short time delay.

This is not the only configuration of transmission line. There are other structures of transmission lines and with these structures other problems such as under reaching and overreaching arises as well. Figure 77 shows, another configuration where there are two lines connected to bus B. Moreover, a generator is also connected to bus D.

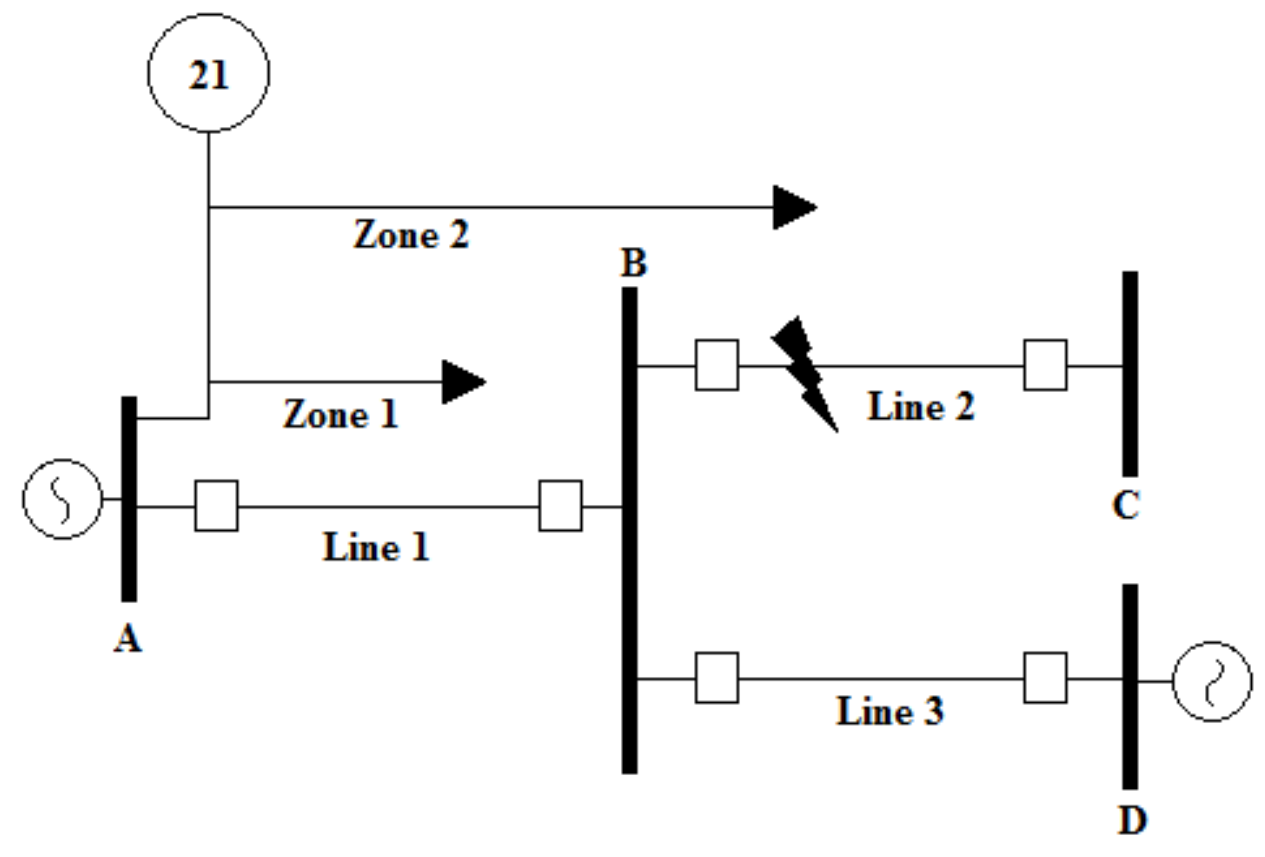

Figure 77: Example of Under-reaching fault detection in transmission line

When there is a fault on line 2, fault current is flowing through line 1 and line 3 to line 2 which falls in protection area of zone 2 of distance relay at bus A. The result is that slightly less current will flow along line 1 to feed the fault so the impedance relay will sense that the fault is a higher apparent impedance and therefore farther out along the line probably outside of the zone 2 . Therefore this relay would no longer provide backup to this particular 
fault. This condition is known as under reaching. Distance relay senses that the fault is further out and beyond its reach and it does not operate.

Another problem occurs where the lines out of bus B are of different lengths. This configuration is shown in figure 78. Distance relay at bus A has its zone 2 set to trip for a point 15 percent along transmission line number 3 . However line 2 is a short distance line and it can be seen that the relay at A reaches beyond line 2 and into line 4 . This will probably result in miss coordination with local relays. This is known as overreach because zone 2 of distance relay responds to fault way beyond the normal required operating distance. For this reason zone 2 relay is usually set to operate closer in 20 to 30 percent distance relays. Generally, these types of circuits are best protected by pilot relays. The discussion of pilot relay is out of context of this report.

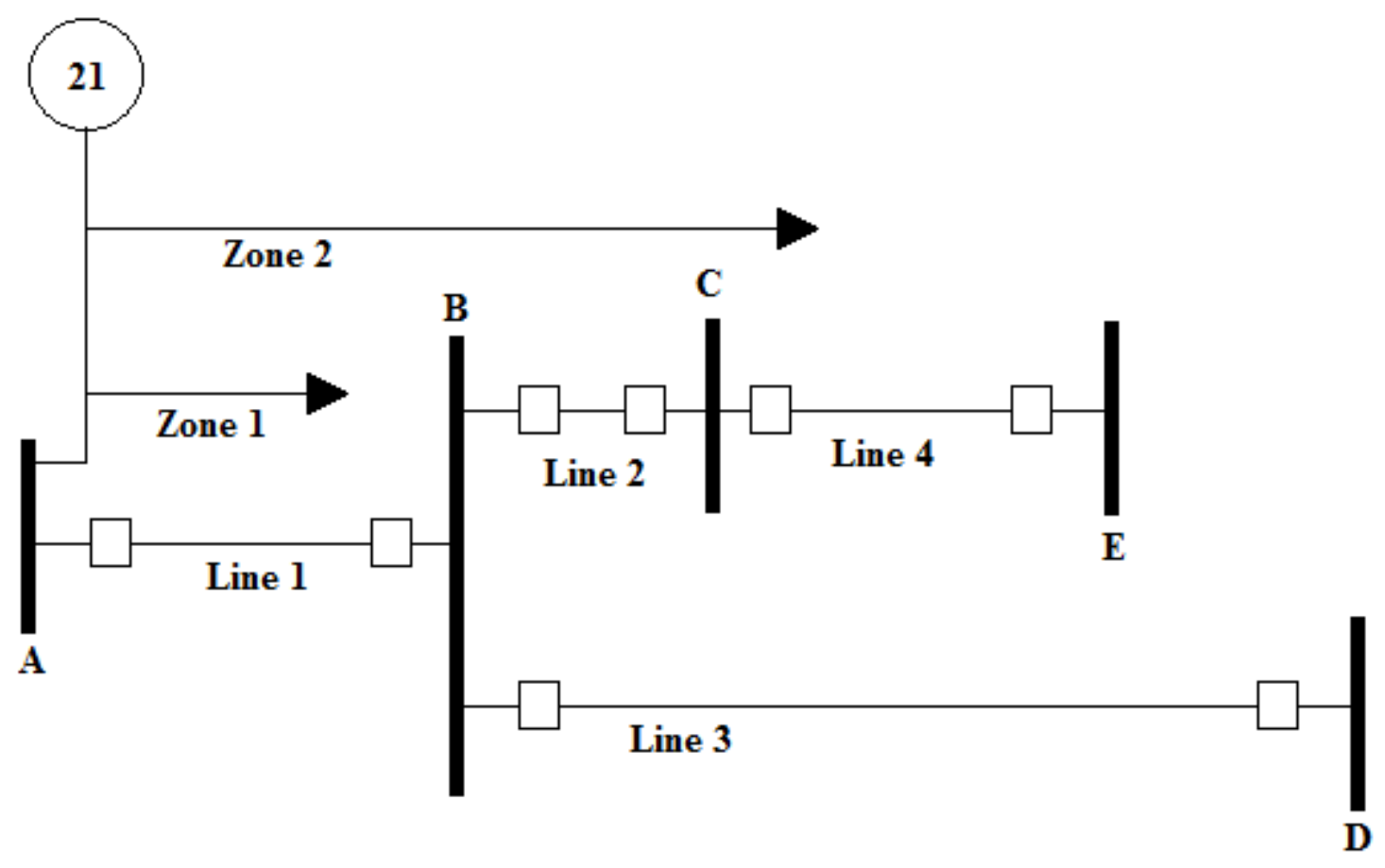

Figure 78: Example of Over-reaching fault detection in transmission line

In summary, designing protection scheme for radial system is easier than for loop system. Moreover, outage on transmission line causes interruption of power to many customers than outage of a single distribution line. Transmission lines covers long distance bringing power from remote generating sources and deliver it to load situated at distant 
location. Under fault condition, current flow is in one direction only. On radial distribution line, protection can be provided by either time overcurrent relay or reclose so that local protection device operate on faults downstream and back up protection is provided by main breaker. Therefore if local protective device fails to operate then back up protection times out and operated on fault. A fault in the system causes impedance to drop and increase the current in the system. The level of fault current is less at far end than fault close to source. Ground fault connection to radial system is provided by time overcurrent relay. Ground fault causes high current flow along the fault line which causes the relay to operate.

Power system connected in loop configuration provides better reliability. The faulty section can be isolated by opening associated breaker leaving rest of system with continuous power supply. The direction of fault current depends upon the location of the fault. Protection against this is provided by directional relay (67). Moreover, since there are multiple sources connected in loop configuration, protection system design part becomes very complex due to maximum and minimum loading conditions. During light load condition, available fault current is much smaller than maximum loading condition. Therefore protective devices are selected and coordinated considering this situation. Furthermore, during light load conditions, some of the generators need to be turned off which result in change in direction of current flow and magnitude of fault current. In some cases, overcurrent relays with voltage restraint is used for better coordination.

Transmission line protection can also be provided by distance relay protection. Voltage and current taken as input and impedance is calculated. If impedance of the line falls below set value then relay will operate. As the distance from source increases, the impedance increases and the level of fault current decreases. Voltage fluctuations do not affect the distance relay operation. Distance relay can be divided to operate in different zones with different fault impedance. If the fault is outside distance relay protection zone then relay will not operate. 


\section{Chapter 7}

\section{Motor Protection}

A motor is an equipment which converts electrical energy to mechanical energy. Figure 79 shows the startup curve of a motor. As it can be seen the $\mathrm{X}$ axis shows two parameters slip and synchronous speed. On the other hand, on Y axis full load torque and stator current is shown.

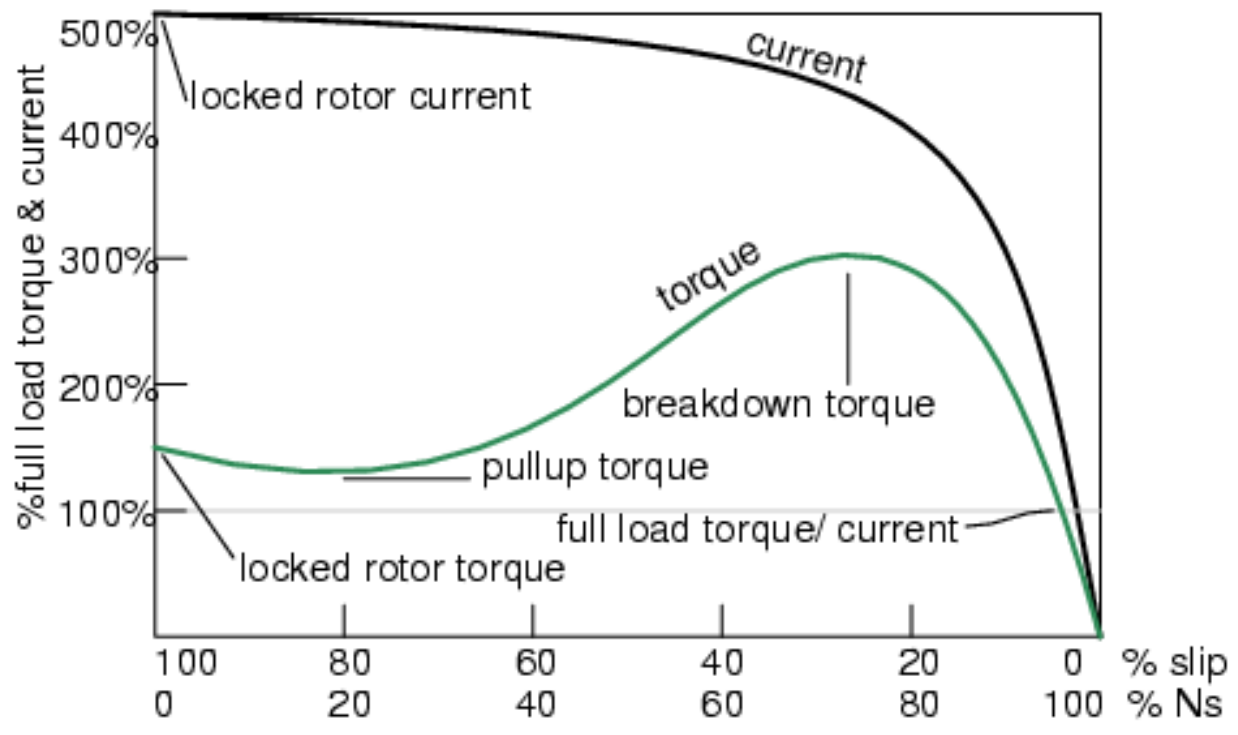

Figure 79: Motor start up curve

The slip is the difference between actual speed and synchronous speed. Percentage of slip varies as the load increases from no load to full load. The synchronous speed of motor is the theoretical speed, which depends on the frequency (f) and number of Poles (P), can be derived from equation below.

$$
N_{S}=\frac{120 * f}{P}
$$

The speed at which stator magnetic field rotates is called synchronous speed. Moreover, the actual speed is less than the synchronous speed. Actual speed is the speed at which motor shaft rotates. During startup, stator winding is first energized and rotor is stationary. Therefore a very large amount of stator current is induced into the rotor 
conductors. As a result, a very large stator current is drawn. However, as soon as the rotor begins to accelerate current drops rapidly. As can be seen from figure 79, full load current decrement is fairly constant, from around $500 \%$ to $450 \%$, until it reaches about $80 \%$ of synchronous speed. As the rotor approaches synchronous speed and the slip rate reduces, stator current falls off rapidly until at 100 percent synchronous speed at which it is zero. At this point the induction motor cannot operate.

On the $\mathrm{Y}$ axis, torque developed by rotor from start up to the time it runs up to the speed is shown. Torque refers to amount of mechanical turning force required to drive the load. At the startup of the motor excess torque is required to drive the rotor. As it can be seen in figure 79 , at around $40 \%$ speed, the torque developed by the motor increases and so does the acceleration of the rotor until about $75 \%$. This point is known as pull out or breakdown torque. From this point the amount of torque required rapidly falls to zero as rotor speed reaches synchronous speed. This is because the magnitude of current induced in rotor conductors decreases as it approaches synchronous speed. However, motor will operate where the torque developed by motor equals the torque required. When the load increases, the amount of torque required and the stator current will increase as well. However, any torque required beyond the maximum point (pull out torque point) will result in motor stalling because the torque available is less than the torque demanded.

Motor protection must be provided against faults such as insulation failure, overload, stalling of motor also called locked rotor, unbalanced power supply, under-voltage, loss of power and rapid restart.

Phase to ground or phase to phase faults on stator winding occurs due to insulation failure as the insulated conductors are tightly fitted into the slots of the iron core. There are higher chances of phase to ground fault. However, if the problem persists for longer period, it will result in phase to phase fault due to the deterioration of the insulation. A more common problem to the motor is overheating. Overheating leads to deterioration and eventual failure of the insulation. This causes short circuit between phases and ground. There are various reasons of overheating. One of the reasons is overload which results due to motor working above rated capacity. This will result in considerable increase in current flow through the 
stator which causes overheating if it allowed for longer period of time. If the overload is very high, perhaps due to a mechanical defect then the motor will stall. This is known as the locked rotor condition in which the stator current increases to a high value (5 to 7 times the normal rated current). This condition can cause severe damage to the rotor and stator winding within a very short period of time. Another cause of overheating is low voltage. Although the driven load is normal, excess current is drawn by the stator winding which will result in overheating. In addition, overheating will also be caused by the loss of one phase of the supply voltage. In a case when one phase failed then the remaining two phases will draw excessive current to continue driving the load. The overheating can also be caused due to unbalanced power supply. Difference between three phase voltages of the power supply will cause negative sequence current to circulate in the stator winding. These negative sequence currents setup a magnetic field rotating in the opposite direction and it produces considerable overeating of the iron core. Suppose there is a power loss for few seconds and it is restored back. In this case the motor speed is going down but when power is restored, the motor will try to gain the fallen speed while drawing a large amount of current. In some cases this acceleration causes the drive shaft to break due to the inertia of heavy machine.

In figure 80 , motor winding failure is shown. The reason for this type of failure can be anything described earlier.

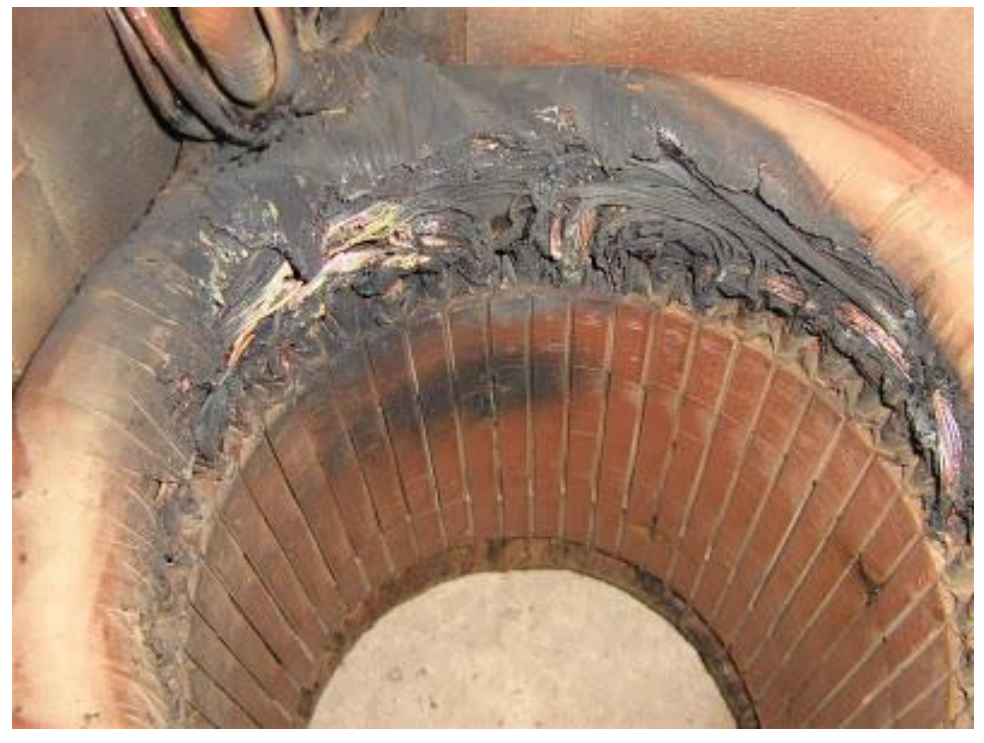

Figure 80: Motor Winding failure 
Small motors are provided with some built in protection. The motor is generally energized through a contactor switch which provides protection against loss of voltage. The contactor is held closed by the contactor coil. If the supply voltage falls below sixty percent then the contactor will open and remain open until the operator operates a manual start. Also a thermal overcurrent relay is usually built into protect the motor against overcurrent. Heavy overcurrent heats a bimetallic strip which opens and interrupts the power supply to the contactor coil.

\subsection{Small Motor Protection}

Figure 81 displays protection scheme for small motor. On the supply side of the motor, current transformer is connected to provide secondary input current to the thermal relay 49. This thermal relay provides overcurrent protection. It consists of heated element which operates a bimetallic switch [23]. Excessive current flow will cause the switch to open and interrupt the power supply to the motor. However, this relay should not trip for either startup current, which is high, or low level permissible overload. Therefore the relay must be set according the thermal limit curve shown in figure 81 to avoid miss-operation.

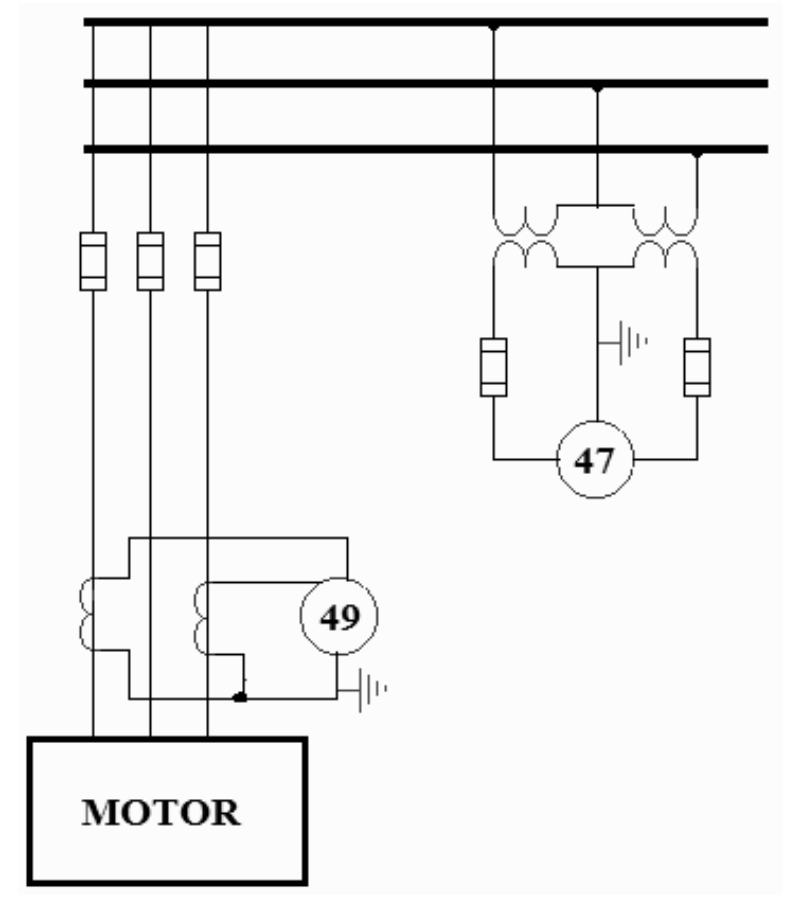

Figure 81: Small motor protection 
The figure below shows the allowable time for specific values of overcurrent for particular motor. As it can be seen, allowable time for the motor to carry twice the rated current is up to 1000s. However, it allows carrying 6 times the rated current for 20 seconds. The thermal limit curve composites several undesirable conditions. The upper portion shows limits of overload when the motor is in operation. Lower limit shows the locked rotor condition which is the magnitude of current and its allowable time limit which can be used for motor protection.

Due to stalling of motor or some other mechanical failure, if motor fails to start then considerable amount of current flow would heat up the rotor. In this case bimetallic switch does not provide adequate protection. Moreover, if motor is shutdown due to the operation of the bimetallic switch, the switch will start to cool down. However, if the motor started again soon after the shutdown then there will be significant heat due to current flow and it would damage rotor before bimetallic switch operated again. Another relay that can provide overcurrent protection is the time overcurrent relay (51). The metallic switch provides protection to motor so that it does not pass the thermal limit curve. Therefore time overcurrent relay will trip before metallic switch operate. Therefore the thermal metallic switch provides backup protection. In order to avoid inadvertent operation, the overcurrent relay is set pickup after $125 \%$ to $150 \%$ overload. 


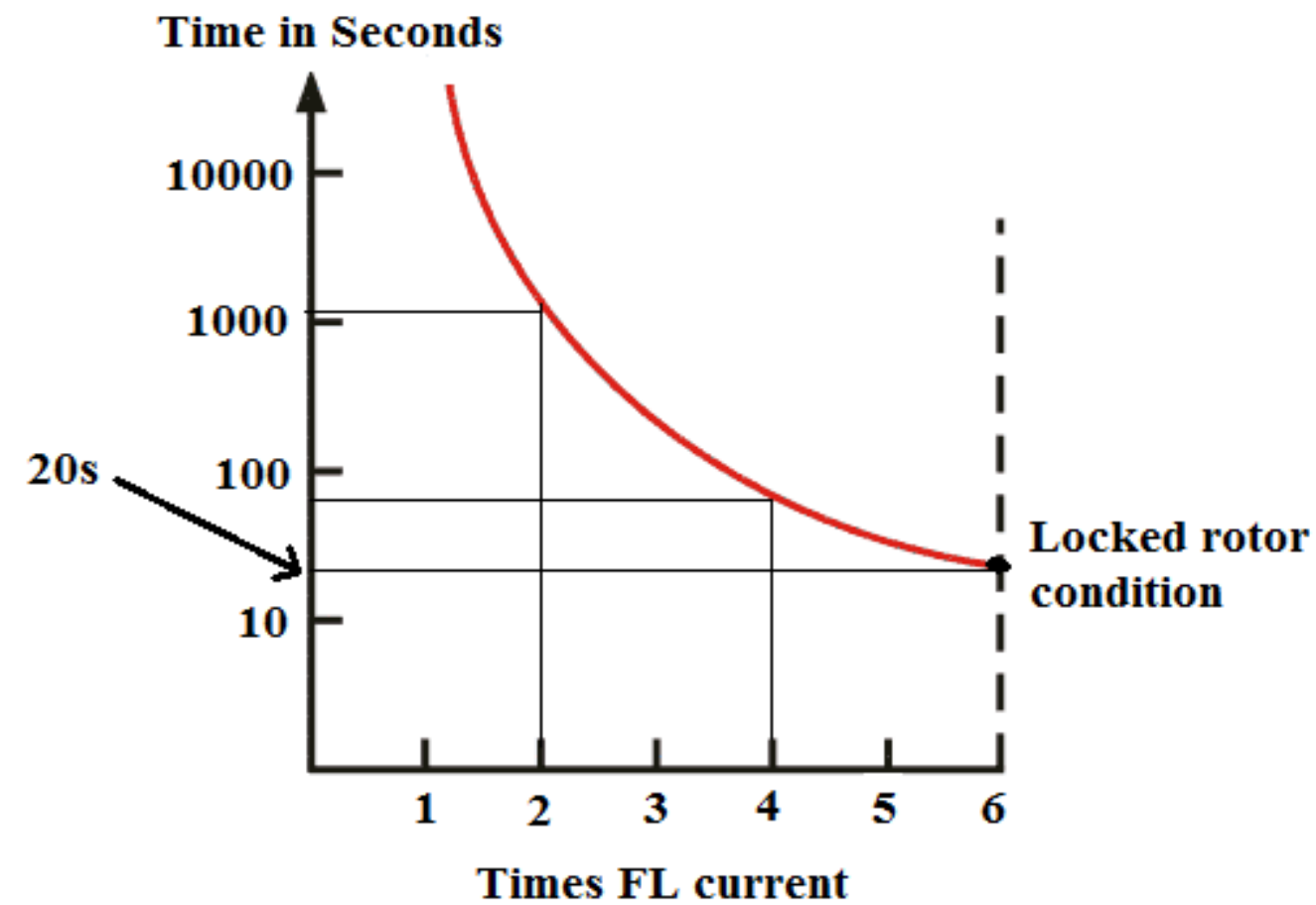

Figure 82: Motor thermal limit curve

Another problem of overheating is due to the change in external temperature. When ambient temperature around motor is cold, it can carry overload for longer period of time. Therefore, an improved method of protection against overheating is to directly measure the actual temperature of the winding and stator core. Temperature is measured by Resistance Temperature Detectors (RTD) and these devices are embedded in stator slots along with stator winding. In operation, RTDs are connected to a temperature relay which measures resistance of the detector. Resistance of any conductor increases as temperature increases. The RTD's detector is made of a material which has linear change in resistance as temperature changes. Therefore, by measuring the value of resistance, relay can accurately determine temperature inside the motor. When the temperature exceeds a specified limit the relay operates and de-energizes the motor.

Overheating can also be caused due to phase unbalance [24]. The solution for this problem is provided by negative sequence overvoltage relay (47). This relay is connected to bus to measure the power supply conditions. Under normal operating conditions the negative 
sequence voltage is very low. Moreover, this relay provides protection against phase reversal also. When the negative sequence current rises, the relay operates.

\subsection{Large Motor Protection}

Overload protection is provided by thermal overload relay. For large motor thermal protection is very crucial aspect. Therefore usually RTD type of thermal relay is used for thermal protection. When this relay operates it will close contacts in tripping circuit of the breaker and so stop the motor. Another protection which is also provided to small motors is the protection against negative sequence currents. As it can be seen on figure 83, a negative sequence relay is connected to supply bus. In the case of unbalanced conditions, this relay will trip all motors connected to that bus. In addition, overcurrent relays are fed from CTs in each phase of the power supply. These instantaneous overcurrent relays (50) are installed 1 per phase to protect against very high-level stator faults. Moreover, relay 51 shown in figure is set to protect the motor against overheating due to overload and it also provides protection against locked rotor conditions. Moreover, relay 46 is connected to same CT to check phase balance. It is connected to provide protection against open circuit within the motor or supply leads. When motor is running at close to full load, phase balance relay will operate if unbalance reaches over certain limit. Furthermore, the under-voltage protection is provided by relay 27 connected to bus. This is because the circuit breaker will not open on loss of a bus voltage [25]. On occurrence of loss of voltage, relay will trip all the motor breakers on the bus preventing rapid recloser while the units are running down. 


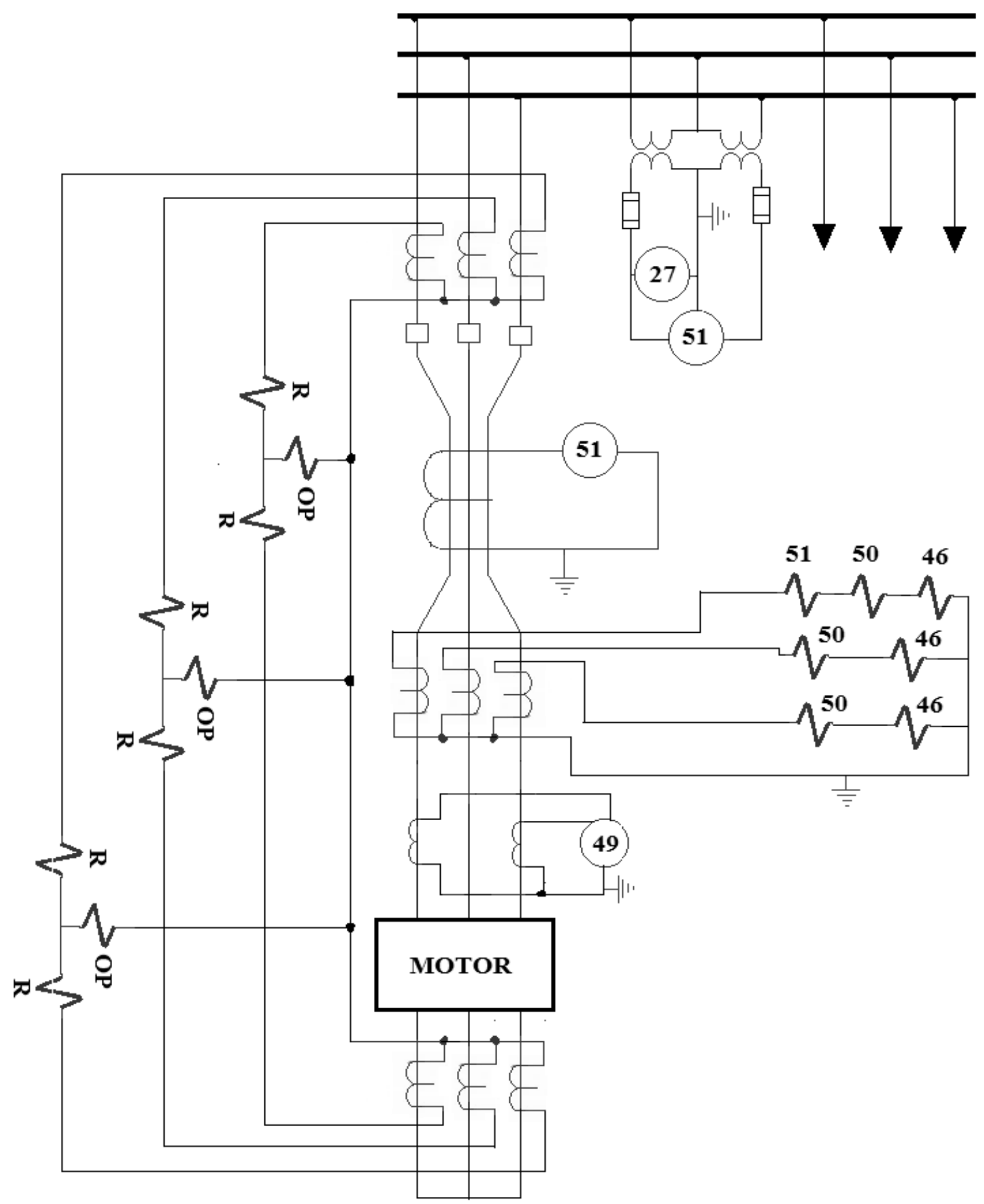

Figure 83: Large Motor Protection

As discussed earlier, the insulation failure leads to a stator ground fault. Protection against this is provided by use of toroidal CT which is connected to instantaneous relay. All 
three supply leads to motor passed through the window of current transformer as shown in figure 84. Under normal operating conditions, when currents are balanced the current flowing through CT secondary will be zero. However, if a ground fault occurs on stator winding then there will be significant out of balance and sufficient residual current will flow through the CT secondary [25]. Therefore instantaneous overcurrent relay (50) will operate.

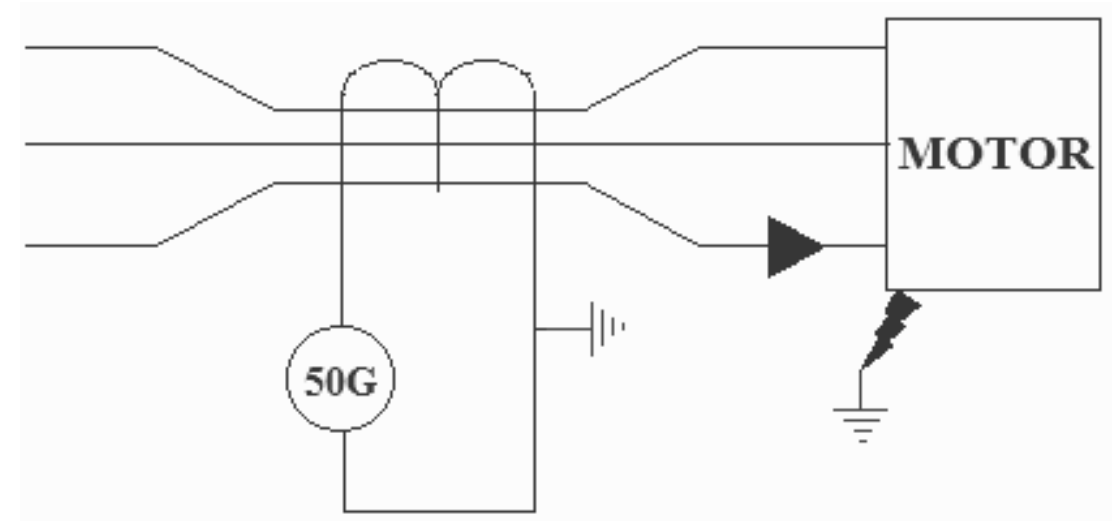

Figure 84: Toroidal CT configuration stator ground fault

In some cases where cables are very large and cannot pass through the CT window then separate CTs will have to be installed and connected to the relay. However, this arrangement does have a disadvantage. During motor start-up period, current is extremely high and with transients. Use of separate CTs may suffer unequal saturation. Consequently the secondary current will be unbalanced and the relay will operate incorrectly and so it will prevent motor from starting up. Therefore, with this type of arrangement, instantaneous ground relay $(51 \mathrm{~N})$ in conjunction with time overcurrent relay can be used with high setting for startup period. However, this will be costlier option because of the number of relays. Another very important protection to motor is the differential protection to detect stator faults. For this configuration, separate CTs should be provided for each phase. The connection of CTs on the supply side of the motor should include breakers. So it will provide protection against the fault in the breaker, supply leads and motor itself. On large motors additional protection is usually provided against locked rotor. If the motor stalls or if it fails to start then excessive current will flow in the rotor winding and cause extensive damage within a short period of time. Another problem to motor is long startup time. During startup 
if relay does not follow the specified curve then the acceleration relay 18 will operate and trip the breaker.

\subsection{Synchronous Motor Protection}

Synchronous motors are used where precise constant speed is required. Main feature of the synchronous motor is the rotor winding which must be provided with a DC current in order to set up its own magnetic field. The rotating magnetic field produced by the stator locks together with the rotor field and causes it to rotate at precise synchronous speed. As load increases the stator will draw more current from the power supply system to enable the rotor to continue to rotate at synchronous speed.

Figure 85 shows synchronous motor connection. As it can be seen, DC supply for the rotor may be produced by a DC generator which is coupled to the motor or the supply may be from an outside DC source. On the contrary to the induction motor where the power factor is fixed at full load, advantage of the synchronous motor is it adjusts the power factor demand of the motor if any adjustment above the DC excitation current.

Reduction of the field current of synchronous motor increases demand for reactive power from the system. On the other hand, increasing the field current actually delivers reactive power (VARs) to the power system so the motor operates at leading power factor which is the most important feature of using the synchronous motor. Therefore, synchronous motor is also used for power factor correction to keep down the cost of electricity. The protection of synchronous motor is similar to indication motor with the addition of few other relays. One particular condition to protect against is the over excitation of rotor. Possibly automatic power factor control or voltage control could result in excessive DC current flowing through the rotor field winding and so lead to overheating of the rotor. Similar to the induction motor, protection is provided by either a time overcurrent relay or a thermal bimetallic relay connected into the field winding circuit. Moreover, over heating of the stator winding is protected by overcurrent relays, thermal relays and current balance relay. Apart from the similarity in protection of induction motor, another relay found on synchronous motor is the loss of excitation relay (40). 


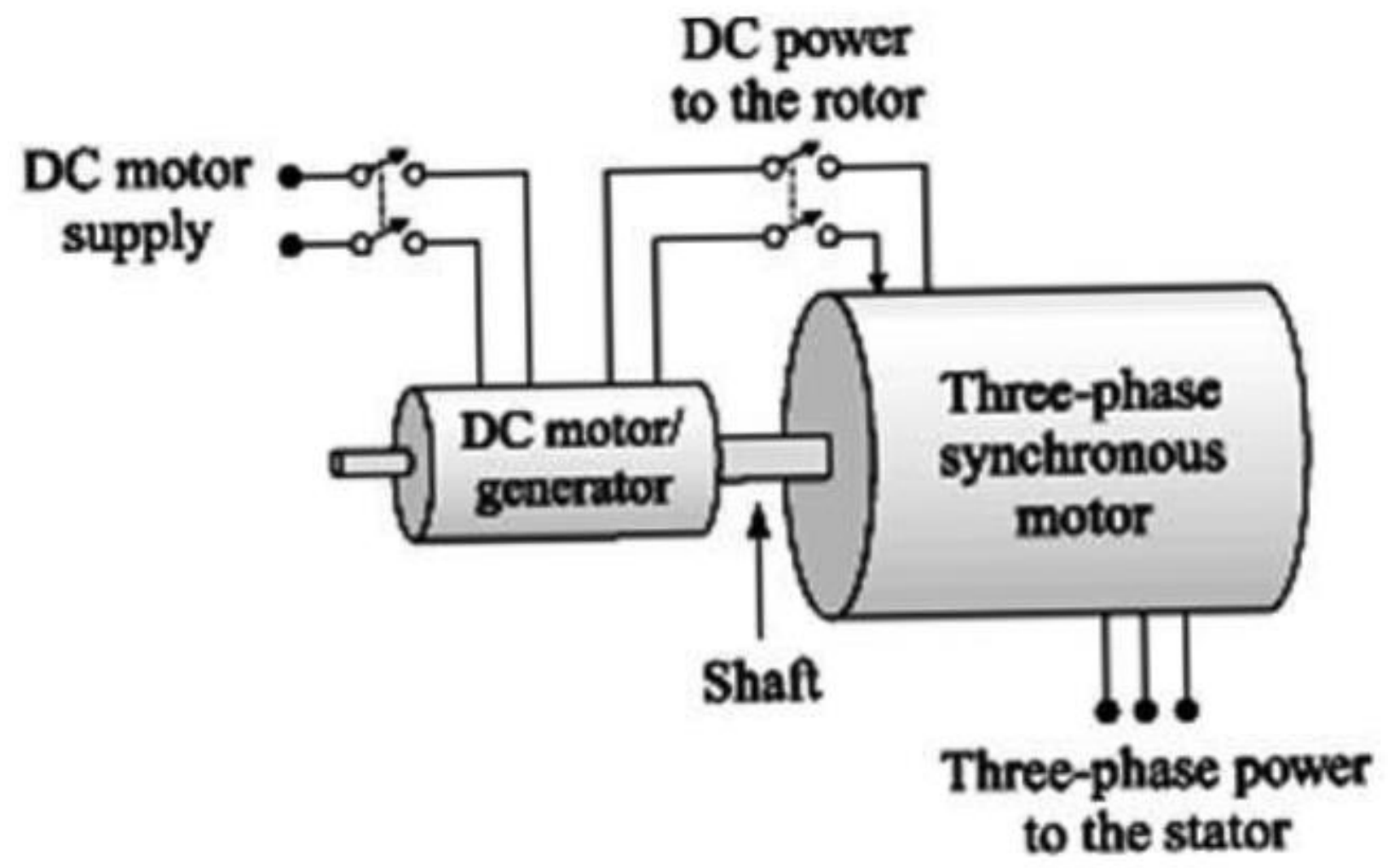

Figure 85: Synchronous motor connection

For some reason, if the current flow to synchronous motor is interrupted then it will work as an induction motor. However, the running speed will lower as well as it will draw heavy reactive power (low power factor) from the system. This will cause serious overheating of both the rotor and the stator winding. The loss of excitation relay operates by measuring current in excitation circuit or by measuring the flow VAR into stator winding. A power factor relay (55) is often set to operate when power factor falls below a specified limit. Furthermore, another protection relay used for synchronous motors is for the loss of synchronism. This might be the case during the loss of excitation situation. However, there are other reasons for the loss of synchronism such as sudden increase in mechanical load or reduction in supply voltage. If the synchronous motor excitation is set to operate at minimum setting for power factor correction and there is a sudden increase in load then the synchronous motor can loss synchronism. In a case where the pole slipping does occur, the stator current increases and the lagging power factor falls to a very low value. If the motor 
continues to slip then the stator current and power factor will fluctuate over a wide range as the rotor tries to pull into the step [26]. To protect the motor against this problem, out of step relay (78) is connected into the system. This relay detects initial decrease in power factor and trips out motor during the first slip cycle.

Moreover, additional protection is provided to synchronous motor by adding an under-voltage relay, under power relay and reverse power relay. The under-voltage relay is to prevent rapid restart if loss of voltage occurs. Moreover, the under power relay measure the power fed into the synchronous motor and it operates when power falls below a specified value. However, under power relay could also trip if the driving machine suffered surges in power demand which is an unexpected operation. If more than one motor is connected to same bus then reverse power relay (32) to prevent the motor from feeding power back into the bus.

In summary, motor protection must be provided against faults such as insulation failure, overload, stalling of motor, unbalanced power supply, under voltage, loss of power supply and rapid restart. These problems cause considerable overheating. This chapter describes protection for small motor, large motor and synchronous motor. Protection for small motor is provided by thermal relay (49). Thermal relay is set to operate above startup current level. Another protection against overcurrent is provided by time overcurrent relay (51). Motor does have a bimetallic protection which does not allow current to reach the thermal limit of motor. Since the bimetallic switch causes shutdown of motor, time overcurrent relay is set to operate before the current reaches bimetallic switch protection level. Overheating is also caused by phase unbalance. Phase unbalance causes flow of negative sequence voltage. Therefore, negative sequence overvoltage relay is added in the system to provide protection against this problem.

In addition to the protection relays used for small motors, large motors are protected by under-voltage relay and instantaneous overcurrent relay. Other relay does not provide protection against loss of a phase. Therefore, under-voltage relay is connected to protect against this situation. Moreover, protection against stator ground fault is provided by use of toroidal CT which measure current unbalance through three phases. In some cases where the 
cables are very large to fit in toroidal CT then protection is provided by differential relay. It provides protection against breaker faults, supply leads and faults within motor.

Synchronous motor must be protected against over excitation which leads to overheating of the rotor. Protection against this issue is provided by proper operation of overcurrent relay, thermal relay and current balance relay. Moreover, protection against loss of excitation is provided by loss of excitation relay (40) because if the current supply to motor is interrupted then it will work as induction motor drawing large amount of current which reduces power factor and heats up both rotor and stator winding. Moreover, a power factor relay (55) is also connected to provide protection against loss of excitation. Furthermore, out of step relay provides protection against loss of synchronism. 


\section{Chapter 8}

\section{Simulation and Calculation}

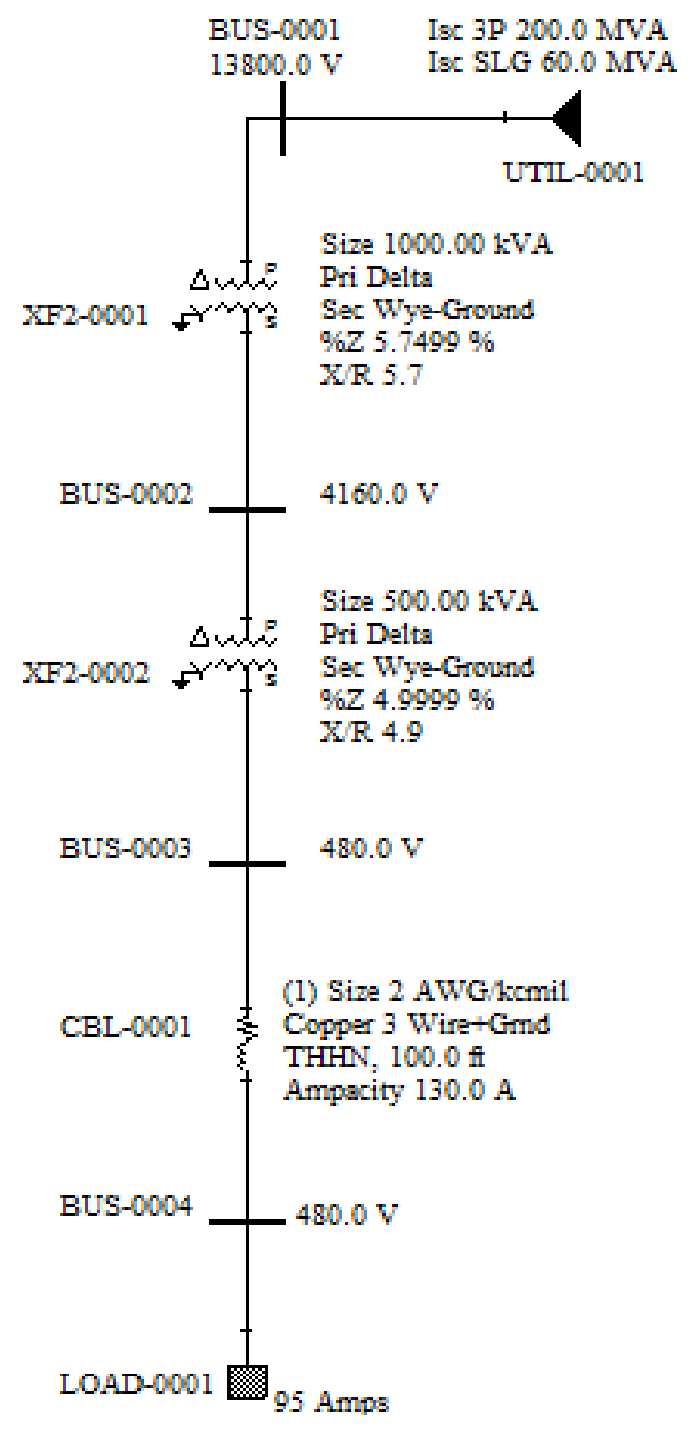

Figure 86: One line diagram without protection

Figure 86 shows a one line diagram without any protection device which is made in SKM Power tool software for protection device coordination. Utility short circuit data is assumed in this case. However, it is handily available in practical situation. Using this one line diagram short circuit tool is run in SKM power tool and the results are shown in table 6. 
Table 6: Fault Analysis Summary

\begin{tabular}{|c|c|c|c|c|c|}
\hline BUS NAME & VOLTAGE & \multicolumn{4}{|c|}{ AVAILABLE FAULT CURRENT } \\
\hline & L-L & 3 - PHASE & X/R & LINE/GRND & X/R \\
\hline BUS-0001 & 13800 & 8367.4 & 8.0 & 7530.66 & 8.0 \\
\hline BUS-0002 & 4160 & 2220.8 & 5.8 & 2281.59 & 5.8 \\
\hline BUS-0003 & 480 & 7403.1 & 5.2 & 8491.63 & 5.2 \\
\hline BUS-0004 & 480 & 5478.6 & 1.6 & 4799.41 & 1.6 \\
\hline
\end{tabular}

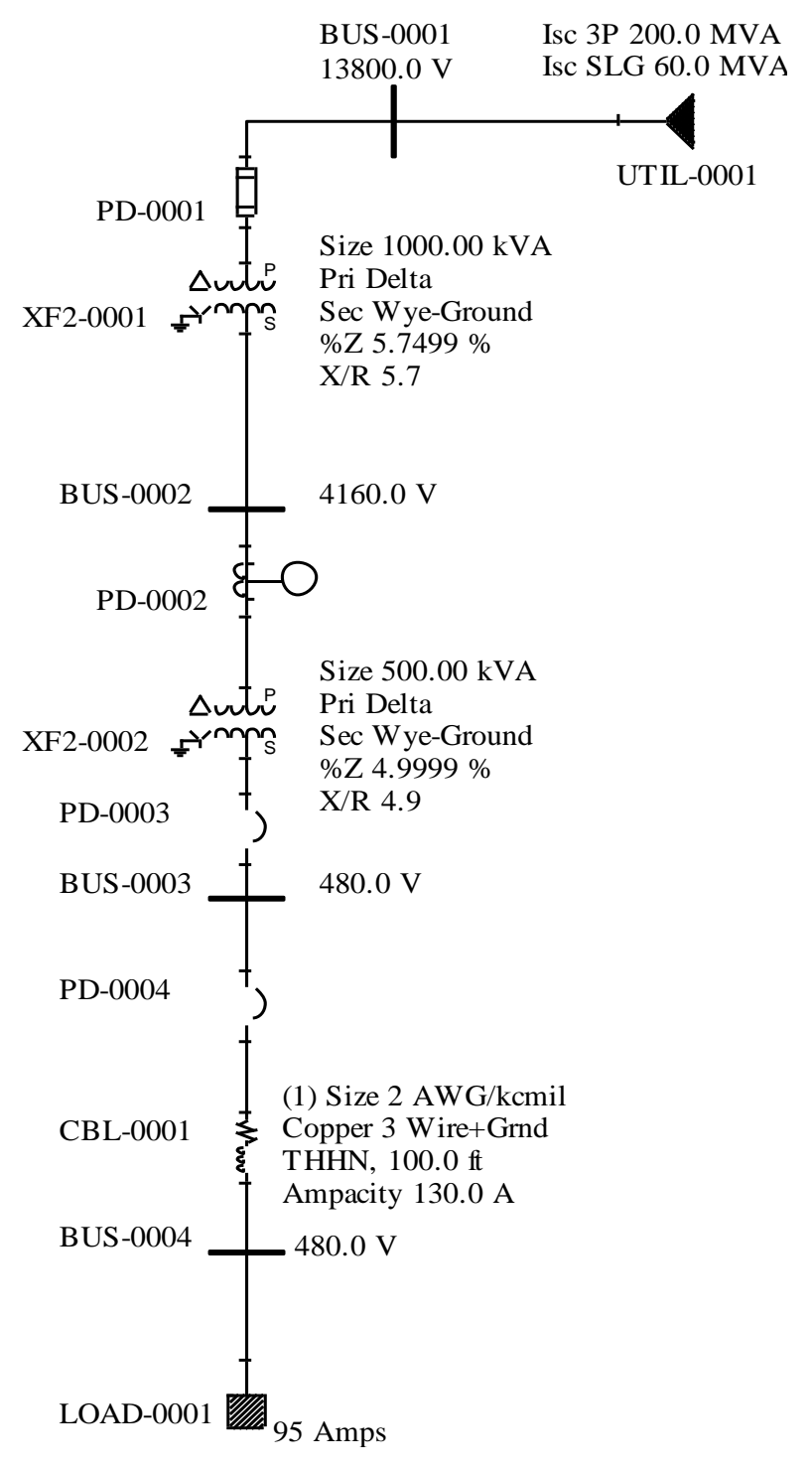

Figure 87: One line diagram with protection 


\section{CURRENT IN AMPERES}

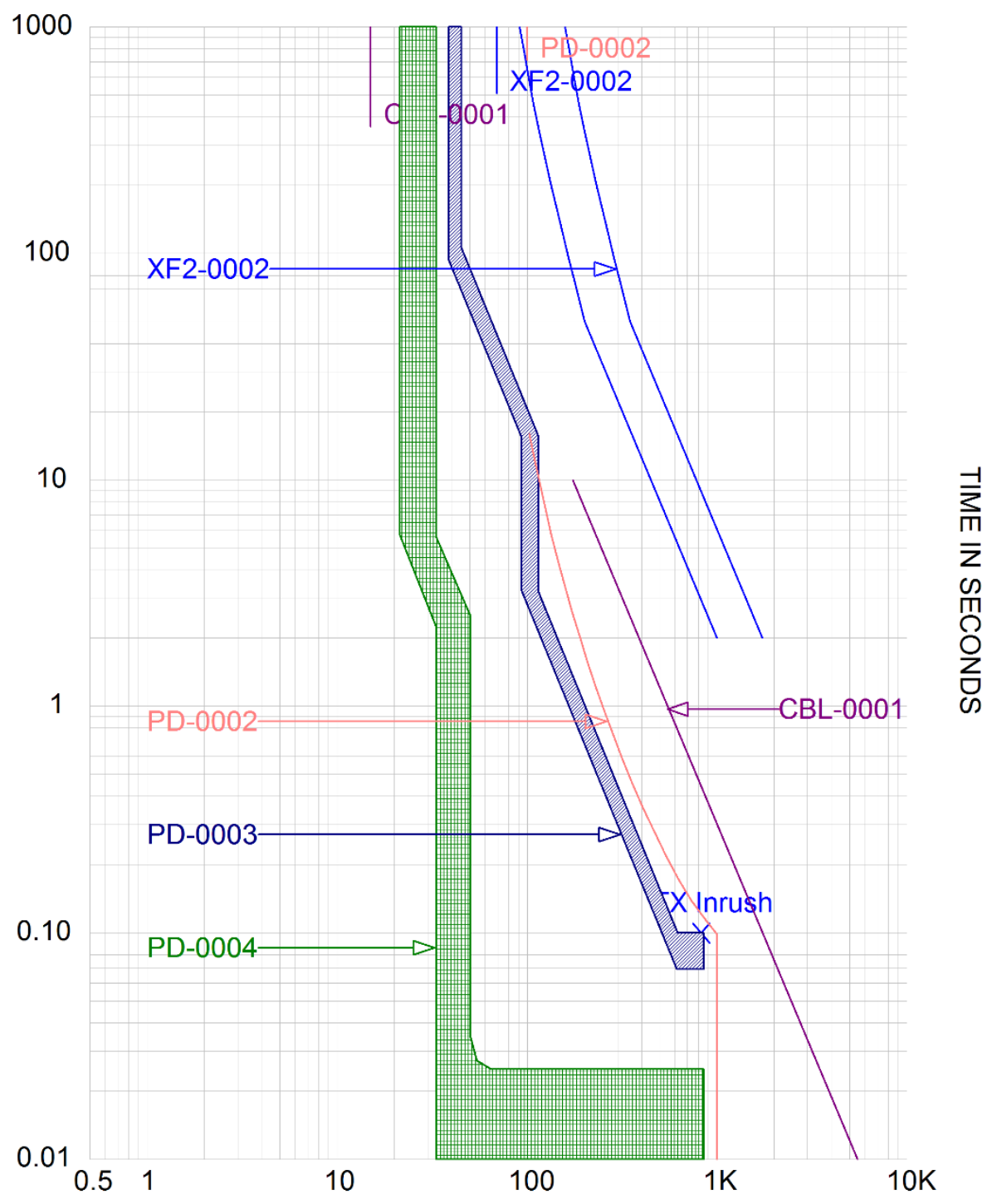

Simulation 1 Bus 0002 - Load 1.tcc Ref. Voltage: 4160V Current in Amps x 1 Simulation 1 Bus

\section{Figure 88: Time current coordination of existing system without changes made}

This is the result of time current coordination (TCC) for system shown in figure 87. It can be seen that the system is not adequately protected against fault. The curve for relay PD0002 and low voltage circuit breaker PD-0003 are very close which means the settings of these protection devices are not properly set. Moreover, the relay curve is very close to the 
transformer inrush current mark which means that, there are chances of this relay tripping if transformer inrush current is at higher value. Therefore there is no such importance of using this relay because in one line diagram the relay is place on the primary side of the transformer.

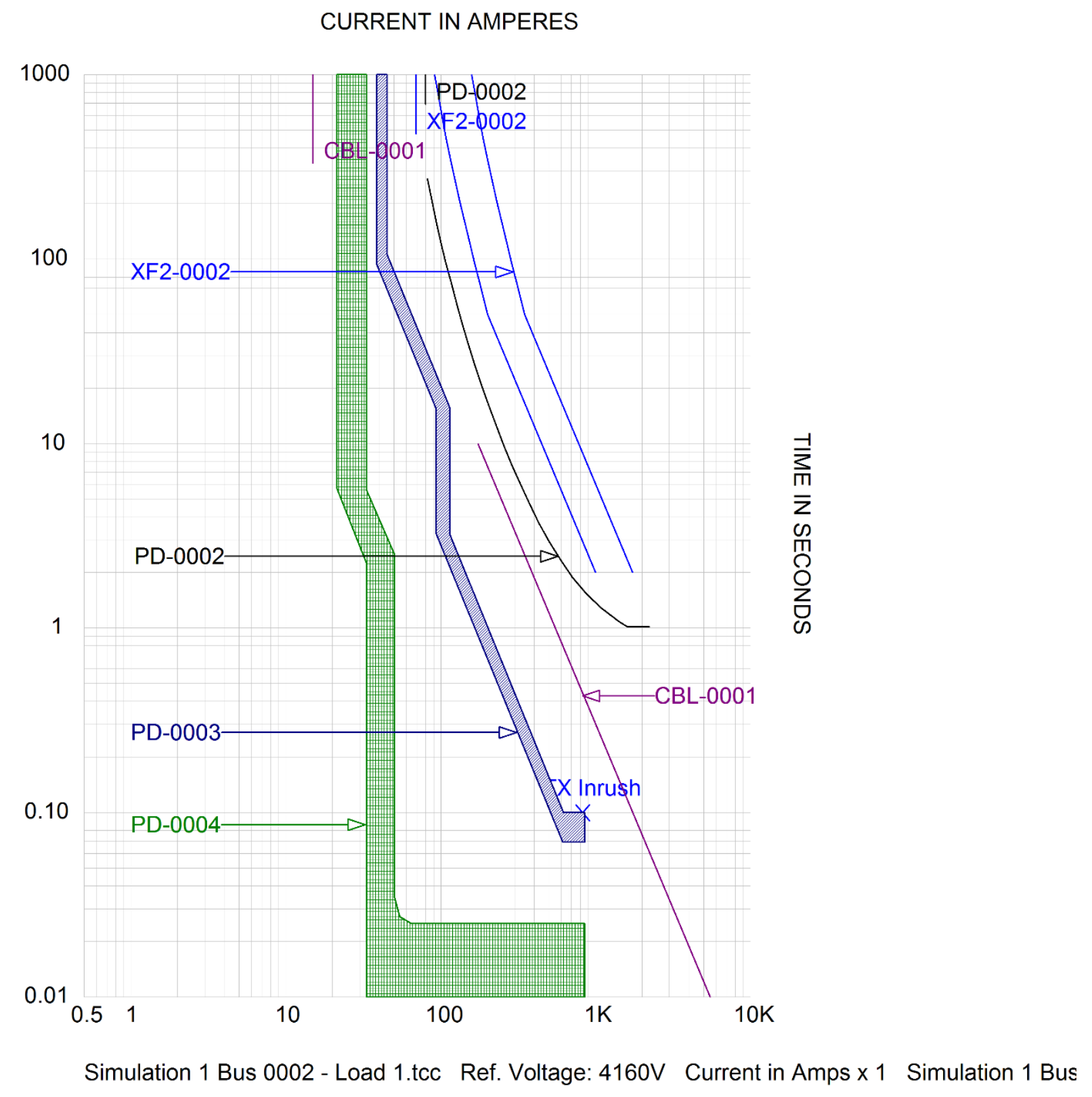

Figure 89: Time current coordination of existing system with changed relay settings 
In the figure above the relay setting changed. Now the relay is close to the transformer damage curve. Moreover, it can be seen that the LV circuit breaker PD-0003 is protecting the cable. It trips way before the current reach the damage curve. Now the system is properly coordinated.

\section{Calculation:}

Short circuit calculation on secondary side of the transformer

Assume Utility fault current level is $18 \mathrm{kA}$. This value is usually available to the engineer.

Full Load Ampere on the 600V secondary side of the $1200 \mathrm{kVA}$ transformer is

$$
\begin{array}{r}
F L A=\frac{\text { Transformer } k V A}{\sqrt{3} * k V_{L L_{\text {sec }}}} \\
F L A=\frac{1200}{\sqrt{3} * 0.6} \\
F L A=1156 A
\end{array}
$$

Therefore short circuit current on transformer secondary can be calculated by

$$
\begin{array}{r}
F C=\frac{F L A * 100}{\% Z_{\text {transformer }}} \\
F C=\frac{1156 * 100}{5.5} \\
F C=21018.2 \mathrm{~A}
\end{array}
$$

In reality the short circuit power injected by utility can be calculated as

$$
\begin{gathered}
S_{U}=I_{S C} * V_{L L_{\text {Primary }}} * \sqrt{3} \\
S_{U}=18000 * 13800 * \sqrt{3} \\
S_{U}=430 \mathrm{MVA}
\end{gathered}
$$

At this fault current, the supply impedance is

$$
\begin{gathered}
Z_{S}=\frac{\left(V_{L L_{s e c}}\right)^{2}}{S_{U}} \\
Z_{S}=\frac{(600)^{2}}{430 * 10^{6}}= \\
Z_{S}=0.00084 \Omega
\end{gathered}
$$

Since the fault current calculation is for primary side of the transformer, the transformer impedance can be directly added. 


$$
Z_{\text {transformer }}=\frac{5.5}{100} \times \frac{600^{2}}{1,200,000}=0.0165 \Omega
$$

Therefore total supply impedance is

$$
Z_{o}=0.00084+0.0165=0.01734 \Omega
$$

If $1200 \mathrm{kVA}$ service transformer has an $\mathrm{X} / \mathrm{R}=8$ (this value is based on transformer manufacturer graphs of power transformer X/R ratio versus MVA rating), the supply resistance $\mathrm{R}_{0}$ and supply reactance $\mathrm{X}_{0}$ can be estimated by using next formulas:

$$
\begin{gathered}
X_{o}=Z_{o} \times \sin \left(\tan ^{-1}(X / R)\right)=0.01721 \Omega \\
R_{o}=Z_{o} \times \cos \left(\tan ^{-1}(X / R)\right)=0.0022 \Omega
\end{gathered}
$$

And

$$
Z_{o}=(0.0022+j 0.01721) \Omega=0.01734 \Omega
$$

Possible fault current is:

$$
I_{F}=\frac{U_{N}}{\sqrt{3} \times Z_{o}}=\frac{600}{\sqrt{3} \times 0.01734}=20000 \mathrm{~A}
$$

Two motors connected to bus have rating of $100 \mathrm{HP}$ with $95.6 \%$ efficiency and 0.875 power factor and $150 \mathrm{HP}$ with $95.8 \%$ efficiency $(\eta)$ and 0.865 power factor (P.F). Rated voltage of both motors is 600V. Full Load Ampere of these motor can be calculated as shown below to add the motor contribution the fault current.

$$
\begin{gathered}
F L A_{M 1}=\frac{H P * 746}{\sqrt{3} * V_{L L} * \eta * P F} \\
F L A_{M 1}=\frac{100 * 746}{\sqrt{3} * 600 * 0.956 * 0.875} \\
F L A_{M 1}=86 A \\
F L A_{M 2}=\frac{H P * 746}{\sqrt{3} * V_{L L} * \eta * P F} \\
F L A_{M 2}=\frac{150 * 746}{\sqrt{3} * 600 * 0.958 * 0.865} \\
F L A_{M 2}=130 A
\end{gathered}
$$

Total current for these two motor is $86+130=216 \mathrm{~A}$.

Therefore all the equipment in the system should be sufficient to carry this current without overloading. 
Assuming motor contribute four times the full load current

The fault current on the $600 \mathrm{~V}$ secondary side of the $1200 \mathrm{kVA}$ transformer is

$$
I_{F}=(216 * 4)+20000 \mathrm{~A}=20864 \mathrm{~A}
$$

Rating of the fuse on the transformer primary side with voltage $13800 \mathrm{~V}_{\mathrm{LL}}$ and $5.5 \%$ impedance can be calculated as below.

Transformer full load primary current is

$$
\begin{gathered}
I_{F L}=\frac{k V A}{\sqrt{3} * k V_{L L}} \\
I_{F L}=\frac{1200}{\sqrt{3} * 13.8}=50.2 \mathrm{~A}
\end{gathered}
$$

Assuming the transformer inrush current is 12 times

$$
I_{\text {inrush }}=50.2 * 12=602.4 \mathrm{~A}
$$

Now primary current for three phase fault on secondary side of the transformer is

$$
I_{\text {Fault }}=\frac{50.2}{0.055}=912.7 \mathrm{~A}
$$

\section{Cable Selection:}

The cable selection shall cover various characteristics related to: conductor type, insulation type, cable insulation voltage level, cable temperature rating and initial conductor size selection based on required ampacity. A design criterion should be completed, identifying and classifying all substation loads to be supplied, in order to determine the required ampacity. According to IEEE Std. 525, cable ampacity should be equal to or larger than the trip rating of the circuit overload protection, which is typically 1.25 times the expected circuit load [27].

\section{Voltage drop calculation:}

Voltage drop calculation for a $1-\varnothing$ conductor or one phase of a 3- $\varnothing$ circuit:

$$
\% V_{D 1}=\frac{2 * I * \sqrt{\left(\left((R * L * P F)^{2}\right)+\left(X * L * \sin \left(\cos ^{-1}(P F)\right)\right)^{2}\right)}}{V} \quad \text { Equation (12) }
$$

Voltage drop calculation for a 3- $\varnothing$ conductor: 


$$
\% V_{D 3}=\frac{I * \sqrt{\left(3 *\left(\left(R * L * P F^{2}\right)+\left(X * L * \sin \left(\cos ^{-1}(P F)\right)\right)^{2}\right)\right)}}{V}
$$

Where:

$\% \mathrm{~V}_{\mathrm{D} 1}=$ Line to neutral voltage drop of the conductor expressed, for a $1-\varnothing$ conductor, [V]

$\% \mathrm{~V}_{\mathrm{D} 3}=$ Line to line voltage drop of the conductor expressed, for a $3-\varnothing$ conductor, [V]

$\mathrm{V}=$ Nominal Voltage of the circuit, [V]

$\mathrm{R}=$ Alternating-Current Resistance to Neutral per $1000 \mathrm{ft},[\Omega]$

$\mathrm{X}=$ Alternating-Current Reactance to Neutral per $1000 \mathrm{ft},[\Omega]$

$\mathrm{I}=\mathrm{Load}$ at 100 percent, $[\mathrm{A}]$

$\mathrm{L}=$ One-way length of the conductor being considered for the voltage drop, [ft]

$\mathrm{PF}=$ Equivalent power factor being considered for the circuit.

\section{Conductor Selection:}

The conductor size must be verified to ensure that it can withstand the available short circuit current at its termination point. Sizing of the conductor based on available fault current is a function of initial or continuous conductor operating temperature, the final conductor temperature after a fault, the maximum possible fault clearing time based on protective devices, and available fault current at the circuit's termination point.

The conductor size which can withstand 22500A short circuit current can be found by equation given below where the fault clearing time is assumed to be 2 cycles which is 0.033 seconds and pre-fault temperature of the conductor is 75 and maximum through fault temperature is 250

$$
A=\frac{I_{S C}}{\left(0.0125 /\left(t_{f} * \log _{10}\left(\frac{T_{2}+234.5}{T_{1}+234.5}\right)\right)\right)^{0.5}}
$$

$$
A=\frac{20864}{\left(0.0125 /\left(0.033 * \log _{10}\left(\frac{250+234.5}{90+234.5}\right)\right)\right)^{0.5}}
$$




$$
A=41070 \mathrm{cmil}
$$

The short circuit withstands capability of the Aluminum conductor is

$$
(I / A)^{2}=\frac{0.0125}{t * \log _{10}\left(\frac{T_{2}+228}{T_{1}+228}\right)}
$$

Where:

$I=$ through-fault current (A)

$A=$ conductor area $(\mathrm{cmil})$

$T_{f}=$ through-fault duration (s)

$T_{1}=$ pre-fault conductor temperature $\left({ }^{\circ} \mathrm{C}\right)$

$T_{2}=$ maximum through-fault conductor temperature $\left({ }^{\circ} \mathrm{C}\right)$

$T_{2}=: \quad 200{ }^{\circ} \mathrm{C}$ for paper, rubber, and varnished cambric insulation

$150{ }^{\circ} \mathrm{C}$ for thermoplastic insulation

$250{ }^{\circ} \mathrm{C}$ for XLP and EPR insulation

\begin{tabular}{|c|c|c|c|c|c|c|c|c|c|}
\hline \multirow{2}{*}{\multicolumn{2}{|c|}{ Conductor size }} & \multirow{3}{*}{$\begin{array}{c}\operatorname{Rdc}^{\mathbf{a}} \\
(\mathrm{m} \Omega / \mathrm{m})\end{array}$} & \multirow{3}{*}{$\begin{array}{c}\operatorname{Rdc}^{\mathbf{a}} \\
(\boldsymbol{\Omega} / \mathbf{1 0 0 0})\end{array}$} & \multirow{3}{*}{$\begin{array}{c}\text { Number } \\
\text { of } \\
\text { conductors }\end{array}$} & \multirow{3}{*}{$\begin{array}{c}90^{\circ} \mathrm{C} \\
\text { ampacity } \\
\text { (A) }\end{array}$} & \multicolumn{4}{|c|}{ Approximate outside diameter (OD) } \\
\hline & & & & & & \multicolumn{2}{|c|}{ Nonshielded } & \multicolumn{2}{|c|}{ Shielded } \\
\hline (AWG) & (cmil) & & & & & $(\mathrm{mm})$ & (in) & (mm) & (in) \\
\hline \multirow[t]{4}{*}{$1 / 0$} & 105600 & 0.400 & 0.122 & 1 & 170 & 15.1 & 0.595 & 17.5 & 0.690 \\
\hline & & & & 2 & 170 & 30.0 & 1.180 & 31.5 & 1.240 \\
\hline & & & & 3 & 170 & 31.8 & 1.250 & 33.5 & 1.320 \\
\hline & & & & 4 & 136 & 35.2 & 1.385 & 36.8 & 1.450 \\
\hline \multirow[t]{4}{*}{$2 / 0$} & 133100 & 0.317 & 0.097 & 1 & 195 & 16.3 & 0.640 & 18.7 & 0.735 \\
\hline & & & & 2 & 195 & 32.3 & 1.270 & 33.8 & 1.330 \\
\hline & & & & 3 & 195 & 34.4 & 1.355 & 36.1 & 1.420 \\
\hline & & & & 4 & 156 & 38.0 & 1.495 & 39.6 & 1.560 \\
\hline \multirow[t]{4}{*}{$4 / 0$} & 211600 & 0.199 & 0.061 & 1 & 260 & 19.2 & 0.755 & 21.6 & 0.850 \\
\hline & & & & 2 & 260 & 38.0 & 1.495 & 39.5 & 1.555 \\
\hline & & & & 3 & 260 & 40.5 & 1.595 & 42.2 & 1.660 \\
\hline & & & & 4 & 208 & 46.5 & 1.830 & 48.1 & 1.895 \\
\hline
\end{tabular}

Table 7: Parameters for common substation cables (600V Insulation)

Therefore 4/0 conductor size is used to supply two motor with combined FLA of 216A. 


\section{Chapter 9}

\section{Conclusion and Future Recommendation}

This report introduced many protection methods for different power system equipment. Power system protection is very important part of the system in providing reliable power supply, safely operating conditions, system stability and safety to equipment by minimizing damage. Faults such as phase to phase, phase to ground, two phases to ground, three phase bolted fault and three phases to ground fault occurs due to various reasons which can be natural events, physical accidents, equipment failure or faulty operation. In wye connected system, line voltages lead phase voltages by $30^{\circ}$. The angle difference between phase components and between line components is $120^{\circ}$. Under balance operating conditions, only positive sequence component flows in the system. But when there is a phase to phase fault negative sequence currents arises and zero sequence current arises when there is a ground fault. The phase angle relationship changes when there is an unbalance in the system due to fault. The circuit breaker will trip after getting a trip signal from relay. Trip signal can be sent for either fault which produces high current in the system or through manual switching contacts when the breaker needs to be out for maintenance.

Distance relaying takes current and voltage as input and measures impedance and operates when the impedance falls below a set range. In directional relay protection current or voltage quantity is taken as reference. If the direction of current flow changes then phase angle changes by $180^{\circ}$. This large change in phase angle will be easy for relay to detect and activate the directional element. The differential protection which works based on measurement of current at each end of the selected zone and operates where there is a difference between them. Differential relay does not operate outside it protection zone. Power system is divided into various zones to discriminate the fault and to provide continuous power supply. Moreover, the overcurrent protection to these zones can be provided by fuses, relays or reclosers.

Generator converts mechanical energy into electrical energy. There are many other components connected to generator. Therefore, they must be shutdown in order to shutdown 
the generator. Protection against generator phase faults can be achieved by differential protection. Moreover, generator can be protected by resistance grounding, impedance grounding or ground differential protection scheme. The protection scheme chosen is based on generator grounding method used in the plant. For ground fault, the fault current has to be reduced to be under $10 \mathrm{~A}$ to limit internal damage. Furthermore, while designing generator protection scheme backup protection is also provided incase primary protection does not operate. Generator backup protection is provided by negative sequence relay, time overcurrent relay with voltage restraint, reverse power relay and loss of field relay. These relays are installed to protect generator against overheating problems.

Bus is an important component of power system as it must be used at every junction point and the damage that can occur is devastating because of the availability of fault current. In normal operating condition, current enters the bus equals the current going out of the bus. Moreover, same principle works for faults outside of bus. Differential protection provides better protection for bus faults. Moreover, one operating coil per phase is recommended for better operation and avoids faulty operation due to core saturation. Up to $10 \%$ error is allowed for current flow up to 20 times the rated current.

Designing protection scheme for radial system is easier than for loop system. Moreover, outage on transmission line causes interruption of power to many customers than outage of a single distribution line. Transmission lines covers long distance bringing power from remote generating sources and deliver it to load situated at distant location. Under fault condition, current flow is in one direction only. For complex loop system use of directional over current is really necessary because under fault condition or under unexpected loading conditions, the flow of current can be in any direction. Transmission line protection can also be provided by distance relay protection. As the distance from source increases, the impedance increases and the level of fault current decreases. Voltage fluctuations do not affect the distance relay operation. Distance relay can be divided to operate in different zones with different fault impedance. If the fault is outside distance relay protection zone then relay will not operate. 
Transformer winding connection can be wye $(\mathrm{Y})$ or Delta $(\Delta)$ to get desired voltage levels and phase relationship. When transformer winding connection is wye on both side then CT connection should be delta to avoid unwanted tripping due to zero sequence currents. Moreover, if transformer winding connection is delta on both sides then Wye connected CTs are used on both sides as there is no 30 degree shift to correct. While applying differential protection to transformer, magnetizing inrush current, phase shift in $\mathrm{Y}-\Delta$ connected transformers, phasing of CT connections, selection of CT taps and the effects of transformer taps should be considered. Transformer protection can be provided by differential protection. Moreover, thermal protection is provided by oil and winding temperature indicator.

Motor protection must be provided against faults such as insulation failure, overload, stalling of motor, unbalanced power supply, under voltage, loss of power supply and rapid restart. These problems cause considerable overheating. For large motors protection is also provided by differential relay. It provides protection against breaker faults, supply leads and faults within motor. Synchronous motor protection does have all the problems that induction motor faces. However, synchronous motors also need protection against loss of excitation, over excitation and loss of synchronism. Therefore adequate protection must be provided which is explained in the report.

Generator protection includes generator phase faults, phase to ground fault and backup protection. Generator protection against abnormal condition can be added as future work. Explanation about load changing conditions which affects the frequency, cold starts which takes several hours to bring a steam turbine generator unit up to the speed.

Moreover, under-reach and overreach situations due to different structure of transmission lines can be solved by pilot protection. Therefore, it can be completed as future tasks. Different types of pilot protection schemes can be used to overcome this problem. 


\section{Glossary}

Actual speed: It is the speed at which motor shaft rotates

Burden: Load impedance imposed by a relay on an input circuit expressed in ohms and phase angle at specified conditions.

Pickup current: It is the minimum current that will cause the relay to initiate action to close contacts

Pullout Torque: It is the highest torque available before the torque decreases when the machine continues to accelerate to working condition

Pull up torque: It is minimum torque developed by motor when it runs from zero to full load speed

Synchronous speed: It is the speed at which stator magnetic field rotates

Stalling or locked rotor torque: is the torque the electrical motor develop when it starts at rest or zero speed

Time Current Coordination: It is a study for evaluation of the time each protective device takes to operate when the current in the system increase to a certain level. 


\section{References}

[1] Stephen Marx and Dean Bender (2013, March 11) An introduction to symmetrical components, system modelling and fault calculation [Online] Available:

https://www.eiseverywhere.com/file_uploads/a4f0ea9ba5ebe8baf31cba17ff378633_Symmetr icalComponents_2013.pdf

[2] Jignesh Parmar (2012, Dec 17). Using Protective relay for fighting against faults [Online] Available: http://electrical-engineering-portal.com/using-protective-relay-for-fightingagainst-faults

[3] Michael Stutz (2011, Oct 14) Protective Relays [Online] Available: http://www.allaboutcircuits.com/vol_4/chpt_5/4.html

[4] Electrical4u (2012, Feb 27) Electromagnetic Relay Working | Types of Electromagnetic Relays [Online] Available: http://electrical4u.com/electromagnetic-relay-working-types-ofelectromagnetic-relays/

[5] Andrew Kunze, (2007, Apr 06) Bus Differential Protection and simulation [online] Available: http://www.ece.mtu.edu/faculty/bamork/EE5223/Bus-Diff.pdf

[6] J. Lewis Blackburn, Thomas J Domin, "Protective relaying: Principle and application," CRC Press, $4^{\text {th }}$ ed. Florida, USA, 2014, ch. 1, pp. 1-30

[7] Hesam Hosseinzadeh (2008) Distribution System Protection [Online] Available FTP: http://www.eng.uwo.ca/people/tsidhu/Documents/ES586B-Hesam\%20Hosseinzadeh250441131.pdf

[8] General Electric (1994) Current transformer ratio factor curve [Online] Available FTP: http://www.gedigitalenergy.com/multilin/notes/artsci/art07.pdf

[9] IEEE Guide for the Application of Current Transformers Used for Protective Relaying Purposes, IEEE Standard C37.110, 2007

[10] Working group chair, Prafulla Pillai, "Grounding and ground fault protection of multiple generator installations on medium-voltage industrial and commercial power systems" Part - 
3 Protection method, An IEEE/IAS working report, Kellogg Brown \& Root Inc, Houston, Texas, 2003

[11] IEEE Guide for AC generation protection, IEEE Standard C37.102, 2006

[12] C. H. Griffin, J. W. Pope, “Generator ground fault protection using overcurrent, overvoltage and undervoltage relay," Georgia Power Co., vol. PAS 101, pp. 4490-4506, Dec. 1982

[13] David L. Swindler, Carl J. Fredericks, "Modified differential ground fault protection for system having multiple source and ground," pp. 1490-1505, December, 1994

[14] Backwith Electric Co. Inc (2014, Oct 17) Generator protection using multifunction digital relays [online] Available: https://www.beckwithelectric.com/docs/techpapers/multirelay.pdf

[15] Electrical4u (2014, Nov 5) Electrical bus system and electrical substation layout [Online] Available: http://electrical4u.com/electrical-bus-system-and-electrical-substationlayout/

[16] IEEE Guide for protective relay application to power system buses, IEEE Standard C37.97, 1979

[17] Ernesto Vazquez - Martinez, EE 434, Power system protection Class Lecture, topic:

"Bus and transformer differential protection", Faculty of Engineering, University of Alberta, Alberta, 2012, Apr 13

[18] General Electric (1994) Line protection with overcurrent relay [Online] Available: http://www.gedigitalenergy.com/multilin/notes/artsci/art13.pdf

[19] IEEE Guide for protective relay application to transmission lines, IEEE Standard C37.113, 1999

[20] Ernesto Vazquez - Martinez, EE 434, Power system protection Class Lecture, topic:

“Distance Protection I, II", Faculty of Engineering, University of Alberta, Alberta, 2012, Apr 13 
[21] Ernesto Vazquez - Martinez, EE 434, Power system protection Class Lecture, topic: “Transformer differential protection example", Faculty of Engineering, University of Alberta, Alberta, 2012, Apr 13

[22] IEEE Guide for protecting power transformer, IEEE Standard C37.91, 2008

[23] Electrical4u (2014, Nov 14) Motor thermal overload protection [Online] Available: http://electrical4u.com/motor-thermal-overload-protection/

[24] Craig Wester (2014 Nov 16) Motor protection principle [Online] Available:

https://www.1-3.com/private/ieee/Motor\%20Protection\%20Principles.pdf

[25] American National Standard Guide for an AC motor protection, IEEE Standard C37.96, 1998

[26] Li Ning, "Out of step protection for synchronous motor," electronic information and automation, Tianjin university of science and technology collage, Tianjin, China, (2011, Dec 09)

[27] IEEE Guide for the Design and Installation of Cable Systems in Substations, IEEE Standard 525 